AN INNOVATIVE CATALYST SYSTEM FOR SLURRY-PHASE FISCHER-TROPSCH SYNTHESIS: COBALT PLUS A WATER-GAS-SHIFT CATALYST

FInal Technical Report

By

Charles N. Satterfleld

Ian C. Yates

Claire Chanenchuk

July 1991

Work Performed Under Contract No. AC22-87PC79816

For

U.S. Department of Energy

Pittsburgh Energy Technology Center

Pittsburgh, Pennsylvania

By

Massachusetts Institute of Technology

Cambridge, Massachusetts 


\section{DISCLAIMER}

This report was prepared as an account of work sponsored by an agency of the United States Government. Neither the United States Government nor any agency thereof, nor any of their employees, makes any warranty, express or implied, or assumes any legal liability or responsibility for the accuracy, completeness, or usefulness of any information, apparatus, product, or process disclosed, or represents that its use would not infringe privately owned rights. Reference herein to any specific commercial product, process, or service by trade name, trademark, manufacturer, or otherwise does not necessarily constitute or imply its endorsement, recommendation, or favoring by the United States Government or any agency thereof. The views and opinions of authors ex pressed herein do not necessarily state or reflect those of the United States Government or any agency thereof.

This report has been reproduced directly from the best available copy.

Available to DOE and DOE contractors from the Office of Scientific and Technical Information, P.O. Box 62, Oak Ridge, TN 37831; prices available from (615)576-8401, FTS 626-8401.

Available to the public from the National Technical Information Service, U. S. Department of Cornmerce, 5285 Port Royal Rd., Springfield, VA 22161. 


\title{
AN INNOVATIVE CATALYST SYSTEM FOR SLURRY-PHASE \\ FISCHER-TROPSCH SYNTHESIS: \\ COBALT PLUS A WATER-GAS-SHIFT CATALYST
}

\author{
Final Technical Report \\ Charles N. Satterfield \\ Ian C. Yates \\ Claire Chanenchuk
}

Department of Chemical Engineering

Massachusetts Institute of Technology

Cambridge, Massachusetts 02139

July, 1991

Prepared for the

U.S. Department of Energy

under

Contract No. DE-AC22-87PC79816 


\section{TABLE OF CONTENTS}

Page

Executive Summary

I. The Fischer-Tropsch Synthesis with a Mechanical Mixture of a Cobalt Catalyst and a Copper-Based Water-Gas-Shift Catalyst: Abstract

3

I.A. Introduction 4

I.B. Experimental 6

I.B.1 Water-Gas-Shift (WGS) Catalysts 6

$\begin{array}{lll}\text { I.B.2 Fischer-Tropsch Catalyst } & 8\end{array}$

I.B.3 Combined System 9

I.C. Results and Discussion: Water-Gas-Shift Catalyst
Alone

$\begin{array}{ll}\text { I.C.1 Stability } & 10\end{array}$

$\begin{array}{lll}\text { I.C.2 Effect of Pressure } & 11\end{array}$

I.C.3 Effect of Inlet $\mathrm{H}_{2} / \mathrm{CO}$ Ratio 11

$\begin{array}{lll}\text { I.C.4 Effect of Temperature } & 12\end{array}$

I.C.5 Effect of 1-Butene 12

I.D. Results and Discussion: Fischer-Tropsch plus
Water-Gas-Shift Catalyst

I.D.1 Fischer-Tropsch Activity 14

I.D.2 Water-Gas-Shift Activity 16

I.D.3 Product Selectivity 17

I.E. Conclusions 20

I.F. Refcrences to Part I 22 
Table I-1 Reduction Procedure for Water-Gas Shift Catalysts

Table I-2 Process Changes for $\mathrm{Cu} / \mathrm{ZnO} / \mathrm{Al}_{2} \mathrm{O}_{3}$ Alone

Table I-3 Standard Operating Conditions and Product Distributions for Combined Systems and Cobalt Catalyst Alone

Figures for Part I

II. The Intrinsic Kinetics of the Fischer-Tropsch Synthesis on a Cobalt Catalyst: Abstract

II.A. Introduction

II.B. Background

II.C. Experimental Section

II.D. Results and Discussion

II.E. Comparison to Literature Data

II.F. Conclusions

II.G. Nomenclature

II.H. Literature Cited

Table II-1 Summary of Kinetic Studies of the Fischer-Tropsch Synthesis on CobaltBased Catalysts

Table II-2 Activity for Repeated Conditions of $240^{\circ} \mathrm{C}, 0.79 \mathrm{MPa}, \mathrm{H}_{2} / \mathrm{CO}=2$, and Synthesis Gas Feed Rate of 0.067 $\mathbf{N} / \mathbf{m i n} / \mathbf{g}$ of Catalyst

Figures for Part II

III. The Hydrocarbon Selectivity of Cobalt Fischer-Tropsch Catalysts: Abstract

III.A. Introduction 
III.B. Literature Review 66

III.C. Hydrocarbon Carbon Number Distributions 68

$\begin{array}{lll}\text { III.C.1 Representative Product Distributions } & 69\end{array}$

III.C.2 The Effect of Operating Parameters 70

$\begin{array}{lll}\text { III.C.3 } & \text { Space Velocity } & 71\end{array}$

$\begin{array}{lll}\text { III.C.4 Pressure } & 72\end{array}$

$\begin{array}{lll}\text { III.C.5 Temperature } & 72\end{array}$

III.C.6 Reactor $\mathrm{H}_{2} / \mathrm{CO}$ Ratio 72

III.D. Selectivity to Various Product Classes 73

III.E. Secondary Reactions of 1-Alkenes 75

III.E.1 Rate of Ethane Formation from Ethene 75

III.E.2 Rate of n-Butane Formation from 1-Butene 75

III.E.3 Rate of 2-Butene Formation from 1-Butene 76

$\begin{array}{lll}\text { III.E.4 Summary } & 77\end{array}$

$\begin{array}{ll}\text { III.F. Conclusions } & 78\end{array}$

$\begin{array}{ll}\text { III.G. Literature Cited } & 79\end{array}$

$\begin{array}{ll}\text { Figures for Part III } & 81-88\end{array}$

IV. The Efiect of 1-Alkene Addition on Hydrocarbon Product Distribution on a Cobalit Catalyst: Abstract $\quad 89$

$\begin{array}{ll}\text { IV.A. Introduction } & 90\end{array}$

$\begin{array}{ll}\text { IV.B. Experimental Procedure } & 93\end{array}$

IV.C. Evidence for Incorpsration on Cobalt 94

IV.D. Mathematical Modelling of Incorporation 97 
IV.D.1 Initiation and Termination by 1-Alkenes

IV.D.2 Initiation, Termination, and Propagation by 1-Alkenes

IV.E. A Model for the Double- $\alpha$ Distribution 102

IV.F. Explanations of Selectivity Trends 103

$\begin{array}{lll}\text { IV.F.1 Cobalt } & 103\end{array}$

$\begin{array}{lll}\text { IV.F.2 Iron } & 105\end{array}$

IV.G. Conclusions 105

$\begin{array}{ll}\text { IV.H. Nomenclature } & 107\end{array}$

$\begin{array}{ll}\text { IV.I. Literature Cited } & 108\end{array}$

$\begin{array}{lll}\text { Table IV-1: } & \text { Interpretation of Observed Process } \\ \text { Variable Effects on Cibalt } & 110\end{array}$

Figures for Part IV 111-117 


\section{Executive Summary}

The feasibility of using a mechanical mixture of a $\mathrm{Co} / \mathrm{MgO} / \mathrm{SiO}_{2}$ Fischer-Tropsch catalyst and a $\mathrm{Cu}-\mathrm{ZnO} / \mathrm{Al}_{2} \mathrm{O}_{3}$ water-gas-shift (WGS) catalyst for hydrocarbon synthesis in a slurry reactor has been established. Such a mixture can combine the superior product distribution from cobalt with the high activity for the WGS reaction characteristic of iron. Weight ratios of $\mathrm{Co} / \mathrm{MgO} / \mathrm{SiO}_{2}$ to $\mathrm{Cu}-\mathrm{ZnO} / \mathrm{Al}_{2} \mathrm{O}_{3}$ of 0.27 and 0.51 for the two catalysts were studied at $240^{\circ} \mathrm{C}, 0.79 \mathrm{MPa}$, and in situ $\mathrm{H}_{2} / \mathrm{CO}$ ratios between 0.8 and 3.0 . Each catalyst mixture showed stable Fischer-Tropsch activity for about 400 hours-onstream at a level comparable to the cobalt catalyst operating alone. The $\mathrm{Cu}-\mathrm{ZnO} / \mathrm{Al}_{2} \mathrm{O}_{3}$ catalyst exhibited a very slow loss of activity under these conditions, but when operated alone it was stable in a slurry reactor at $200-220^{\circ} \mathrm{C}, 0.79-1.48 \mathrm{MPa}$, and $\mathrm{H}_{2} / \mathrm{CO}$ in situ ratios between 1.0 and 2.0. The presence of the water-gas-shift catalyst did not affect the long-term stability of the primary Fischer-Tropsch selectivity, but did increase the extent of secondary reactions, such as l-alkene hydrogenation and isomerization.

The rate of synthesis gas consumption over the catalyst was measured at 220 to $240^{\circ} \mathrm{C}, 0.5$ to $1.5 \mathrm{MPa}, \mathrm{H}_{2} / \mathrm{CO}$ feed ratios of 1.5 to 3.5 and conversions of 6 to $68 \%$ of hydrogen and 11 to $73 \%$ of carbon monoxide. The inhibiting effect of carbon monoxide was determined quantitatively and a Langmuir-Hinshelwood-type equation of the following form was found to best represent the results:

$$
-\mathrm{R}_{\mathrm{H}_{2}+\mathrm{CO}}=\frac{\therefore \mathrm{P}_{\mathrm{CO}} \mathrm{P}_{\mathrm{H}_{2}}}{\left(1+b \mathrm{P}_{\mathrm{CO}}\right)^{2}}
$$

The apparent activation energy was 93 to $95 \mathrm{~kJ} / \mathrm{mol}$. Data from previous studies on cobalt-based Fischer-Tropsch catalysts are also well correlated with this rate expression. 
Increasing space velocity (decreasing conversion) or decreasing reactor $\mathrm{H}_{2} / \mathrm{CO}$ ratio decreased the yield of (undesired) $C_{1}$ products and increased the yield of (desired) $\mathrm{C}_{10}+$ products. Reactor temperature and pressure had little effect on the carbon number distribution. These findings are interpreted in terms of the extent of the readsorption of 1-alkenes into growing chains on the catalyst surface. The relative selectivity to 1 -alkenes by the primary synthesis and secondary reaction of 1 -alkenes to $n$ alkanes and 2-alkenes depends on reactor $\mathrm{H}_{2} / \mathrm{CO}$ ratio and $\mathrm{CO}$ concentration.

The cobalt-catalyzed reactions of $\mathrm{C}_{2} \mathrm{H}_{4}, \mathrm{C}_{3} \mathrm{H}_{6}$, or $1-\mathrm{C}_{4} \mathrm{H}_{8}$ added to synthesis gas in concentrations ranging from 0.5 to $1.2 \mathrm{~mol} . \%$ of total feed were studied at $220^{\circ} \mathrm{C}$, and 0.45 to $1.48 \mathrm{MPa}$. $\mathrm{H}_{2} / \mathrm{CO}$ feed ratios were varied between 1.45 to 2.25 and $\mathrm{H}_{2}+\mathrm{CO}$ conversions between 5 and $30 \%$ were observed.

1-Alkenes incorporate into growing chains on the catalyst surface, probably by initiating and/or terminating the chain growth process. Only ethene may propagate chain growth significantly. The propensity of the 1-alkenes to incorporate decreases with increasing carbon number of the 1-alkene and is affected by the extent cf competitive reactions, notably hydrogenation to the alkane and isomerization to the 2-alkene. Incorporation is most evident in products above about $\mathrm{C}_{10}+$.

The double- $\propto$ behavior exhibited by most Fischer-Tropsch catalysts can be interpreted as the sum of two growth processes, one a stepwise single-carbon giuwth process and the other a 1-alkene incorporation process. Many of the effects of process variables on the hydrocarbon selectivity of Fischer-Tropsch catalysts are consistent with this theory.

The results of the study are divided into four parts, as outlined in the Table of Contents. 


\title{
I. The Fischer-Tropsch Synthesis with a Mechanical Mixture of a Cobalt Catalyst and a Copper-Based Water-Gas-Shift Catalyst
}

\author{
Abstract
}

The feasibility of using a mechanical mixture of a $\mathrm{Co} / \mathrm{MgO} / \mathrm{SiO}_{2}$ Fischer-Tropsch (atalyst and a $\mathrm{Cu}-\mathrm{ZnO} / \mathrm{Al}_{2} \mathrm{O}_{3}$ water-gas-shift (WGS) catalyst for hydrocarbon synthesis in a slurry reactor has been established. Such a mixture can combine the superior product distribution from cobalt with the high activity for the WGS reaction characteristic of iron. Weight ratios of $\mathrm{Co} / \mathrm{MgO} / \mathrm{SiO}_{2}$ to $\mathrm{Cu}-\mathrm{ZnO} / \mathrm{Al}_{2} \mathrm{O}_{3}$ of 0.27 and 0.51 for the two catalysts were studied at $240^{\circ} \mathrm{C}, 0.79 \mathrm{MPa}$, and in situ $\mathrm{H}_{2} / \mathrm{CO}$ ratios between 0.8 and 3.0 . Each catalyst mixture showed stable Fischer-Tropsch activity for about 400 hours-onstream at a level comparable to the cobalt catalyst operating alone. The $\mathrm{Cu}-\mathrm{ZnO} / \mathrm{Al}_{2} \mathrm{O}_{3}$ catalyst exhibited a very slow loss of activity under these conditions, but when operated alone it was stable in a slurry reactor at $200-220^{\circ} \mathrm{C}, 0.79-1.48 \mathrm{MPa}$, and $\mathrm{H}_{2} / \mathrm{CO}$ in situ ratios between 1.0 and 2.0. The presence of the water-gas-shift catalyst did not affect the long-term stability of the primary Fischer-Tropsch selectivity, but did increase the extent of secondary reactions, such as l-alkene hydrogenation and isomerization. 


\section{I.A. Introduction}

Cobalt-based Fischer-Tropsch catalysts exhibit many performance characteristici superior to those based on iron. Carbon formation on cobalt is minimal, which may increase catalyst life and facilitate purification of the product, and oxygenates such as aldehydes, ketones and alcohols are formed in much lower quantities, and make product workup easier. However an advantage of iron catalysts is that they are generally active for the water-gas shift reaction. Thus, Fischer-Tropsch reactors can be fed with the hydrogen-lean synthesis gas produced by modern coal gasifiers, and hydrogen can be generated in situ simultaneously with the synthesis reaction, via the water-gas shift reaction.

Cobalt catalysts lack water-gas-shift (WGS) activity at the optimum temperatures of the synthesis reaction. Thus, a mechanical mixture of a cobalt catalyst and a watergas shift catalyst may make possible a combination of the product advantages of cobalt and the operating advantages of a slurry reactor.

Shell patents ${ }^{1.2}$ indicate that a mechanical mixture of a $\mathrm{Co} / \mathrm{ZrO}_{2} / \mathrm{SiO}_{2}$ FischerTropsch catalyst and a $\mathrm{Cu} / \mathrm{ZnO} / \mathrm{Al}_{2} \mathrm{O}_{3}$ shift catalyst can be successfully used to carry out Fischer-Tropsch synthesis in a fixed-bed reactior. The cited preferred conditions are 175 $275^{\circ} \mathrm{C}$ and 1 to $7.5 \mathrm{MPa}$. The ratio of cobalt to shift catalyst is adjusted depending on the $\mathrm{H}_{2} / \mathrm{CO}$ feed ratio, with a higher portion of shift catalyst recommended for lower $\mathrm{H}_{2} / \mathrm{CO}$ ratios.

Tominaga et al. ${ }^{3}$ report results of studies with a fixed-bed at $0.3 \mathrm{MPa}$ and between 
220 and $280^{\circ} \mathrm{C}$ using a 10 wt.\% $\mathrm{Co}$ on $\mathrm{SiO}_{2}$ catalyst mixed with a $\mathrm{Cu} / \mathrm{Cr}_{2} \mathrm{O}_{3}$ shift catalyst. The primary focus of their research was the Köelbel-Engelhardt synthesis, in which CO and $\mathrm{H}_{2} \mathrm{O}$, rather than synthesis gas, are fed to the reactor. However, they report some data on feeds containing only $\mathrm{H}_{2}$ and $\mathrm{CO}$ with a $\mathrm{H}_{2} / \mathrm{CO}$ ratio of 0.5 . Two trends were observed. First, when the shift catalyst was added, the $\mathrm{CO}_{2}$ in the products increased from 0.1 to $6.0 \mathrm{~mol} . \%$, indicating a large enhancement in shift activity. Second, the weight fraction of $\mathrm{C}_{5}+$ products remained unaffected by addition of the shift catalyst to the system.

Post and co-workers give no information on possible change in activity and selectivity with time. Tominaga et al. report that the yield of $\mathrm{CO}_{2}$ decreased to $50 \%$ of its initial value within the first 6 hours of operation, attributed to competitive inhibition of the shift teaction by hydrocarbons. They state that this decreased activity is the steady-state value, but present no data after 12 hours-on-stream.

Therefore, no data on the long-term stability of water-gas shift and a FischerTropsch catalyst system are available. Further, the performance of such a system in a fixed-bed may be difficult to understand because of changing conditions along the bed. Poisons or reaction conditions may deactivate the shift catalyst or the Fischer-Tropsch catalyst in one region of the bed, while catalyst activity may be maintained in another region. In a well-mixed slurry reactor, as used there, operating conditions are the same throughout the vessel.

The primary objective of this work was to search for a combination of a shift catalyst and a cobalt Fischer-Tropsch catalyst that could operate simultaneously and efficiently in a slurry reactor. Ideally, the combined system should exhibit stable activity 
and selectivity, with neither catalyst adversely affecting the other.

\section{I.B. Experimental}

Our approach was to study the Fischer-Tropsch synthesis and the water-gas-shift reaction independently before combining these catalysts. The experiments were performed in a continuous, mechanically-stirred, one-liter autoclave. The slurry reactor and ancillary equipment are described in detail elsewhere. ${ }^{45,6}$ In all runs, an impeller speed of 800 RPM or higher was used, to eliminate possible mass transfer effects.

I.B.1. Water-Gas-Shift (W/GS) Catalysts. Three commercially-available WGS catalysts were studied by themselves. Two Cu- $\mathrm{Cr}_{2} \mathrm{O}_{3}$ catalysts $\left(52 \% \mathrm{CuO}\right.$ and $48 \% \mathrm{Cr}_{2} \mathrm{O}_{3}$ or $50 \% \mathrm{CuO}, 4 \% \mathrm{MnO}$ and $46 \% \mathrm{Cr}_{2} \mathrm{O}_{3}$ ) were found to have insufficient stability or activity and are not discussed further here (for details, see Yates ${ }^{7}$ ). Satisfactory performance was achieved with Katalco $52.2\left(33 \% \mathrm{CuO}, 33 \% \mathrm{ZnO}\right.$ and $33 \% \mathrm{Al}_{2} \mathrm{O}_{3}$, surface area $=36 \mathrm{~m}^{2} / \mathrm{g}$, bulk density $62 \mathrm{lb} / \mathrm{ft}^{3}$, as reported by the manufacturer).

The three shift catalysts were each ground and sieved to 50 to $90 \mu \mathrm{m}$ and loaded into the reactor, which had been previously charged with recrystallized octacosane, the carrier used in our slurry Fischer-Tropsch experiments. The octacosane was recrystallized in HPLC grade tetrahydrofuran as recommended by Huff and Satterfield. ${ }^{4}$ The catalysts were then reduced according to the manufacturers' guidelines (see Table 1). For the studies reported here, which utilized the $\mathrm{Cu} / \mathrm{ZnO} / \mathrm{Al}_{2} \mathrm{O}_{3}$ catalyst, the reduction procedure was slightly modified as outlined in Table I-1.

Following completion of the reduction, flow of vapor comprising $42.9 \mathrm{~mol} . \% \mathrm{CO}$, $21.4 \mathrm{~mol} . \% \mathrm{H}_{2}$, and $35.7 \mathrm{~mol} . \% \mathrm{H}_{2} \mathrm{O}$ at $0.019 \mathrm{Nl} / \mathrm{min} / \mathrm{g}$.cat. (unreduced basis) was 
begun. The rate at which water was fed is approximately five times that which would be typically synthesized in our reactor with a cobalt Fischer-Tropsch catalyst. ${ }^{7}$ For the initial stability testing, temperature and pressure were held constant at $200^{\circ} \mathrm{C}$ and 0.79 MPa. All data presented here on gas composition and gas flow rates are on a wet-gas basis.

Water was delivered by a Waters Associates, Inc., Model 6000A pump, which is accurate to $\pm 0.005 \mathrm{ml}$ of liquid $/ \mathrm{min}\left(1.12 \times 10^{-4} \mathrm{Nl}\right.$ of water vapor $\left./ \mathrm{min}\right)$. Before being charged, the water was purified in a two-step process. First, the water was passed through a reverse-osmosis Millipore HEMO-RO"60 filtration system which removes ions and produces water with a resistivity of greater than $10 \mathrm{MO} / \mathrm{cm}$. The deionized water was then passed through a Millipore Milli-Q Reagent $\mathrm{H}_{2} \mathrm{O}$ systern with ion-exchange and activated carbon beds. The purified water was verified by HPLC to contain less than 1 ppm of total impurities.

The water was fed to the reactor through a $0.159 \mathrm{~cm}(1 / 16 \mathrm{inch})$ O.D. tube which was heated to $20^{\circ} \mathrm{C}$ above reactor temperature to vaporize the water. The outlet of the tube was at the same height as the reactor's impeller and was therefore submerged in slurry wax during operation. The temperature of the outlet line from the reactor was held at $250^{\circ} \mathrm{C}$ to minimize the possibility of reflux of water during operation.

Activity was monitored by calculating the percent approach to equilibrium, either from disappearance of $\mathrm{CO}$ or appearance of $\mathrm{H}_{2}$ and $\mathrm{CO}_{2}$. Based on $\mathrm{CO}, \mathrm{X}_{\mathrm{CO}}$ is given by: 


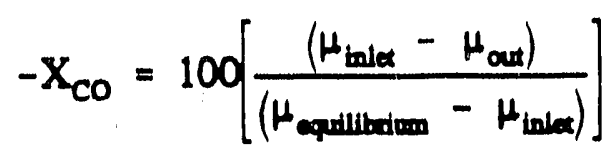

As a cross-check for a material balance, the equivalent value based on the products, $\mathrm{H}_{2}$ and $\mathrm{CO}_{2}, \mathrm{X}_{\text {product }}$ is defined as:

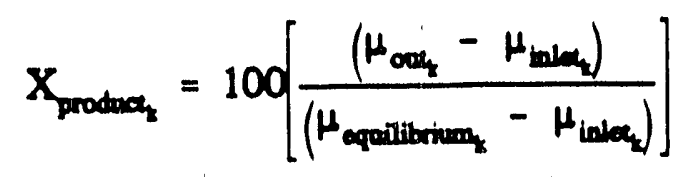

where, for component $k$

$$
\begin{array}{ll}
\mu_{\text {out,k }} & =\text { measured flow rate at outlet }[\mathrm{mmol} / \mathrm{min}] \\
\mu_{\text {inlet,k }} & =\text { measured flow rate at inlet }[\mathrm{mmol} / \mathrm{min}] \\
\mu_{\text {equitibrium,k }} & =\text { outlet flow rate at equilibrium }[\mathrm{mmol} / \mathrm{min}] .
\end{array}
$$

The inlet $\mathrm{CO}_{2}$ is zero. Ranging from $0 \%$ at no activity to $100 \%$ at equilibrium conversion, equations 1 and 2 provide a convenient benchmark for comparison of different feed compositions and/or flow rates. All material balances on WGS-only data were required to close within $3 \%$ on carbon.

I.B2. Fischer-Tropsch Catalyst. The cobalt Fischer-Tropsch catalyst was prepared by an outside supplier and is of the approximate composition of the cobalt catalysts used at Ruhrchemie. ${ }^{8}$ The nominal composition of the catalyst, as reported to us by its manufacturer, is $21.4 \mathrm{wt} . \% \mathrm{Co}$ (as Co), $3.9 \mathrm{wt} . \% \mathrm{Mg}$ (as $\mathrm{Mg}$ ), and the remainder diatomaceous earth.

Supplied as an extrudate, the catalyst was ground and sieved to 50 to $90 \mu \mathrm{m}$. Following sieving, the catalyst was placed in an external reduction vessel. It was held in this unit with a $7 \mu \mathrm{m}$ frit while hydrogen (prepurified, MedTech Gases, Inc.) was brought 
on stream at a flow of $1.36 \mathrm{Nl} / \mathrm{min}$ (approximately $10,000 \mathrm{~V} / \mathrm{V} / \mathrm{hr}$ ). At this flow rate the pressure in the vessel was approximately $0.72 \mathrm{MPa}$. The temperature of the reduction tube was increased steadily from $25^{\circ} \mathrm{C}$ to $330^{\circ} \mathrm{C}$ over 4.75 hours while the inlet flow rate was held constant. The reduction unit was then held at $330^{\circ} \mathrm{C}$ for 0.75 hours and subsequently the unit was pressurized with helium and rapidly cooled.

I.B.3. Combined System. The reduced cobalt catalyst was transferred under helium to the autoclave reactor which contained the reduced water-gas-shift catalyst, also under helium. The reactor was brought on-stream at $0.79 \mathrm{MPa}, 187^{\circ} \mathrm{C}$, and $\mathrm{H}_{2} / \mathrm{CO}=1.5$ at a flow rate of $1.0 \mathrm{Nl} / \mathrm{min}$. The $\mathrm{CO}$ used in these experiments was $\mathrm{CP}$ grade (North East Airgas, Inc.) and the $\mathrm{H}_{2}$ was prepurified grade (MedTech Gases, Inc.).

The reactor conditions were held constant for the first 66 hours and then the $\mathrm{H}_{2} / \mathrm{CO}$ feed ratio was adjusted to about 1.0 with an inlet flow' of $0.59 \mathrm{Nl} / \mathrm{min}$ and the temperature was increased to $240^{\circ} \mathrm{C}$ over a period of 8 hours. The following reactor conditions were then considered to be "standard" conditions: $0.79 \mathrm{MPa}, 240^{\circ} \mathrm{C}$, and inlet $\mathrm{H}_{2} / \mathrm{CO}=1.0$ at a flow rate of about $0.60 \mathrm{Nl} / \mathrm{min}$.

Two combined-system runs were performed. Run $L$ was operated with 9.0 grams of $\mathrm{Co} / \mathrm{MgO} / \mathrm{SiO}_{2}$ catalyst and 33 grams of $\mathrm{Cu}-\mathrm{ZnO} / \mathrm{Al}_{2} \mathrm{O}_{3}$ (both on an unreduced basis) for a weight ratio of 0.27 ; run $\mathrm{H}$ was operated with 17.0 grams of $\mathrm{Co} / \mathrm{MgO} / \mathrm{SiO}_{2}$ catalyst and 33 grams of $\mathrm{Cu}-\mathrm{ZnO} / \mathrm{Al}_{2} \mathrm{O}_{3}$ catalyst for a weight ratio of 0.51 . In run $\mathrm{L}$ "standard" conditions were utilized for the entire run of about 400 hours-on-stream. Under these conditions, about $16.5 \%$ of the $\mathrm{H}_{2}+\mathrm{CO}$ fed was converted to Fischer-Tropsch products.

In run $\mathrm{H}$, "standard" conditions were held for the first 220 hours-on-stream. Subsequently, the feed to the reactor was varied systematically over a $\mathrm{H}_{2} / \mathrm{CO}$ feed ratio 
of 1 to 2 , and at either of two flow rates, about 0.30 and $0.60 \mathrm{Nl} / \mathrm{min}$. These conditions provided conversions of $\mathrm{H}_{2}+\mathrm{CO}$ between 29 and $75 \%$. At 350 hours-on-stream, operating conditions were returned to "standard" to verify catalyst stability, and the run was ended after about 400 hours on stream. All material balances reported on the combined Fischer-Tropsch/water-gas-shift system closed within 3\% on oxygen. Oxygen was chosen as the material balance closure element because carbon and bydrogen accumulate in the reactor in the form of heavy waxes under Fischer-Tropsch synthesis conditions, which makes it more difficult to base material balances on these elements.

\section{C. Results and Discussion: Water-Gas-Shin Catalyst Alone}

A preliminary run with the $\mathrm{Cu} / \mathrm{ZnO} / \mathrm{Al}_{2} \mathrm{O}_{3}$ catalyst showed stable activity, but it appeared desirable to modify the reduction procedure (see Table I-1) by increasing the length of the helium purge and decreasing the severity of the final reduction period. This reduction procedure was found to be superior.

We present here the results of a single run that extended over about 1030 hours and is outlined in Table I-2. No process changes were made during the first 300 hourson-stream. Then, either the pressure, temperature or feed composition was changed and the $\%$ of equilibrium conversion was monitored for an interval of 48 to 100 hours. The reactor was then returned to "base case" conditions which would in turn be monitored for 48 to 100 hours. Thus, we were able to monitor both the effect of the process change on activity and on catalyst stability.

1.C.1. Stability. Figure I-1 shows the \% of equilibrium conversions for the "base case" conditions. As Figure I-1 illustrates, the catalyst deactivated very slowly with time- 
on-stream.

1.C.2. Efrect of Pressure. Total pressure does not affect the equilitrium of the shift reaction, so increasing pressure would be expected to change conversion only by its effect on the reaction rate, which in turn may change the concentrations of the components in the reactor. After 303 hours-on-stream, the pressure was increased from 0.79 to $1.48 \mathrm{MPa}$. Temperature, space velocity, and feed composition were held constant. After a further 55 hours, the reactor was returned to the "base case" conditions and held there for 67 hours.

Figure I-2 shows the conversion data for the time period before, during, and after the pressure change. Increased pressure has no significant effect on the rate of water-gas shift or the long-term stability of the catalyst.

1.C.3. Efrect of Inlet $\mathrm{H}_{2} / \mathrm{CO}$ Ratio. The $\mathrm{H}_{2} / \mathrm{CO}$ ratio is an important consideration for evaluating the stability of a shift catalyst for the Fischer-Tropsch synthesis. $A\left(\mathrm{H}_{2} / \mathrm{CO}\right)_{\text {in }}$ ratio of 0.5 was chosen for the base case, because, after undergoing the shift reaction, it provided an in situ $\mathrm{H}_{2} / \mathrm{CO}$ ratio of approximately two, the usage ratio for cobalt catalysts. To elucidate the effect of $\mathrm{H}_{2} / \mathrm{CO}$, two additional feed ratios, 0.7 and 1.0, were studied. These produced in situ $\mathrm{H}_{2} / \mathrm{CO}$ ratios near 2.5 and 3, respectively. Higher $\mathrm{H}_{2} / \mathrm{CO}$ ratios were examined because higher hydrogen partial pressures might increase the likelihood of sintering and higher $\mathrm{CO}$ partial pressures are reported not to have deleterious effects on low-temperature shift catalysts. ${ }^{9,10}$

Figure I-3 shows that the $\%$ of equilibrium fell about 3 to $5 \%$ upon increased reactor $\mathrm{H}_{2} / \mathrm{CO}$ ratios. In order to simplify the figure, the component conversions are not shown. This decrease is consistent with a simple equilibrium-limited rate expression, 
presented by $\mathrm{Moe}^{9}$, of the form:

$$
R_{\text {maxam inin }}=k\left[\mathrm{P}_{\mathrm{CO}} \mathrm{P}_{\mathrm{H}_{2} \mathrm{O}}-\frac{\mathrm{P}_{\mathrm{H}_{2}} \mathrm{P}_{\mathrm{CO}_{2}}}{\mathrm{~K}_{\mathrm{P}}}\right]
$$

In equation 6, increasing $\mathrm{P}_{\mathrm{H}_{2}}$ and decreasing $\mathrm{P}_{\mathrm{co}}$ would decrease the "driving force" for reaction, thereby slowing the rate of reaction.

I.C.4. Efrect of Temperature. Because copper-based shift catalysts sinter readily ${ }^{11}$, catalyst manufacturers recommend that these catalysts not be used above $250^{\circ} \mathrm{C}$. For most of the run, the reactor was operated at $200^{\circ} \mathrm{C}$, the lowest temperature at which $\mathrm{Cu} / \mathrm{ZnO} / \mathrm{Al}_{2} \mathrm{O}_{3}$ catalysts reportedly have appreciable activity. ${ }^{10}$ Figure I-1, which presents the "base case" data, indicates that at $200^{\circ} \mathrm{C}$ the catalyst converted approximately $65-70 \%$ of the $\mathrm{H}_{2} \mathrm{O}$ and $\mathrm{CO}$ fed. After 637 hours-on-stream, the reactor temperature was increased from 200 to $220^{\circ} \mathrm{C}$, and at 693 hours-on-stream, the temperature was returned to $200^{\circ} \mathrm{C}$. At $220^{\circ} \mathrm{C}, \%$ of equilibrium conversion increased to around $80 \%$ (Figure I-4), but it reverted to its former performance when the temperature was returned to $200^{\circ} \mathrm{C}$.

1.C.5. Effect of 1-Butene. It has been suggested that alkenes may adsorb on the surface of shift catalysts, inhibiting their activity. To test this possibility, 1-butene was added to the feed at $\$ 24$ hours-on-stream, in the form of a mixture of 2 mol.\% 1-butene in prepurified $\mathrm{H}_{2}$ (Matheson Gases, Inc.). 1-Butene is representative of 1-alkenes from the Fischer-Tropsch reaction and is easy to study in our reactor system, as it is the highest molecular weight 1-alkene that is not condensed in the product traps. ${ }^{12,13}$

Figure I-5 shows that shift activity remains essentially unchanged by the addition 
of the 1-butene at this concentration. The amount of hydrogen consumed by 1-butene hydrogenation was negligible. About $96 \%$ of the added 1-butene was either hydrogenated to butane or isomerized to cis-2-butene and trans"2-butene; no significant amount was cracked to smaller hydrocarbons. The product composition was about $4 \%$ 1-butene, $53 \%$ n-butane, $29 \%$ trans- 2 butene and $14 \%$ cis- 2 butene. The bydrogenation probably occurs on reduced copper, a known hydrogenation catalyst, and the isomerization on acidic sites on the $\mathrm{Al}_{2} \mathrm{O}_{3}$ support. Cis-2-butene and trans-2-butene are formed in almost equilibrium ratios.

In summary, a reduction procedure was achieved that allowed stable water-gasshift behavior for a $\mathrm{Cu}-\mathrm{ZnO} / \mathrm{Al}_{2} \mathrm{O}_{3}$ catalyst in a slurry reactor. Within the ranges studied, the catalyst was not adversely affected by increased temperature, pressure, in situ ratio of $\mathrm{H}_{2} / \mathrm{CO}$, or the presence of 1-butene. 


\section{I.D. Results and Discussion: Fischer-Tropsch plus Water-Gas-Shif Catalyst}

Two weight ratios of $\left[\mathrm{Co} / \mathrm{MgO} / \mathrm{SiO}_{2}\right]$ to $\left[\mathrm{Cu}-\mathrm{ZnO} / \mathrm{A}_{2} \mathrm{O}_{3}\right]$ were studied, termed run $\mathrm{L}$ and run $\mathrm{H}$, with results summarized in Table I-3 and displayed in Figures I-6 through I-16.

I.D.1. Fischer-Tropsch Activity. Figure I-6 shows that, for each run, the combined catalyst system retained steady-state Fischer-Tropsch activity for the entire time of about 400 hours-on-stream. The average rate of $\mathrm{H}_{2}+\mathrm{CO}$ consumption was $0.53 \mathrm{mmol} / \mathrm{min}$ g.Co-cat., on an unreduced basis, for run $\mathrm{L}$ and $0.55 \mathrm{mmol} / \mathrm{min}-\mathrm{g}$.Co-cat. for run $\mathrm{H}$. (both at "standard" conditions). The reactor gas compositions were different for the two runs, but the inherent Fischer-Tropsch activity can be compared to each other and to that of the $\mathrm{Co} / \mathrm{MgO}_{2} / \mathrm{SiO}_{2}$ catalyst operating alone by the following rate expression developed for this cobalt catalyst. ${ }^{14}$

$$
-R_{\mathrm{H}_{2}+\mathrm{CO}}=\frac{a \mathrm{P}_{\mathrm{CO}} \mathrm{P}_{\mathrm{H}_{2}}}{\left(1+\mathrm{bP} \mathrm{P}_{\mathrm{CO}}\right)^{2}}
$$

At $240^{\circ} \mathrm{C}, \mathrm{a}=75.76 \mathrm{mmol} / \mathrm{min}-\mathrm{g} . \mathrm{cat} .-\mathrm{MPa}^{2}$ and $\mathrm{b}=11.61 \mathrm{MPa}^{-1}$.

Figure I-7 shows the average rate of $\mathrm{H}_{2}+\mathrm{CO}$ consumption and the rate as predicted from equation 7 for the reactor conditions of run $\mathrm{L}$. The activity of the combined system appears to be slightly higher than that predicted. This may represent additional hydrogen consumption by hydrogenation on the water-gas shift catalyst, or may have been caused by a slight variation in the reduction procedure of the cobalt catalyst. Within our ability to reproduce catalyst reduction procedures, the cobalt catalyst acting alone and the cobalt catalyst operating in conjunction with the water-gas 
shift catalyst display similar activity.

Since operating conditions were varied during run $\mathrm{H}$, comparisons can be made of not only the absolute Fischer-Tropsch activity, but also the form of the rate equation. Equation 7 can be linearized as follows:

$$
\left[\frac{P_{\mathrm{H}_{2}} P_{C O}}{-R_{\mathrm{H}_{2}+\mathrm{CO}}}\right]^{H_{\mathrm{H}}}=\frac{1}{a^{H_{2}}}+\frac{b}{a^{H_{2}}} \mathbf{P}_{\mathrm{CO}}
$$

Figure I-8, a plot of the left side of equation 8 versus $P_{\text {Co }}$ for run $H$, shows that the form of this equation is obeyed in the presence of the WGS catalyst as well as in its 
absence. The parameter values for the combined system were non-linearly regressed and found to be $a=81.7 \pm 9.7 \mathrm{mmol} / \mathrm{min}-\mathrm{g}$.Co-cat.- $\mathrm{MPa}^{2}$ and $b=8.1 \pm 0.8 \mathrm{MPa}^{-1}$ at $240^{\circ} \mathrm{C}$.

These values are remarkably close to the values obtained with the Co-based FischerTropsch catalyst acting alone.

Figures I-6 through I-8 show that neither the absolute activity nor the long-term stability of the cobalt Fischer-Tropsch catalyst was adversely affected by the presence of the copper WGS catalyst.

1.D.2. Water-Gas-Shift Activity. At the temperatures of interest for the FischerTropsch synthesis, the equilibrium of the water-gas-shift reaction favors the production of $\mathrm{H}_{2}$ and $\mathrm{CO}_{2}$. Thus, a good measure of shift activity is the extent to which $\mathrm{H}_{2} \mathrm{O}$ reacts to form $\mathrm{CO}_{2}$ as measured by $\mathrm{X}_{\text {wos }}$ where:

$$
\mathbf{X}_{\text {was }}=\frac{\mathbf{P}_{\mathrm{CO}_{2}}}{\left(\mathbf{P}_{\mathrm{CO}_{2}}+\mathbf{P}_{\mathrm{H}_{2} \mathrm{O}}\right)}
$$

$\mathrm{X}_{\text {was }}$ is independent of Fischer-Tropsch synthesis gas consumption, as it depends only on the relative rates of formation of $\mathrm{CO}_{2}$ and $\mathrm{H}_{2} \mathrm{O}$. At $240^{\circ} \mathrm{C}$, if the system achieved equilibrium conversion, $\mathbf{X}_{\text {was }}$ would exceed 0.99 . For the fused iron ammonia synthesis catalyst used in a similar manner in many previous studies in our laboratories, $\mathrm{X}_{\text {wGS }}$ ranged from 0.8 at $232^{\circ} \mathrm{C}$ to 1.0 at $263^{\circ} \mathrm{C}^{15}$

Figure I-9 shows the extent of water-gas shift, expressed as shown in equation 9 , for runs $L$ and $H$. In run $L$, an average of $94 \%$ of the water formed was converted to $\mathrm{CO}_{2}$, indicating that the system approached equilibrium. The shift catalyst retained its activity, even in the presence of the cobalt catalyst and the Fischer-Tropsch synthesis 
products. Cobalt has little shift activity $7,8,16$ and, therefore, the shift activity. shown in Figure I-9 must come from the shift catalyst. The extent of the water-gas shift decreased steadily with time-on-stream for run $\mathrm{H}$, but did not correlate with percent synthesis gas conversion, eliminating alkene inhibition as a possible cause of the deactivation.

The combined catalyst system in run $L$ produced higher yields of methanol than were produced in run $\mathrm{H}$ or when the cobalt catalyst was operated alone (see Figures $\mathrm{I}-15 \mathrm{a}, \mathrm{b}$, and $\mathrm{c}$ ), although these decreased with time (Fig. I-10). The $\mathrm{Cu}-\mathrm{ZnO} / \mathrm{Al}_{2} \mathrm{O}_{3}$ catalyst is active for methanol synthesis as well as the water-gas-shift. Despite intensive study, there is still controversy over the chemical state of copper on the catalyst during methanol synthesis and the kinetics of the reaction are complex. ${ }^{17}$ The relative activity for the two reactions must vary in response to different nuances of surface structure and gas composition, judging from some of the results here. In run $L$ the rate of methanol production decreased with time-on-stream, whereas the WGS activity remained constant, as did reactor conditions (Figure I-10). In run $\mathrm{H}$, however, WGS activity decreased steadily with time (Fig. I-9).

I.D.3. Product Selectivity. Figures I-11a and I-11b show Schulz-Flory overhead product distributions (oxygenates plus hydrocarbons) at several times during the entire run, for runs $\mathrm{L}$ and run $\mathrm{H}$. The distribution is essentially invariant for run $\mathrm{L}$, but there is a moderate increase in the heaviest products with time for run $\mathrm{H}$. This is probably caused by the subtle interaction of several effects. 1-Alkenes, formed as a primary product, may undergo secondary reactions such as hydrogenation to n-paraffins or isomerization, predominantly to 2-alkenes. Figures I-12a and I-12b show the ratio of 1 butene/n-butane and 1-butene/2-butene versus time-on-stream. The lower these ratios, 
the greater the extent of secondary reaction. In run $\mathrm{L}$ secondary reaction activity did not seem to vary significantly with time-on-stream. For run $\mathrm{H}$, the degree of secondary reactions appeared to decrease moderately with time-on-stream. The resulting increase in l-alkene/alkane ratio would allow an increasing degree of alkene incorporation into growing chains (see below).

There are two possible explanations for the decrease in secondary reactions with time in run $\mathrm{H}$. Catalyst sintering reduces the accessible surface area of the catalyst and would be expected to cause a decline in all three types of activity, hydrogenation on reduced $\mathrm{Cu}$, isomerization on acidic $\mathrm{Al}_{2} \mathrm{O}_{3}$ sites, and water-gas shift. Young and Clark ${ }^{11}$ recommend that low-temperature shift catalysts not be operated at temperatures above $250^{\circ} \mathrm{C}$ because of the low melting point of copper. Some sintering may have occurred at the temperature of $240^{\circ} \mathrm{C}$ used for the mixed catalyst runs, versus the WGS scouting experiments performed at slightly lower temperatures $\left(200-220^{\circ} \mathrm{C}\right)$, which could explain the long-term stability of the catalyst then.

Alternatively, loss in hydrogenation and isomerization activity may have been caused by the loss in WGS activity. In run $\mathrm{H}$, the extent of WGS activity decreased with time, causing the reactor $\mathrm{H}_{2} / \mathrm{CO}$ to decrease as feed conditions were held constant (Fig. I-9). Hydrogenation is approximately first order in hydrogen partial pressure and inhibited by adsorbed CO.' Thus, as the data labels on figure I-12b show, the decrease in secondary reactions may not be an intrinsic characteristic of the catalyst system, but rather caused by a decreasing $\mathrm{H}_{2} / \mathrm{CO}$ ratio.

Figure I-13 shows that the 1-alkene/n-alkane ratio of the Fischer-Tropsch products is indeed a strong function of the $\mathrm{H}_{2} / \mathrm{CO}$ ratio in the reactor (run $\mathrm{H}$ ). This 
ratio was varied by feeding gas with three different $\mathrm{H}_{2} / \mathrm{CO}$ ratios at each of two different space velocities. For any given reactor $\mathrm{H}_{2} / \mathrm{CO}$, a lower feed rate results in a lower 1 butene/n-butane ratio in the products. This shows that hydrogenation is occurring as a secondary reaction, which would increase as the residence time increases. Figure I-14 illustrates the effect of reactor $\mathrm{H}_{2} / \mathrm{CO}$ on the hydrogenation activity of the cobalt catalyst studied alone. ${ }^{7}$ Note that higher in situ $\mathrm{H}_{2} / \mathrm{CO}$ values occurred here because the cobalt catalyst itself lacks WGS activity. For a specified reactor $\mathrm{H}_{2} / \mathrm{CO}$ ratio, the ratio (1butene/n-butane) was much higher, indicating less secondary hydrogenation. Apparently, much of the hydrogenation and isomerization activity of the mixed catalyst systems was derived from the WGS catalyst, making these runs more sensitive to changes in reactor conditions. Consistent with this hypothesis, the average 1-butene/n-butane ratio in run $\mathrm{L}$ was lower than that in run $\mathrm{H}$ (Figures I-12a and I-12b).

Figure I-15a is a representative component Schulz-Flory diagram from the Fischer-Tropsch cobalt catalyst studied alone ${ }^{7}$, that may be compared to similar diagrams for the two mixed catalyst runs (Fig. I-15b and c). For similar operating conditions (Table I-3), the overall product distributions of the mixed catalyst systems are similar to that of the Co catalyst acting alone, with a few exceptions. In all cases, the predominant Fischer-Tropsch products are n-alkanes. Selectivity to 2-alkenes, 1-alkenes, and nalcohols drops off sharply with increased $C$ number. The presence of the WGS catalyst may increase the secondary reaction activity which impacts upon the component selectivity, and in turn, the overall molecular weight distributions.

Table I-3 gives the average selectivity to various product cuts for the three runs. The selectivity to fuel range products, $\mathrm{C}_{5}+$, is approximately 50 wt.\% for run $\mathrm{L}, 77 \%$ for 
run $\mathrm{H}$, and $76 \%$ for Co-only.

Recent work by Yates and Satterfield ${ }^{18}$ suggests that yields of high molecular weight products on cobalt are significantly affected by the incorporation of low molecular weight alkenes into growing product chains. 1-Alkenes, the primary synthesis product, may undergo isomerization or hydrogenation, instead of incorporation into growing chains. Thus the low yield to beavy molecular weight products in run $\mathrm{L}$ may bave been caused by a high degree of hydrogenation of 1 -alkenes. At low space velocities (high conversions) these secondary reactions become more noticeable, decreasing alkene concentrations and thus the probability of alkene incorporation.

Figures I-16a and $b$ show analyses of the pot liquid at the end of runs $L$ and $H$. The normalized Schulz-Flory plots, with the carrier, $\mathrm{C}_{28} \mathrm{H}_{58}$, subtracted from the distributions, both show $\alpha$ values of 0.83 . These represent the high molecular weight products that have accumulated throughout the run. The end-of-run slurry from the cobalt catalyst alone, operated over a wide range of conditions, exhibited an $\propto$ of 0.87 . These values of $\alpha$ are comparable.

\section{I.E. Conclusions}

$\mathrm{A} \mathrm{Cu}-\mathrm{ZnO} / \mathrm{Al}_{2} \mathrm{O}_{3}$ water-gas-shift catalyst was found to exhibit stable activity in a slurry reactor under typical Fischer-Tropsch conditions. The stability of the catalyst was not adversely affected by increased pressure, temperature, variation in in situ $\mathrm{H}_{2} / \mathrm{CO}$ ratio, or the addition of 1-butene, a representative Fischer-Tropsch product. 1-Butene underwent considerable hydrogenation and isomerization, but did not crack.

A Co/ $\mathrm{MgO} / \mathrm{SiO}_{2}$ Fischer-Tropsch catalyst was operated in conjunction with this shift catalyst at two different $\left[\mathrm{Co} / \mathrm{MgO} / \mathrm{SiO}_{2}\right] /\left[\mathrm{Cu}-\mathrm{ZnO} / \mathrm{Al}_{2} \mathrm{O}_{3}\right]$ weight ratios, 0.27 and 
0.51. Operating conditions were $240^{\circ} \mathrm{C}, 0.79 \mathrm{MPa}$, and feed $\mathrm{H}_{2} / \mathrm{CO}$ ratios from 1.0 to 2.0 at 0.3 to $0.6 \mathrm{~N} 1 / \mathrm{min}$. In both runs, the Fischer-Tropsch catalyst maintained steadystate activity for the entire run of about 400 hours-on-stream at a level comparable to the cobalt catalyst operating alone. The rate of the Fischer-Tropsch reaction in the mixture followed a rate expression for the cobalt catalyst alone. The $\mathrm{Cu}-\mathrm{ZnO} / \mathrm{Al}_{2} \mathrm{O}_{3}$ WGS catalyst exhibited a very slow loss of its activity.

Each mixed catalyst system exhibited stable long-term Fischer-Tropsch selectivity, but the presence of the WGS catdlyst increased the extent of the secondary reactions, thereby lowering the overall selectivity to fuel range products. The feasibility of a mechanical mixture of a cobalt-based Fischer-Tropsch catalyst and a Cu-ZnO WGS catalyst in a slurry reactor has been established. 


\section{F. References to Part I}

(1) Post, M.F.M., and Sie, S.T., European Patent Application, Pub. No. 0153780 , February 12, 1985a.

(2) Post, M.F.M., and Sie, S.T., European Patent Application, Pub. No. 0153781, February 12, $1985 b$.

(3) Tominaga, H., Miyachiharu, M. and Fujimoto, K, Bull, Chem. Soc. Jpn, $1987,60,2310$.

(4) Huff, G.A., Jr., and Satterfield, C.N., Ind. Eng Chem. Fund, 1982, 21, 479.

(5) Donnelly, T.J., and Satterfield, C.N., Appl Catal., 1989, 56, 231.

(6) Huff, G.A., Jr., Satterfield, C.N., and Wolf, M.H., Ind Eng. Chem. Fund, $1983,22,258$.

(7) Yates, I.C., The Slurry-Phase Fischer-Tropsch Synthesis, Ph.D. Thesis, Massachusetts Institute of Technology, Cambridge, Massachusetts (1990).

(8) Storch, H.H., Golumbic, N., and Anderson, R.B., The Fischer Tropsch and Belated Syntheses, John Wiley \& Sons, New York, 1951.

(9) Moe, J.M., Chem. Eng. Prog, 1962, 58(3), 33.

(10) Newsome, D.S., Catal. Rev.-Sci.Eng, 1980, 21(2), 275.

(11) Young, P.W. and Clark, C.B., Chem. Eng. Prog, 1973, 69 (5), 69.

(12) Hanlon, R.T., Catalyst Characterization and Secondary Reaction Effects in Iron-Catalyzed Fischer-Tropsch Synthesis, Sc.D. Thesis, Massachusetts Institute of Technology, Cambridge, Massachusetts, 1985. 
(13) Matsumoto, D.K., The Effects of Selected Process Variables on the Performance of an Iron Fischer-Tropsch Catalyst, Sc.D. Thesis, Massachusetts Institute of Technology, Cambridge, Massachusetts 1985.

(14) Yates, I.C., and Satterfield, C.N., Energy and Fuels, 1991, 5, 168.

(15) Huff, G.A., Jr., Eischer-Tropsch Synthesis in a Slurry Reactor, Sc.D. Thissis, Massachusetts Institute of Technology, Cambridge, Massachusetts, 1982.

(16) Anderson, R. B., The Fischer-Tropsch Synthesis, Harcourt, Brace \& Jovanovich, New York, 1984.

(17) Satterfield, C.N., Heterogeneous Catalysis in Industrial Practice, second edition, McGraw-Hill, 1991, p. 453.

(18) Yates, I.C., and Satterfield, C.N., to be published. 
TABLE I-1

REDUCTION PROCEDURE FOR WATER-GAS SHIFT CATALYSTS

\begin{tabular}{|c|c|c|}
\hline $\begin{array}{l}\text { Hours- } \\
\text { on-stream }\end{array}$ & $\begin{array}{l}\text { Temperature } \\
\left({ }^{\circ} \mathrm{C}\right)\end{array}$ & Flow, (N1/min/g.cat.) \\
\hline & & Initial Procedure \\
\hline 0 to 2 & 70 to 120 & 0.015 of gas C \\
\hline 2 to 2.5 & 120 & 0 to 0.015 gas $A, 0.015$ to 0 of gas $C$ \\
\hline 2.5 to 6 & 120 to 200 & 0.015 of gas $A$ \\
\hline 6 to 7 & 200 & 0 to 0.015 of gas B, 0.015 to 0 of gas A \\
\hline \multirow[t]{2}{*}{7 to 20} & 200 & 0.015 of gas B \\
\hline & & Modified Procedure \\
\hline 0 to 16 & 70 & 0.015 of gas C \\
\hline 16 to 18 & 70 to 120 & 0.015 of gas C \\
\hline 18 to 19 & 120 & 0 to 0.015 of gas $A, 0.015$ to 0 of gas $C$ \\
\hline 19 to 21.5 & 120 to 200 & 0.015 of gas $\mathrm{A}$ \\
\hline 21.5 to 24 & 200 & 0 to 0.015 of gas D, 0.015 to 0 of gas $A$ \\
\hline 24 to 25 & 200 & 0.015 of gas $D$ \\
\hline
\end{tabular}


TABLE I-1 (Continued)

Notes: Time and temperature periods shown indicate a smooth ramping of conditions. Typically, process changes were made every 15 minutes. The modified procedure was used for the data reported here.

Gas A was 1000 ppm prepurified $\mathrm{H}_{2}$ in prepurified $\mathrm{N}_{2}$ (Matheson Gases, Inc.).

Gas B was prepurified $\mathrm{H}_{2}$ (MedTech Gases, Inc.).

Gas C was prepurified He (Colony, Inc.).

Gas D was 3 vol.\% prepurified $\mathrm{H}_{2}$ in prepurified $\mathrm{N}_{2}$ (Matheson Gases, Inc.). 
TABLE I.2

PROCESS CHANGES FOR Cu/ZnO/ $/ \mathrm{Al}_{2} \mathrm{O}_{3}$ ALONE

\section{Time-on-stream [hours] Process Change}

0

303

358

425

473

637

693

783

830

924

1030
On-stream with base case conditions ${ }^{2}$.

Base case except pressure $=1.48 \mathrm{MPa}$.

Returned to base case conditions.

Base case except $\mathrm{H}_{2} / \mathrm{CO}$ feed ratio increased to 1.0.

Returned to base case conditions.

Base case except temperature increased to $220^{\circ} \mathrm{C}$.

Returned to base case conditions.

Base case except $\mathrm{H}_{2} / \mathrm{CO}$ feed ratio increased to 0.7 .

Returned to base case conditions.

Base case except 2 mol.\% 1-butene added to $\mathrm{H}_{2}$ feed.

Returned to base case conditions.

- "Base case" conditions are $200^{\circ} \mathrm{C}, 0.79 \mathrm{MPa}$, and a feed of $42.9 \mathrm{~mol} . \% \mathrm{CO}, 21.4$ mol.\% $\mathrm{H}_{2}$, and 35.7 mol.\% $\mathrm{H}_{2} \mathrm{O}$. Feed rate (includes water vapor) $=0.019$ $\mathrm{Nl} / \mathrm{min} / \mathrm{g} . \mathrm{cat}$. (unreduced basis). $25 \mathrm{~g}$. of catalyst (unreduced basis) were charged to the reactor containing $400 \mathrm{~g}$. of recrystallized octacosane. 


\section{STANDARD OPERATING CONDITIONS AND PRODUCT DISTRIBUTIONS FOR COMBINED SYSTEMS AND COBALT CATALYST ALONE}

\begin{tabular}{|c|c|c|c|}
\hline & $\begin{array}{l}\text { Run L } \\
{\left[\mathrm{Co} / \mathrm{MgO} / \mathrm{SiO}_{2}\right] /} \\
{\left[\mathrm{Cu}-\mathrm{ZnO} / \mathrm{A}_{2} \mathrm{O}_{3}\right]=0.27}\end{array}$ & $\begin{array}{c}\text { Run } \mathrm{H} \\
{\left[\mathrm{Co} / \mathrm{MgO} / \mathrm{SiO}_{2}\right] /} \\
{\left[\mathrm{Cu}-\mathrm{ZnO} / \mathrm{Ad}_{2} \mathrm{O}_{3}\right]=0.51}\end{array}$ & $\begin{array}{l}\text { Cobalt-Catalyst } \\
\text { Only" }\end{array}$ \\
\hline Temperature $\left({ }^{\circ} \mathrm{C}\right)$ & 240 & 240 & 240 \\
\hline Pressure (MPa) & 0.79 & 0.79 & 0.79 \\
\hline$\left(\mathrm{H}_{2} / \mathrm{CO}\right)$ In Situ & 1.02 & 0.98 & 1.52 \\
\hline $\begin{array}{l}\text { Feed Flow Rate } \\
\text { (Nl/min-g.Co-cat.) }\end{array}$ & 0.065 & 0.035 & 0.026 \\
\hline Weight Fraction $C_{1}$ & 0.26 & 0.08 & 0.09 \\
\hline Weight Fraction $C_{2-4}$ & 0.24 & 0.14 & 0.15 \\
\hline Weight Fraction $C_{5-9}$ & $\cap 27$ & 0.29 & 0.31 \\
\hline Weight Fraction $\mathrm{C} 10+{ }^{b}$ & 0.23 & 0.48 & 0.45 \\
\hline
\end{tabular}

- Data of Yates.?

b Calculated for the $C_{10}-C_{100}$ fraction by extrapolation, using overhead composition data for the $\mathrm{C}_{3}-\mathrm{C}_{16}$ fraction. ${ }^{7}$ 


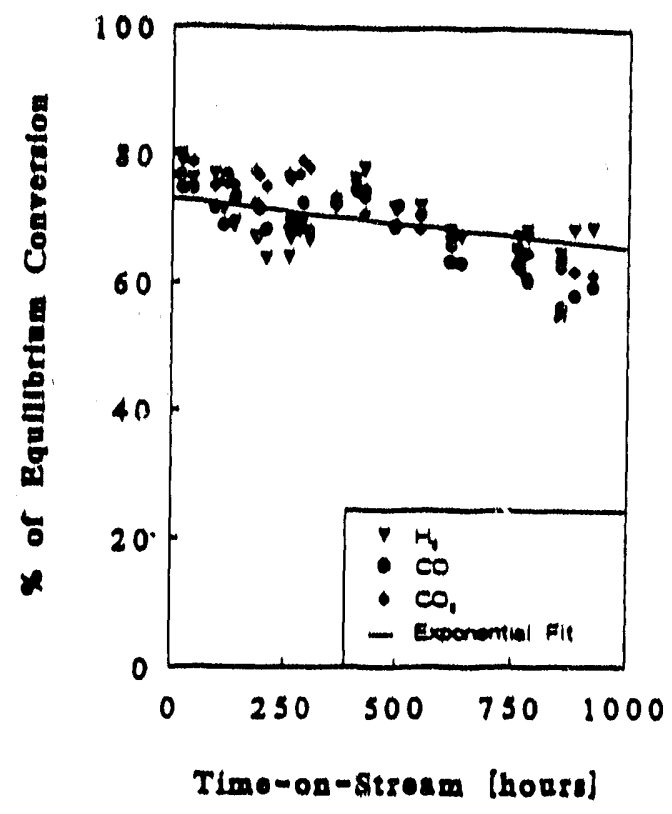

Fig.l-1 Stable activity of $\mathrm{Cu}-\mathrm{ZnO} / \mathrm{Al}_{2} \mathrm{O}_{3}$ at "base case" conditions (see note to Table 2).

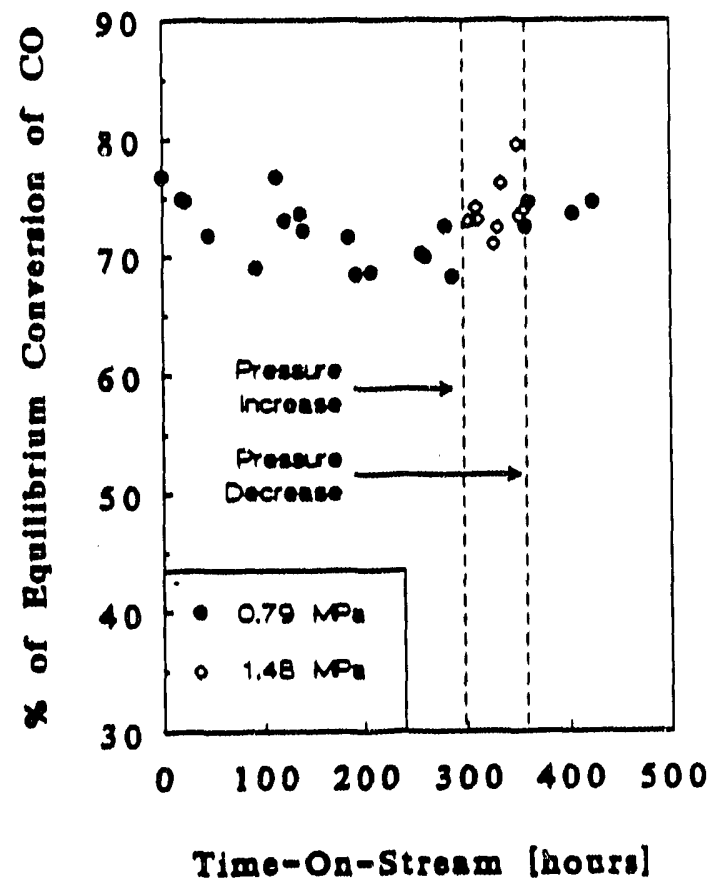

Fig.I-2 Pressure has no deleterious effect on the activity of the $\mathrm{Cu}-\mathrm{ZnO} / \mathrm{Al}_{2} \mathrm{O}_{3}$ shift catalyst. 


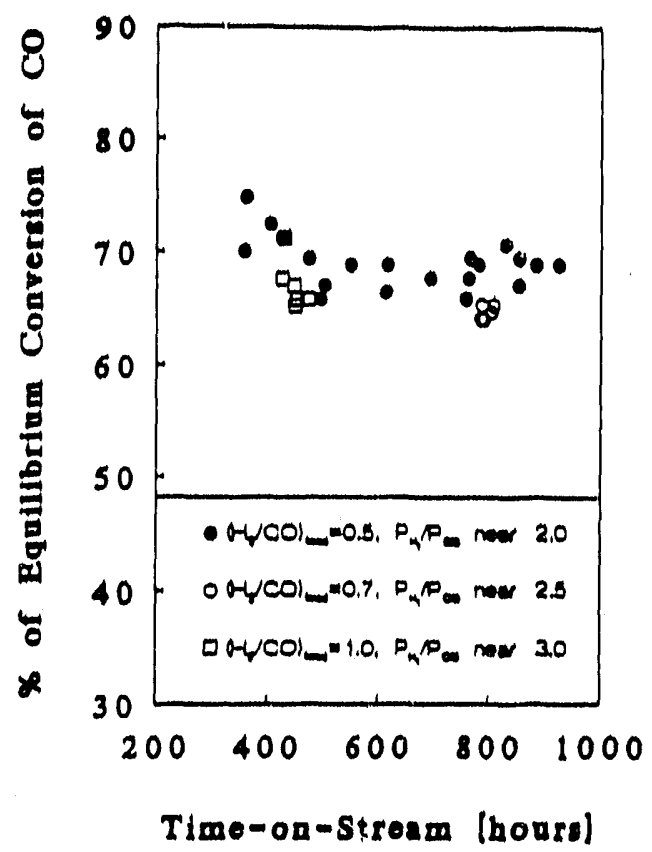

Fig.l-3 Increasing hydrogen-to-carbon monoxide ratio reduces rate, but intrinsic activity remains stable for the $\mathrm{Cu}-\mathrm{ZnO} / \mathrm{Al}_{2} \mathrm{O}_{3}$ shift catalyst $\left(200^{\circ} \mathrm{C}, 0.79 \mathrm{MPa}\right.$, $\mathrm{H}_{2}+\mathrm{CO}=0.0122 \mathrm{Nl} / \mathrm{min} / \mathrm{g}$.cat., and $\mathrm{H}_{2} \mathrm{O}$ at $0.0068 \mathrm{Nl} / \mathrm{min} / \mathrm{g}$.cat. (unreduced basis)).

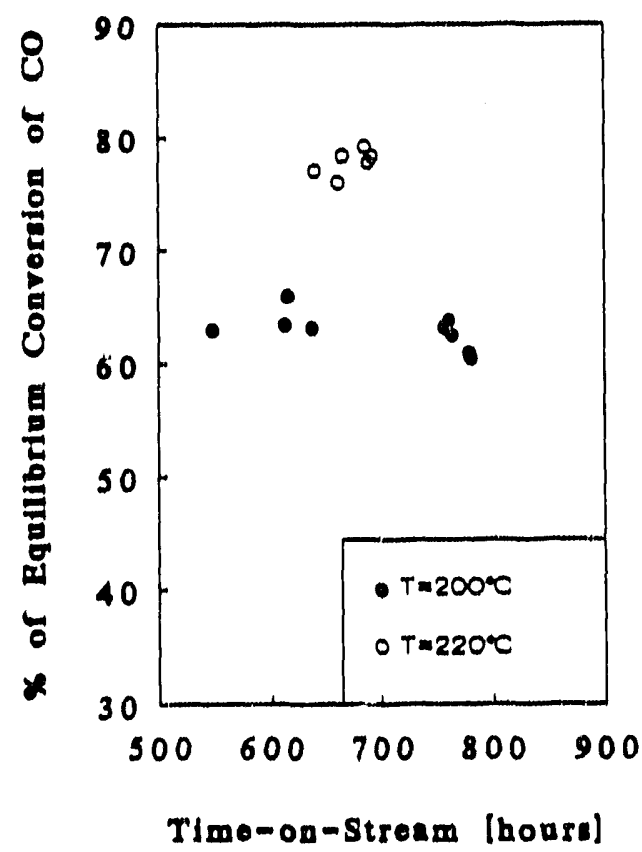

Fig.I-4 Temperature increases $\%$ of equilibrium conversion. Standard conditions. 


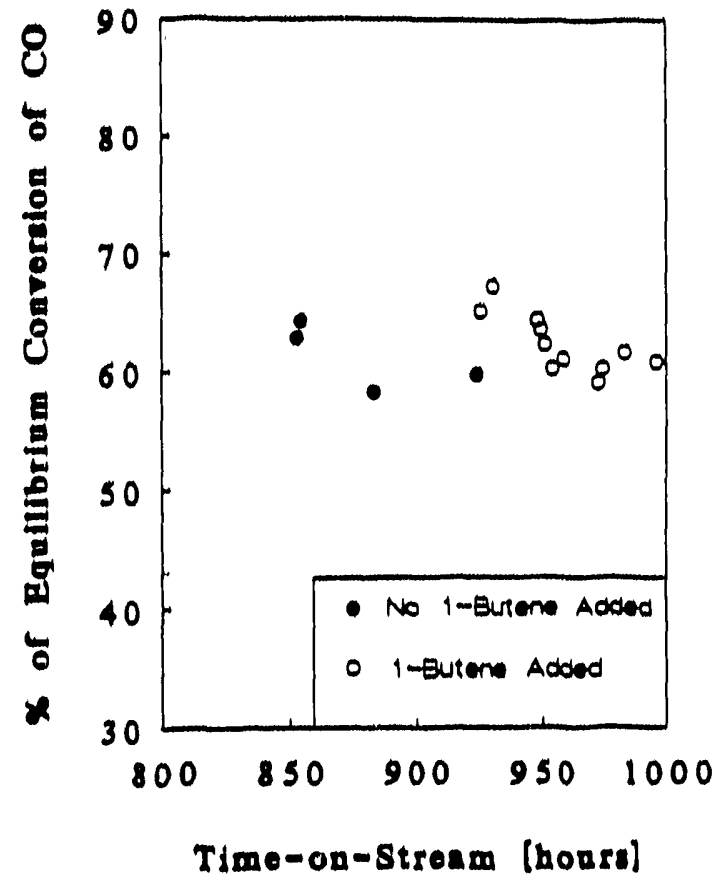

Fig. 1-5 1-Butene has no significant inhibiting effect on the shift activity of the Cu$\mathrm{ZnO} / \mathrm{Al}_{2} \mathrm{O}_{3}$ shift catalyst. 1-butene added as $2 \mathrm{~mol} . \%$ of $\mathrm{H}_{2}$.

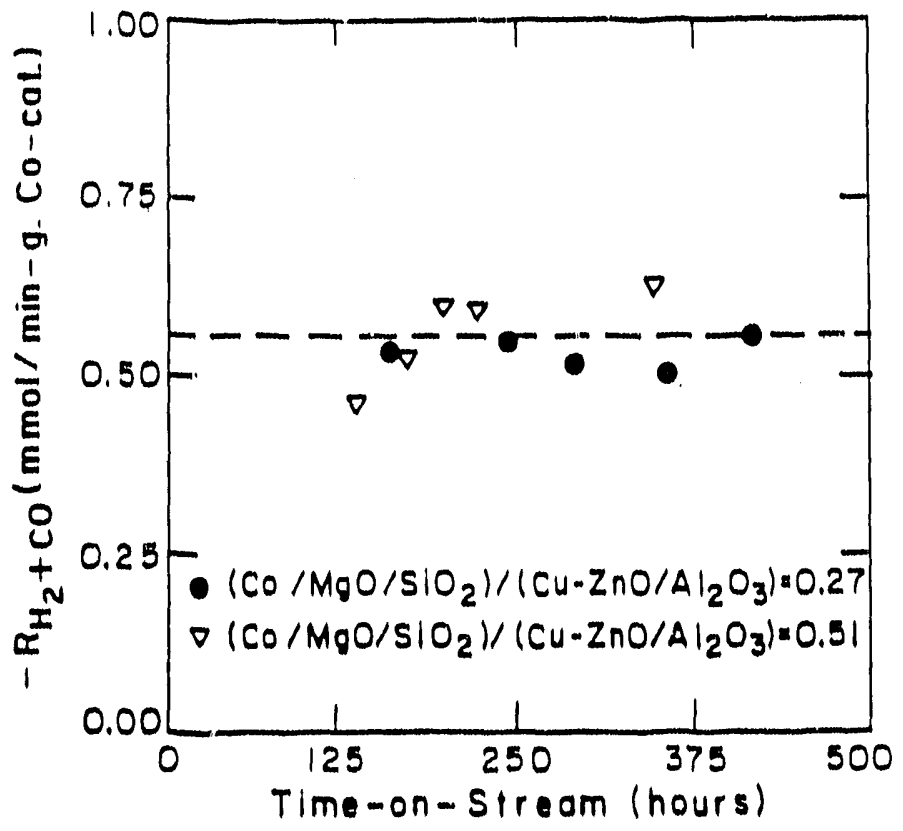

Fig. I-6 The Fischer-Tropsch activity of the catalysts in both run $H$ and run $L$ remained stable for the entire runs of about 400 hours-on-stream each. Feed rate about $0.60 \mathrm{Nl} / \mathrm{min}$. 


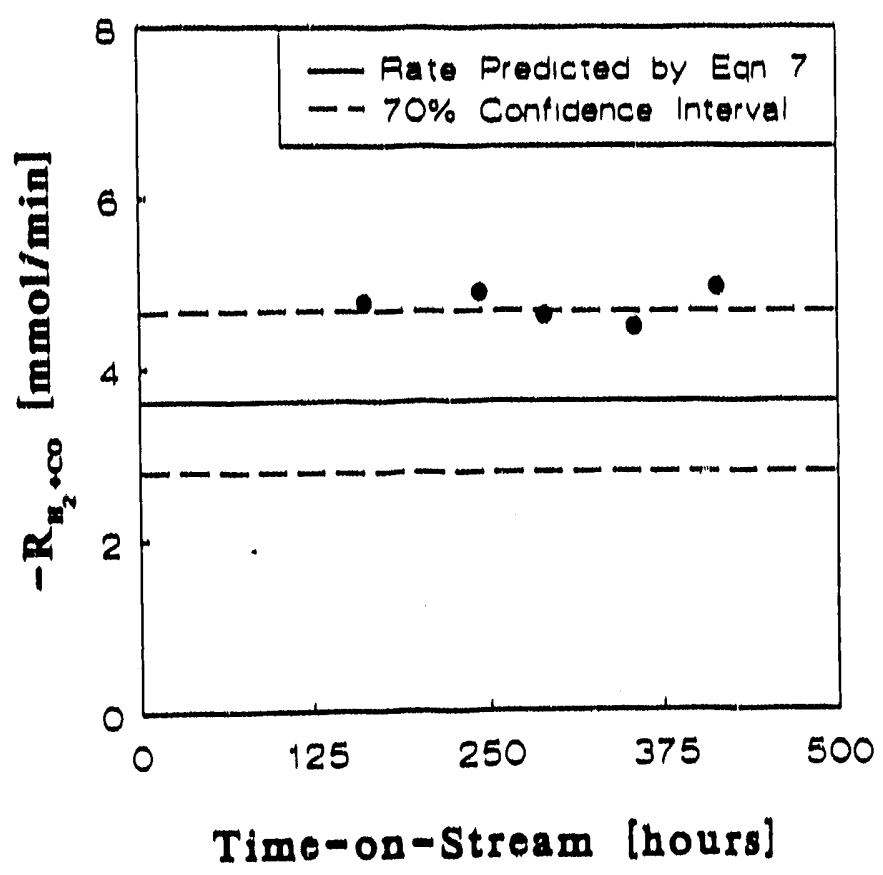

Fig. 1-7 Activity of combined catalyst system run $\mathrm{L}$ ([Co/ $\left.\mathrm{MgO} / \mathrm{SiO}_{2}\right] /[\mathrm{Cu}$ $\left.\left.\mathrm{ZnO} / \mathrm{Al}_{2} \mathrm{O}_{3}\right]=0.27\right)$ matches that predicted by equation 7 . $\left(240^{\circ} \mathrm{C}, 0.79 \mathrm{MPa}\right.$, in situ $\mathrm{H}_{2} / \mathrm{CO}=1.02$, and fed $0.065 \mathrm{Nl} / \mathrm{min}-\mathrm{g}$.Co-cat).

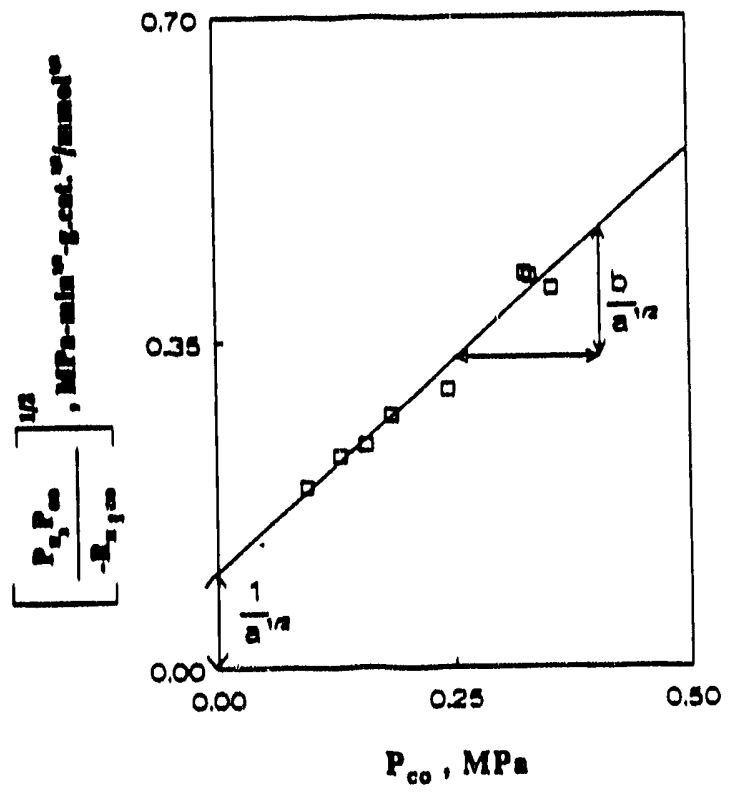

Fig. I-8 Data from combined catalyst system, run $\mathrm{H}$, are well fit by linearized form of recommended rate equation (equation 8 ). Intercept $=1 / a^{-k}$, Slope $=b / a^{k / 2}$. 


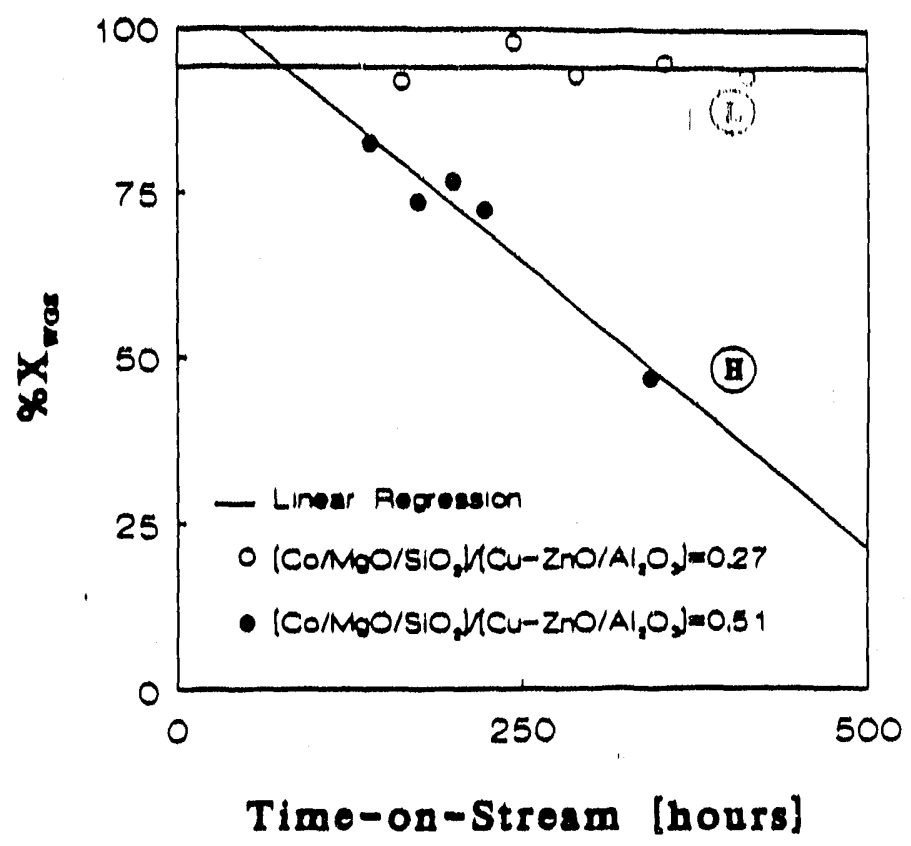

Fig. 1-9 The water-gas-shift reaction approached equilibrium limitations for run $L$, while the activity declined for run $\mathrm{H}$. Standard conditions.

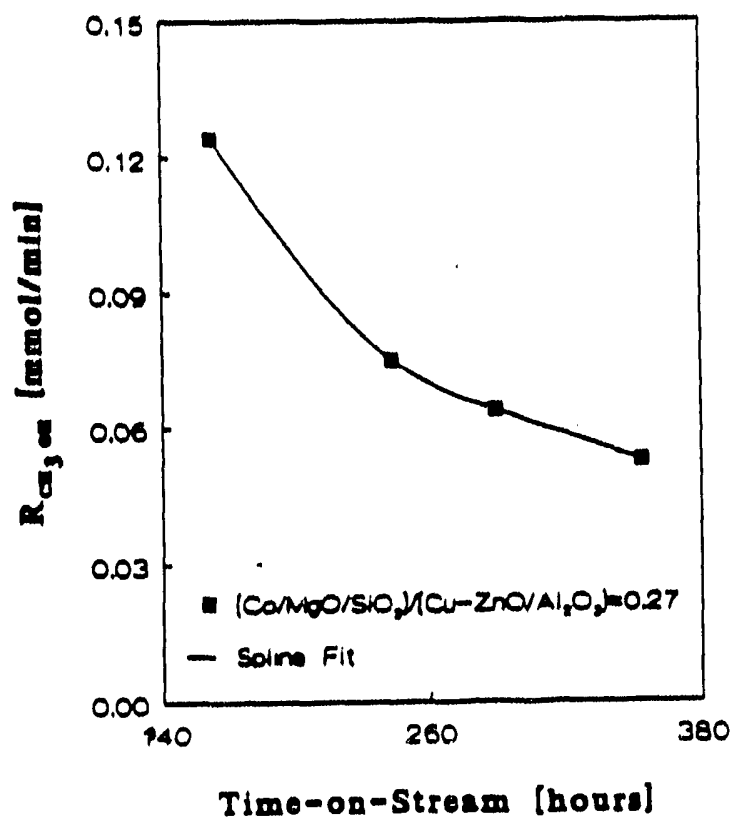

Fig. I-10 The rate of methanol synthesis decreased with time during run L. Standard conditions. 


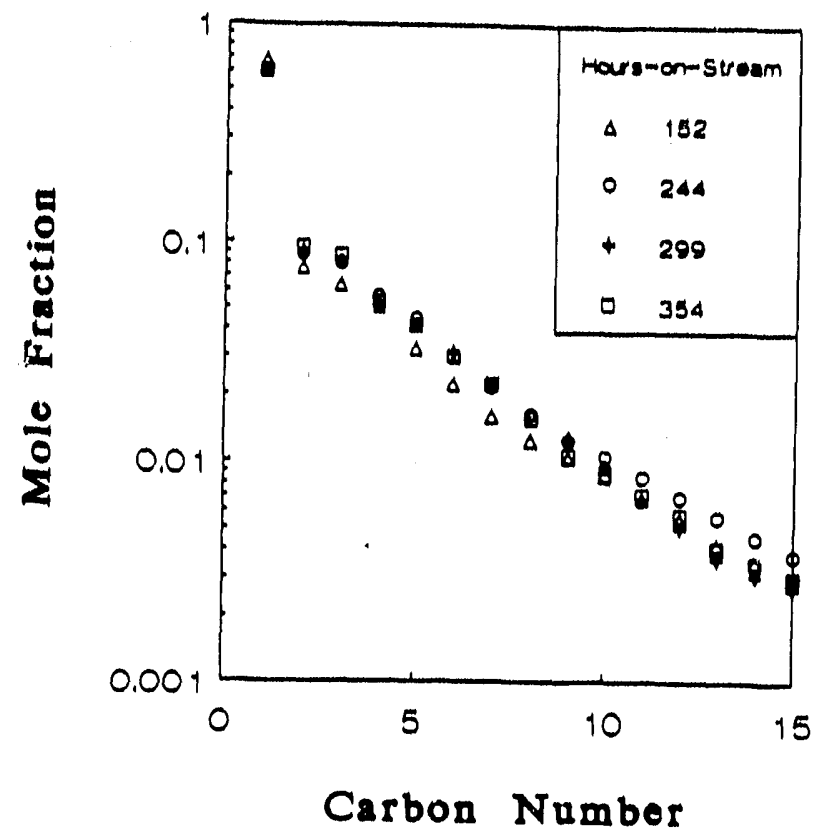

Fig. I-11a Schulz-Flory Diagrams obtained at various time periods show stable FischerTropsch selectivity for run $L$. Standard conditions.

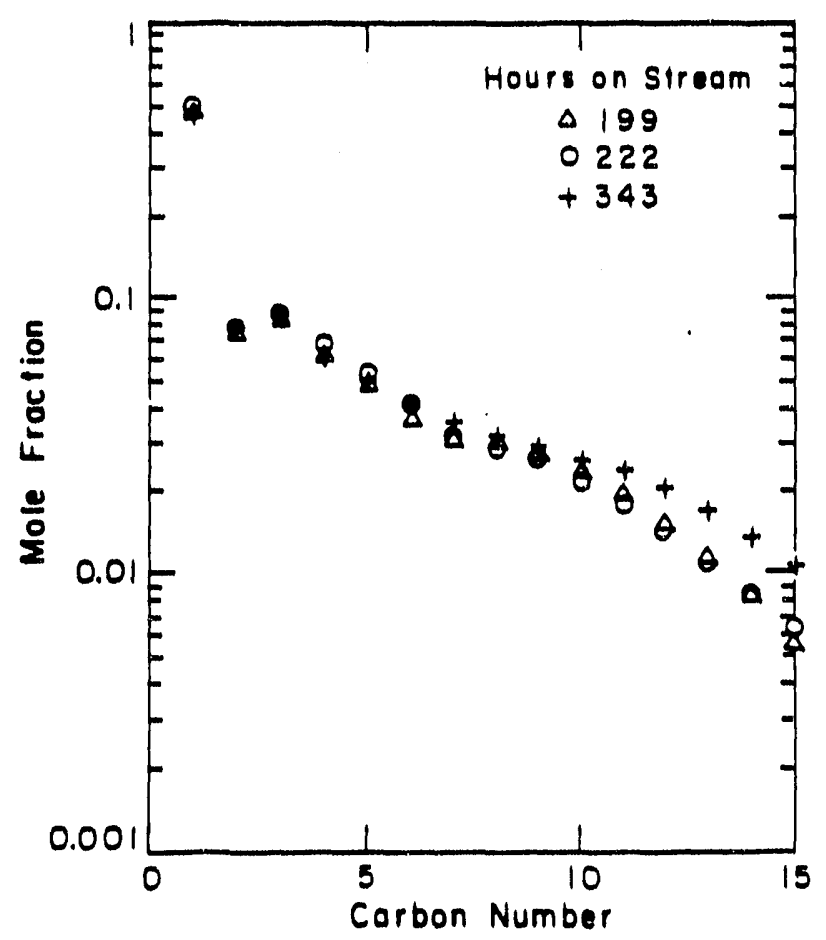

Fig. I-11b Schulz-Flory Diagrams obtained over a 400-hour time period show stable Fischer-Tropsch selectivity for run $\mathrm{H}$. Standard feed conditions. 


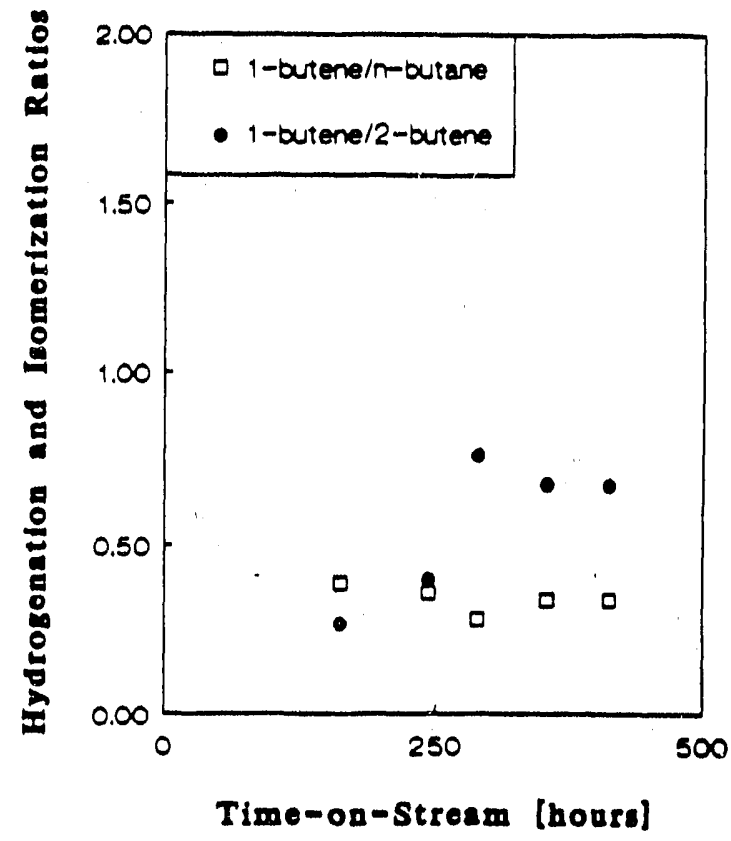

Fig. I-12a The secondary reaction activity of run $\mathrm{L}$ remained stable. Standard conditions.

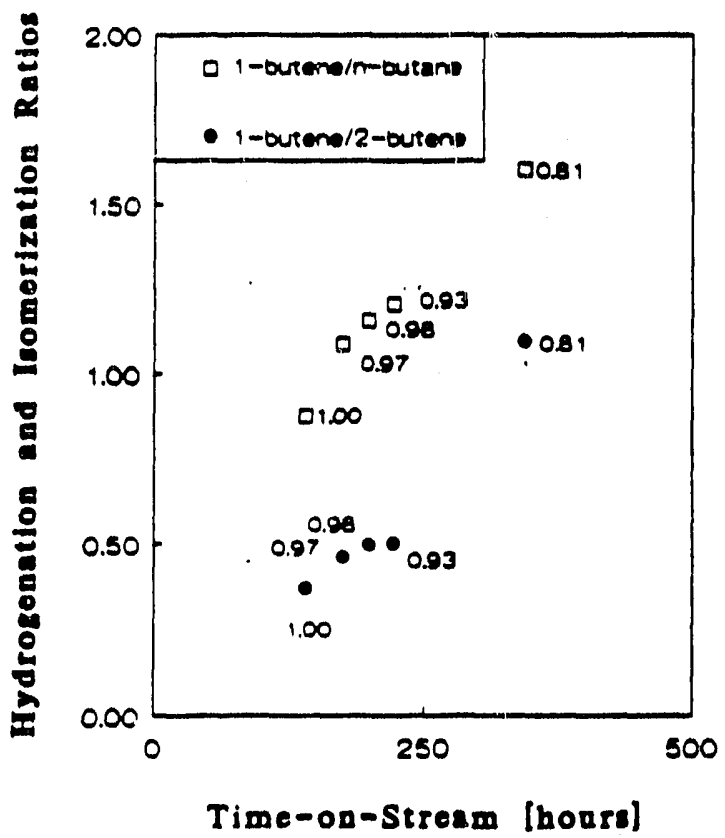

Fig. 1-12b The secondary reaction activity of run $\mathrm{H}$ appeared to decline with time but may have been caused by decreasing in situ $\mathrm{H}_{2} / \mathrm{CO}$ (See data labels). Standard feed conditions. 


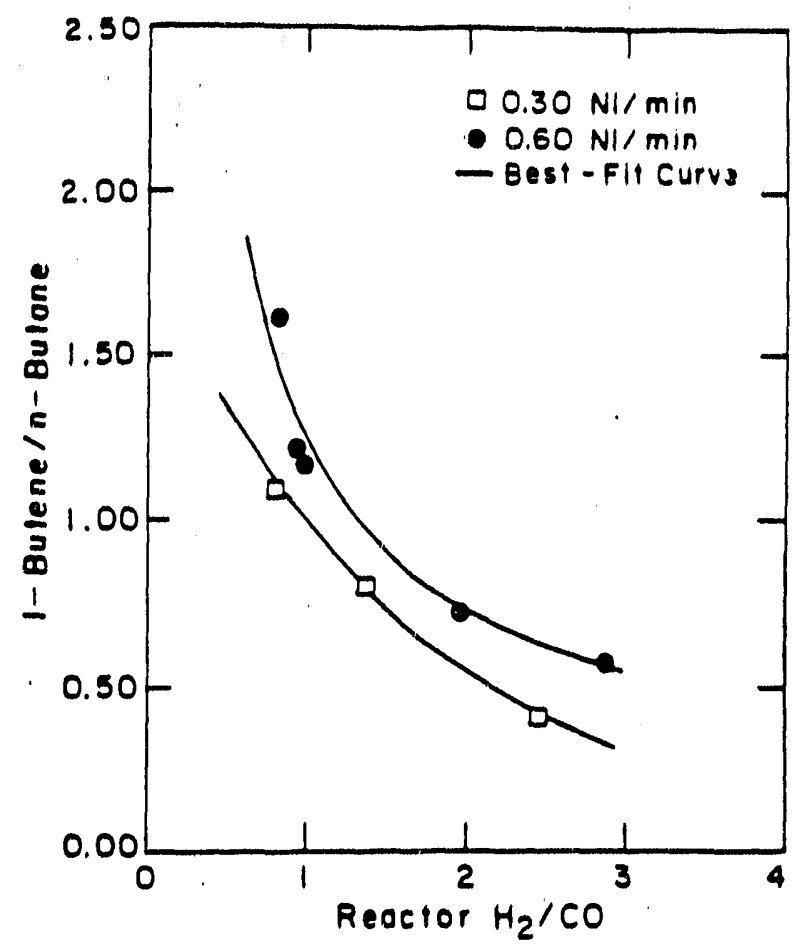

Fig. I-13 The hydrogenation activity was markedly affected by the in situ $\mathrm{H}_{2} / \mathrm{CO}$. Standard conditions but with 0.30 or $0.60 \mathrm{Nl} / \mathrm{min}$. feed rate (run $\mathrm{H}$ ).

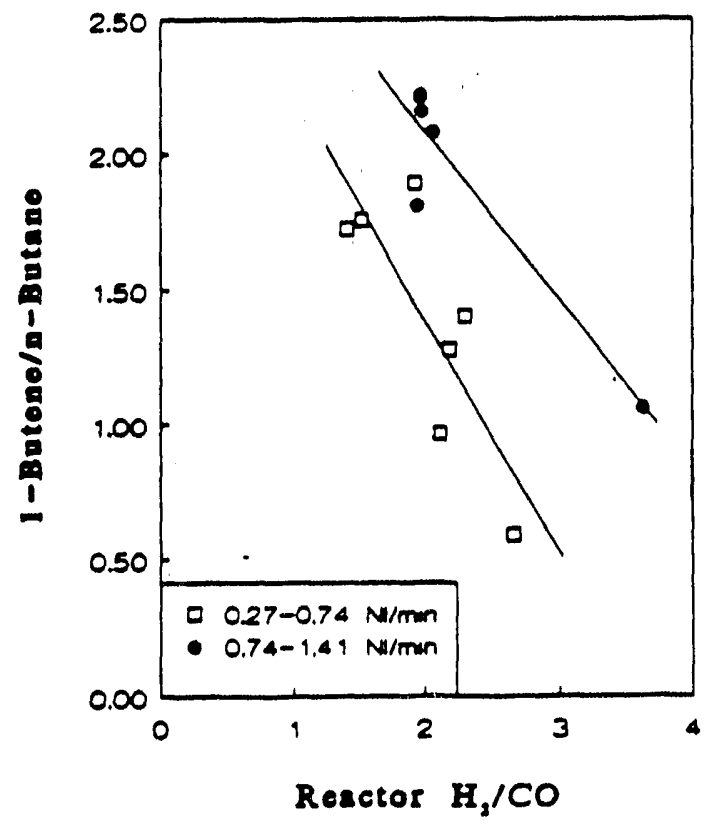

Fig. I-14 The hydrogenation activity of $\mathrm{Co} / \mathrm{MgO} / \mathrm{SiO}_{2}$ alone increases with increasing in situ $\mathrm{H}_{2} / \mathrm{CO}$. $\left(240^{\circ} \mathrm{C}, 0.79 \mathrm{MPa}\right)$ Data of Yates. ${ }^{7}$ 


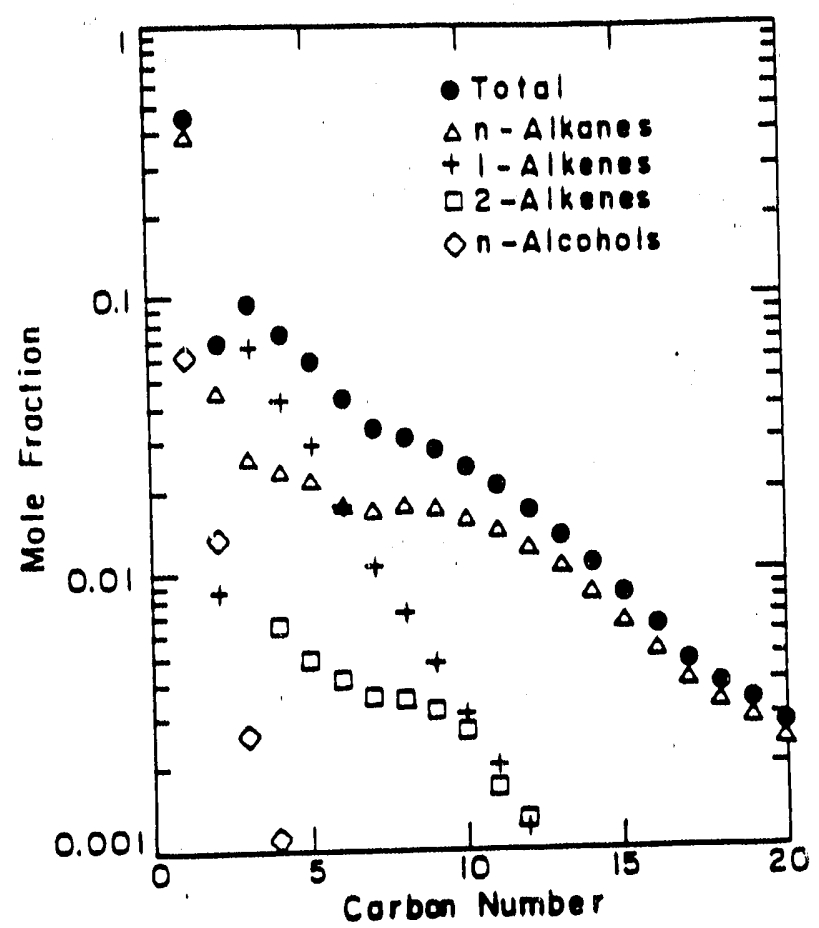

Fig. I-15a A typical component Schulz-Flory diagram from the $\mathrm{Co} / \mathrm{MgO} / \mathrm{SiO}_{2}$ catalyst operating alone (Yates ${ }^{7}$ ).

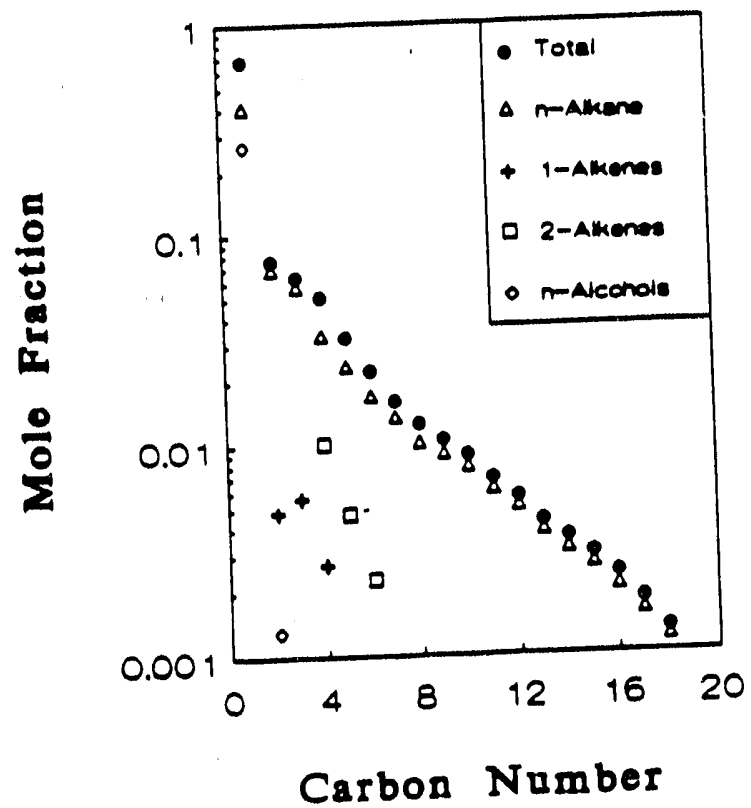

Fig. I-15b A typical component Schulz-Flory diagram from run L. Standard conditions. 


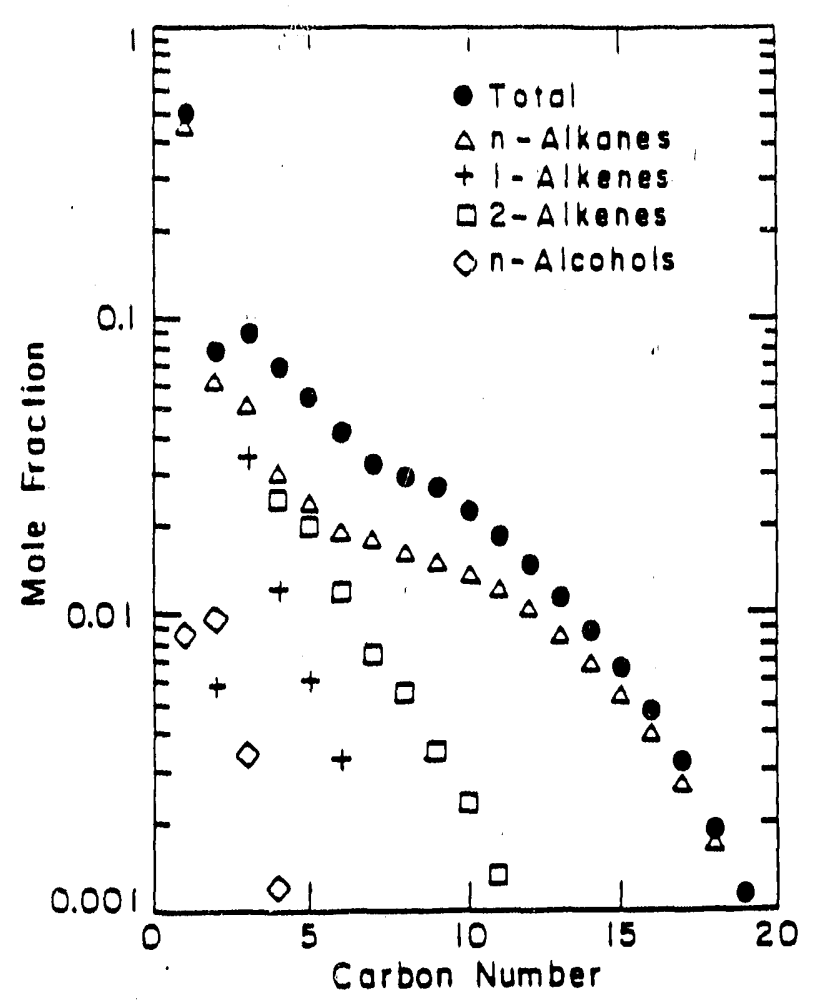

Fig. I-15c A typical component Schulz-Flory diagram from run H. Standard conditions.

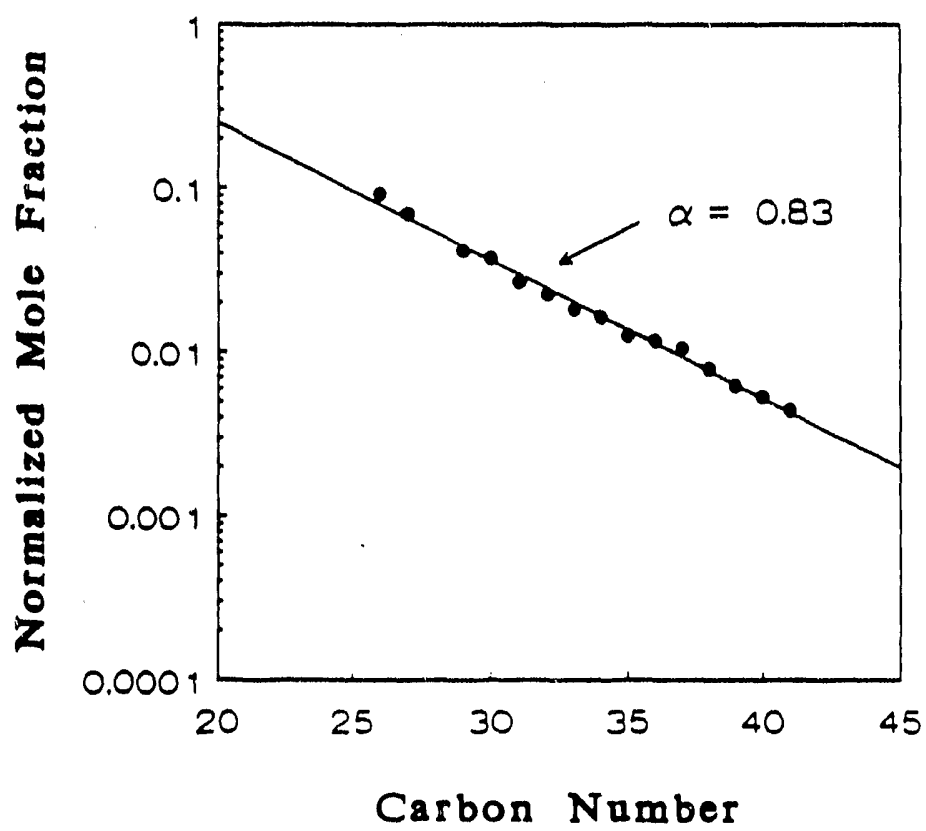

Fig. I-16a Normalized Schulz-Flory diagram from slurry wax sample of run L. Value of $\alpha=0.83$ determined from linear regression of $\mathrm{C}_{29}-\mathrm{C}_{40}$. Standard conditions. 


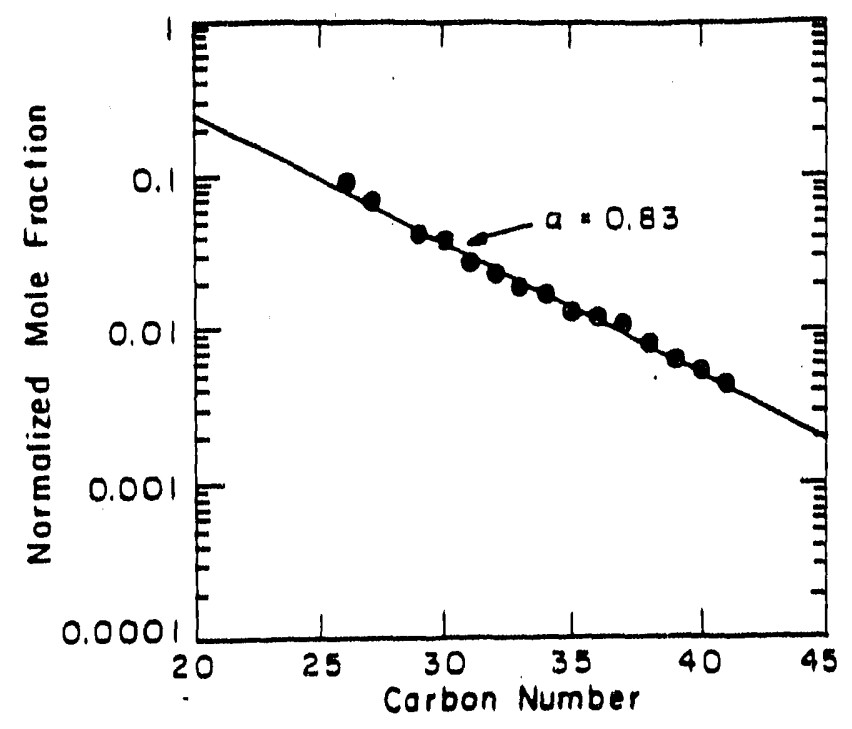

Fig. I-16b Normalized Schulz-Flory diagram from slurry wax sample of run $\mathrm{H}$. Value of $\alpha=0.83$ determined from linear regression of $\mathrm{C}_{29} \cdot \mathrm{C}_{40} \cdot\left(240^{\circ} \mathrm{C}, 0.79 \mathrm{MPa}, 0.80\right.$ $\leq$ in situ $\mathrm{H}_{2} / \mathrm{CO} \leq 3.0$ ). 


\title{
II. THE INTRINSIC KINETICS OF THE FISCHER-TROPSCH SYNTHESIS ON A COBALT CATAL,YST
}

\begin{abstract}
Abstrac:
The rate of synthesis gas consumption over the catalyst was measured at 220 to $240^{\circ} \mathrm{C}, 0.5$ to $1.5 \mathrm{MPa}, \mathrm{H}_{2} / \mathrm{CO}$ feed ratios of 1.5 to 3.5 and conversions of 6 to $68 \%$ of hydrogen and 11 to $73 \%$ of carbon monoxide. The inhibiting effect of carbon monoxide was determined quantitatively and a Langmuir-Hinshelwood-type equation of the following form was found to best represent the results:

$$
-\mathrm{R}_{\mathrm{H}_{2}+\mathrm{CO}}=\frac{{ }^{\mathrm{P}} \mathrm{CO}^{\mathrm{P}} \mathrm{H}_{2}}{\left(1+\mathrm{b} \mathrm{P}_{\mathrm{CO}}\right)^{2}}
$$

The apparent activation energy was 93 to $95 \mathrm{~kJ} / \mathrm{mol}$. Data from previous studies on cobalt-based Fischer-Tropsch catalysts are also well correlated with this rate expression.
\end{abstract}

\section{A. Introduction}

A number of kinetic studies of the Fisher-Tropsch synthesis over cobalt catalysts have been performed..$^{18}$ All of the expressions found to fit rate data on these catalysts show that carbon monoxide inhibits the rate of synthesis. However, a wide array of proposed forms for the rate expression exist which is partly a result of the considerable variation in reaction conditions studied. Further, some studies, particularly the earlier work, were performed in fixed-bed reactors. Integral kinetic data from a complex reaction such as the Fischer-Tropsch synthesis cannot be interpreted easily and a fixed- 
bed reactor may be difficult to maintain isothermal. In other cases, data are reported only for very low conversions.

Our objective for this part of the study was to develop an intrinsic kinetic expression for the rate of synthesis gas conversion on a cobalt catalyst over a range of industrially-relevant conditions. A mechanically-stirred, one-liter, continuous-flow, slurry reactor was used. The reactor behaves as a CSTR, providing data at uniform temperature and composition which are easy to analyze.

\section{B. Background}

The Fischer-Tropsch synthesis over cobalt-based catalysts produces mostly nalkanes and 1-alkenes. The reaction stoichiometry may be approximated as:

$$
\mathrm{nCO}+2 \mathrm{n} \mathrm{H}_{2} \longrightarrow\left(-\mathrm{CH}_{2}\right)_{\mathrm{n}}+\mathrm{n}_{2} \mathrm{O}
$$

Cobalt is not very active for the water-gas-shift reaction'; thus, in contrast to most ironbased Fischer-Tropsch catalysts, only a small fraction of the water produced is subsequently converted to carbon dioxide.

The rate of the Fischer-Tropsch reaction is defined here as the moles of hydrogen plus carbon monoxide converted per time per mass of unreduced catalyst, $-\mathrm{R}_{\mathrm{H}_{2}}+\mathrm{CO}$. Some previous studies report the rate of conversion of carbon monoxide only, $-\mathrm{R}_{\mathrm{CO}}$. If the extent of water-gas-shift is negligible, the two rate measures, $-\mathrm{R}_{\mathrm{H}_{2}}+\mathrm{CO}$ and $-\mathrm{R}^{\mathrm{CO}}$ ' are related by a constant, as can be seen from eq 1 .

Published intrinsic expressions for the rate of Fischer-Tropsch synthesis over various cobalt catalysts are presented in Table II-1. The rate expressions of Yang et al. ${ }^{3}$, Pannell et al. ${ }^{4}$, and $\mathrm{Wang}^{6}$ were all developed by regression of a power-law equation of 
the general form:

$$
-\mathrm{R}=\mathrm{aP}_{\mathrm{H}_{2}}{ }^{\mathrm{b}}{ }_{\mathrm{P}} \mathrm{CO}
$$

In all of these kinetic expressions, the coefficient $b$ was positive and the coefficient $c$ was negative, suggesting inhibition by adsorbed $\mathrm{CO}$.

Anderson ${ }^{2}$ found the equation developed by Brötz $z^{1}$ to be inadequate for data over a wide range of inlet $\mathrm{H}_{2} / \mathrm{CO}$ ratios. From data taken in a fixed-bed at atmospheric pressure over a wide range of $\mathrm{H}_{2} / \mathrm{CO}$ ratios and temperatures, Anderson and co-workers at the Bureau of Mines ${ }^{10}$ (Storch et al., p.529) developed an equation, eq 4, by postulating that the rate is proportional to the desorption of chains. The concentration of growing chains on the catalyst surface was related empirically to $\mathrm{P}_{\mathrm{H}_{2}}{ }^{2} \mathrm{P} \mathrm{CO}$. From samples withdrawn from the beginning of the bed, $A_{n d e r s o n}^{2}$ (p. 270) and Storch et al. report that eq 4 does not satisfactorily fit the data at high values of $\mathrm{P}_{\mathrm{H}_{2}}{ }^{2} \mathrm{P}_{\mathrm{CO}}$. They speculate that this lack-of-fit may be a result of either a hot-spot in the initial part of the bed or a different rate-controlling process being in effect at high values of $\mathrm{P}_{\mathrm{H}_{2}}{ }^{2} \mathrm{P}_{\mathrm{CO}}$. Rautavuoma and van der Baan ${ }^{5}$ studied the rate of reaction at atmospheric pressure, $250^{\circ} \mathrm{C}$ and cunversions below $2 \%$. They examined five possible rate determining steps. The expression which fit their data best, eq 7 , is consistent with a mechanism in which the reaction proceeds via $\mathrm{CO}$ dissociation and formation of a "- $\mathrm{CH}_{2}$-" surface intermediate. The formation of this surface intermediate is the rate determining step. The model also assumes that hydrogen is adsorbed onto the catalyst surface dissociatively, however the authors suggest that the predominant surface species is dissociated $\mathrm{CO}$ and therefore do not include a term for dissociated $\mathrm{H}_{2}$ in the denominator of the rate expression. 
In the most recently-published work, Sarup and Wojclechowski describe six different possible mechanisms for the Fischer-Tropsch reaction on cobalt catalysts that are compared to experimental data obtained at $190^{\circ} \mathrm{C}$ in a Berty internal recycle reactor. The rate of reaction was measured both by the rate of carbon disappearance and by the rate of oxygen appearance as $\mathrm{H}_{2} \mathrm{O}$ plus $\mathrm{CO}_{2}$. A wide range of values of $\mathrm{P}_{\mathrm{H}_{2}}$ and $\mathrm{P}_{\mathrm{CO}}$ were studied, but conversions are not reported.

Four of their proposed expressions presume that dissociated CO participates in the reaction, while two postulate that $\mathrm{CO}$ is adsorbed but not dissociated. The development of kinetic expressions from each of their proposed mechanisms is detailed by Sarup and Wojciechowski ${ }^{7}$ and reviewed by Wojciechowski ${ }^{8}$.

The general form of rate expression which they propose is:

$$
-R_{\mathrm{CO}}=\frac{k{ }^{P_{C O}}{ }^{a} P_{H_{2}}^{b}}{\left(1+\Sigma K_{1} P_{C O}{ }^{d} P_{H_{2}}{ }^{d i}\right)^{2}}
$$

In eq $11, \mathrm{k}$ is a kinetic parameter, $\mathrm{a}$ and $\mathrm{b}$ are the reaction orders of the rate-controlling step, $K_{i}$ represents an adsorption parameter for the $i^{\text {th }}$ adsorption term, and $c_{i}$ and $d_{i}$ describe the dependence of surface coverage of the $\mathrm{i}^{\text {th }}$ adsorption term on the reactant partial pressures. All of the possible reaction mechanisms considered by Sarup and Wojciechowksi involve a bimolecular surface reaction, thus the denominator of eq 11 is squared.

To discriminate among the six models, they regress their data nonlinearly. Because no a priori assumptions are made about the relative magnitude of possible inhibition terms, the regression determines all of the model parameters, $\mathrm{k}$ and various values of $\mathrm{K}_{\mathrm{i}}$. Three of the models fit the data comparably on the basis of residual sum 
of squares, the sum over all the data points of the squared difference of the actual minus the predicted rate. These three models are eq 9 and 10 (Table II-1) and eq 12 (Sarup and Wojciechowksi's models 1,5 , and 6, respectively).

$$
\cdot \mathrm{R}_{\mathrm{CO}}=\frac{\mathrm{aP}_{\mathrm{CO}} \mathrm{P}_{\mathrm{H}_{2}}}{\left(1+b \mathrm{P}_{\mathrm{CO}}+\mathrm{cP}_{\mathrm{H}_{2}}{ }^{k}+\mathrm{dP}_{\mathrm{CO}} \mathrm{P}_{\mathrm{H}_{2}}{ }^{k}\right)^{2}}
$$

$a, b, c$, and $d$ in eq 9, 10, and 12 are model-specific, temperature-dependent constants.

Of the three models, eq 12 fits their data best but is rejected by Sarup and Wojciechowski, because one of the adsorption coefficients, either $b, c$, or $d$ in eq 12 , not stated by the authors, is negative, representing a physically-unreasonable situation.

The constant $d$ in eq 9 is reported to be statistically insignificant and they remove it from the model and re-regress the data, making the firial form of the equation:

$$
-R_{\mathrm{CO}}=\frac{a \mathrm{P}_{\mathrm{CO}}{ }^{k / P_{\mathrm{H}_{2}}}{ }^{k /}}{\left(1+\mathrm{bP}_{\mathrm{CO}}{ }^{h /}+\mathrm{cP}_{\mathrm{H}_{2}}{ }^{k / 2}\right.}
$$

The authors state that they are unable to distinguish between eq 10 and 13 on the basis of goodness-of-fit.

\section{C. Experimental Section}

In this study, the experiments were performed in a continuous, mechanicallystirred, one-liter autoclave. The slurry reactor and ancillary equipment are described in detail elsewhere ${ }^{11}$. The reactor and its contents are well-mixed. Studies with iron-based catalysts of similar particle sizes, catalyst loadings and reaction rates show that the 
reactor operated without mass transfer limitations ${ }^{11,12,13}$, as indicated by the lack of effect of stirring rate and other variables ${ }^{12}$. Calculations as described by Satterfield ${ }^{14}$ further Indicate that there are no mass transfer limitations either gas-liquid or within the catalyst particles.

The reactor was initially charged with $400 \mathrm{~g}$ of n-octacosane (>99\% purity, Humphrey Chemical, Inc.). The n-octacosane had been previously recrystallized in tetrahydrofuran ( $>99.9 \%$ purity, Mallinkrodt, Inc.) to remove a bromine impurity.

The cobalt catalyst used is a $\mathrm{Co} / \mathrm{MgO}$ on $\mathrm{SiO}_{2}$. This catalyst was prepared for us by an outside laboratory and is of the approximate composition of the cobalt catalysts used at Ruhrchemie ${ }^{10}$. The nominal composition of the catalyst, as reported to us by its manufacturer, is: 21.4 wt.\% Co (as Co), $3.9 w t . \% \mathrm{Mg}$ (as $\mathrm{Mg}$ ), and remainder diatomaceous earth.

Supplied as an extrudate, the catalyst was ground and sieved to 52 to $92 \mu \mathrm{m}$ (170 to 270 ASTM Mesh). Following sieving, 17 grams of the catalyst were placed in a tubular reduction vessel. The catalyst was held in this reduction unit with $7 \mu \mathrm{m}$ stainlesssteel sintered frits while hydrogen (prepurified, MedTech Gases, Inc.) was brought onstream at a flow of $1.36 \mathrm{Nl} / \mathrm{min}$ (approximately $10,000 \mathrm{~V} / \mathrm{V} / \mathrm{hr}$ ). At this flow rate, the pressure in the vessel was $0.79 \mathrm{MPa}$. The temperature of the reduction tube was increased steadily from $25^{\circ} \mathrm{C}$ to $330^{\circ} \mathrm{C}$ over 4 hours while the inlet flow rate was held constant. During this period the pressure in the reduction vessel increased to $0.97 \mathrm{MPa}$. The reduction unit was held at $330^{\circ} \mathrm{C}$ for 1.5 hours and then pressured with helium and rapidly cooled. The unit with the catalyst was weighed and comparison with the initial weight indicated that the catalyst lost $18 w t . \%$ during reduction. The reduced catalyst was 
added to the one-liter autoclave reactor which was being held under helium.

The reactor was brought on-stream at $0.79 \mathrm{MPa}, 187^{\circ} \mathrm{C}$, and $\mathrm{H}_{2} / \mathrm{CO}=2.0$ at a flow rate of $2.0 \mathrm{NI} / \mathrm{min}$. The $\mathrm{CO}$ used in these experiments was $\mathrm{CP}$ grade (Northeast Airgas, Inc.) and the $\mathrm{H}_{2}$ was prepurified grade (MedTech Gases, Inc.). These gases pass through a $13 \mathrm{X}$ molecular sieve, an activated carbon trap, and a $2 \mu \mathrm{m}$ filter before entering the base of the reactor. The zeolite and activated carbon remove various potential impurities from the feed gases, including iron carbonyls, water, and sulfurcompounds.

The reactor conditions were held constant for the first 65 hours and then the reactor temperature was increased to $240^{\circ} \mathrm{C}$ over a period of 7 hours. The reactor was then kept at $0.79 \mathrm{MPa}, 240^{\circ} \mathrm{C}$, and $\mathrm{H}_{2} / \mathrm{CO}=2.0$ at a flow rate of $2.0 \mathrm{Nl} / \mathrm{min}$ for 72 hours to allow the catalyst to achieve steady-state activity and to ensure that the overhead products were representative of those being synthesized.

Material balances over a wide range of conditions were performed for periods of 6 to 24 hours, with at least 12 hours allowed between material balances to ensure steadystate operation. When the reactor temperature or pressure was changed, at least 48 hours were allowed between material balances.

Products, liquid hydrocarbons and water, were condensed in two traps, one kept at $85^{\circ} \mathrm{C}$ and reactor pressure, the other at $1^{\circ} \mathrm{C}$ and $0.34 \mathrm{MPa}$. Material balances, including analyses of all condensed and non-condensed products, closed between 97 and $103 \%$ on oxygen, which was chosen as the material balance closure criterion because carbon and hydrogen accumulate in the reactor in the form of high molecular weight hydrocarbons $^{12,15}$. Table II-2 shows that returning to a standard set of conditions 
periodically verified that the catalyst did not deactivate significantly during the run.

Reactor temperature was set between 220 and $240^{\circ} \mathrm{C}$. Pressures were changed from 0.5 to $1.5 \mathrm{MPa}$ and $\mathrm{H}_{2} / \mathrm{CO}$ feed ratios from 1.5 to 3.5. Total synthesis gas conversion was varied from 11 to $70 \%$ by changing space velocity between 0.085 and $0.008 \mathrm{Nl} / \mathrm{min} / \mathrm{g}$ of catalyst (unreduced basis).

Products were analyzed with three gas chromatographs, as described by Huff et al. ${ }^{16}$. A Hewlett-Packard 5880 with a dimethyl silicone capillary column and flame ionization detector (FID) was used for hydrocarbon analyses of non-condensable gases and the organic phases from the hot and cold traps. Aqueous liquid samples from the hot and cold traps, and non-condensed water and oxygenated hydrocarbons were analyzed with a Hewlett-Packard 5710 using a glass column packed with 60/80 mesh Tenax and a thermal conductivity detecto) (TCD). A Carle/Hach refinery gas analyzer Series S AGC 111-H was used for the analysis of non-condensable gases, particularly $\mathrm{H}_{2}$ ' $\mathrm{CO}$, and $\mathrm{CO}_{2}$. Tie components, $\mathrm{CO}_{2}, \mathrm{CH}_{4}$, and $\mathrm{C}_{2}$ and $\mathrm{C}_{3}$ compounds, were used to match the analyses from the three gas chromatographs and provide complete product distributions for each material balance. The partial pressures of $\mathrm{H}_{2}$ and $\mathrm{CO}$ in the reactor were calculated from the molas flow rates of all vapor-phase species present. For the organic products the molar flow rates of each species were calculated by a computer program. There was little change in $\mathrm{H}_{2} / \mathrm{CO}$ usage ratio with reaction conditions. This averaged slightly above 2 .

\section{D. Results and Discussion}

The forms of eq 3.13 all have subtle differences in their functional dependence on 
$\mathrm{P}_{\mathrm{H}_{2}}$ and $\mathrm{P}_{\mathrm{CO}}$, so experiments were rin over a broad range of $\mathrm{H}_{2} / \mathrm{CO}$ ratios in an attempt to avoid a covariance between these two independent variables of regression. Figures $\Pi-1$ and $\Pi-2$ are plots of $\mathrm{P}_{\mathrm{H}_{2}}$ versus $\mathrm{P}_{\mathrm{CO}}$ at 220 and $240^{\circ} \mathrm{C}$. These figures show no significant correlation between reactant partial pressures.

It was decided that the rate expression should contain only two adjustable parameters, a simplifying approach appropriate for reaction systems with this degree of complexity. In terms of Langmuir-Hinshelwood kinetics, one of these parameters would represent a surface rate constant and the other an adsorption coefficient.

Additional adjustable parameters make the kinetic expression unnecessarily complex. Potential inhibitors of the rate of synthesis are frequently closely related (i.e. co-vary), for example $\mathrm{bP}_{\mathrm{CO}}{ }^{k}$ and $\mathrm{dP}_{\mathrm{CO}}$ in eq 9. Thus, the addition of numerous inhibition terms in the denominator can rarely be justified statistically. An example of this covariance between inhibition terms for the rate of Fischer-Tropsch synthesis on a reduced fused magnetite catalyst is illustrated by Yates and Satterfield ${ }^{17}$. There, it is shown that the inhibiting effects of $\mathrm{H}_{2} \mathrm{O}$ on the synthesis had been incorrectly attributed to $\mathrm{CO}_{2}$ by previous researchers, as a result of the high degree of correlation between $\mathrm{P}_{\mathrm{H}_{2} \mathrm{O}}$ and $\mathrm{P}_{\mathrm{CO}_{2}}$.

Eq 4 and eq 7 both contain only two parameters and are thus examined as possible rate expressions without modification. Eq 9, eq 10, and eq 12 contain more than two adjustable parameters. In the case of eq 10 and eq 12, it was assumed that $\mathrm{CO}$ was the predominant surface species, which is justified by non-reacting, single-component adsorption data on cobalt surfaces ${ }^{18}$; these data indicate that $\mathrm{CO}$ is more strongly adsorbed than $\mathrm{H}_{2}$. The same simplification is also made by Rautavuoma and van der 
Baan in the development of eq 7. In the case of eq 9 , which has terms for surface coverage of undissociated $\mathrm{CO}$ and dissociated $\mathrm{CO}$, it was assumed that dissociated $\mathrm{CO}$ was the predominant surface species. This assumption was implicitly made by Sarup and Wojciechowski ${ }^{7}$ when they removed the constant $\mathrm{d}$ from eq 9 and $\mathrm{r}$-regressed their data. The following equations represent the simplified, two-parameter forms of eq 9, 10, and 12:

$$
\begin{aligned}
& -\mathrm{R}_{\mathrm{CO}}=\frac{{ }^{a \mathrm{P}} \mathrm{CO}^{k / \mathrm{P}_{\mathrm{H}}} \mathrm{H}_{2}^{k /}}{\left(1+\mathrm{bP}_{\mathrm{CO}}{ }^{k / 2}\right)^{2}} \\
& -\mathrm{R}_{\mathrm{CO}}=\frac{{ }^{a P_{C O}} \mathrm{P}_{\mathrm{H}_{2}}{ }^{k}}{\left(1+\mathrm{bP}_{\mathrm{CO}}\right)^{2}} \\
& -R_{\mathrm{CO}}=\frac{{ }^{a P} \mathrm{CO}^{\mathrm{P}} \mathrm{H}_{2}}{\left(1+\mathrm{bP}_{\mathrm{CO}}\right)^{2}}
\end{aligned}
$$

In eq 14-16, $a$ and $b$ are assumed to be temperature dependant constants, $a$ representing $a$ kinetic parameter and $b$ an adsorption coefficieat.

Eq $4,7,14,15$, and 16 were taken to be the five proposed models. All equations were expressed in terms of the rate of hydrogen plus carbon monoxide consumption. As discussed earlier, in the absence of appreciable vater-gas-shift activity, this rate measure is related to the rate of carbon monoxide consumption by a constant.

Three methods were used to determine which expression best fit the data. First, the equations were linearized and plotted to look for outlying data points and general goodness-of-fit. Second, the linearized forms of the expressions were regressed to 
quantify goodness-of-fit. Third, the data were regressed nonlinearly with the models and model parameters being tested for statistical significance.

The proposed equations were first linearized as follows:

$$
\begin{aligned}
& \frac{P_{\mathrm{H}_{2}}^{2} P_{\mathrm{CO}}}{-R_{\mathrm{H}_{2}+\mathrm{CO}}}=\frac{1}{a}+\frac{b P_{\mathrm{H}_{2}}^{2} P_{\mathrm{CO}}}{a} \\
& {\left[\frac{P_{\mathrm{H}_{2}} P_{\mathrm{CO}}^{K}}{-R_{\mathrm{H}_{2}+\mathrm{CO}}}\right]^{1 / 3}=\frac{1}{a^{1 / 3}}+\frac{b P_{\mathrm{CO}}^{K /}}{a^{1 / 3}}} \\
& {\left[\frac{P_{\mathrm{H}_{2}}^{1 / 2} P_{\mathrm{CO}}^{k / 2}}{-R_{\mathrm{H}_{2}+\mathrm{CO}}}\right]^{/ / 2}=\frac{1}{a^{1 / 2}}+\frac{b P_{\mathrm{CO}}^{\hbar /}}{a^{1 / 2}}} \\
& {\left[\frac{P_{\mathrm{H}_{2}}^{H_{2}} P_{\mathrm{CO}}}{-R_{\mathrm{H}_{2}+\mathrm{CO}}}\right]^{1 / 2}=\frac{1}{a^{1 / 2}}+\frac{b P_{\mathrm{CO}}}{a^{1 / 2}}} \\
& {\left[\frac{P_{\mathrm{H}_{2}} P_{\mathrm{CO}}}{-R_{\mathrm{H}_{2}+\mathrm{CO}}}\right]^{1 / 2}=\frac{1}{a^{1 / 2}}+\frac{b P_{\mathrm{CO}}}{a^{1 / 2}}}
\end{aligned}
$$

The majority of the data were collected at 220 and $240^{\circ} \mathrm{C}$. The data at $240^{\circ} \mathrm{C}$ were regarded as more meaningful since they covered a wider range of relative rates. Figures II-3 through II-7 show plots of the data at $240^{\circ} \mathrm{C}$ according to the five linearized 
forms given by eq 17-21. Best-fit linear regression lines are plotted to facilitate visual estimation of goodness-of-fit and scatter. Similar plots were made for the data at $220^{\circ} \mathrm{C}$, but are not shown here. Table $\Pi$-3 gives R-squared values for the fit of the data to the linearized forms of the proposed rate expressions at both 220 and $240^{\circ} \mathrm{C}$. The equation which fits the data best is eq 21 , the linearized form of eq 16 .

Visual examination and regression of linearized rate expressions is a useful tool, but can be misleading because variance in the original data is distorted when the rate expressions are linearized. Table II-4 shows the results of nonlinear regression of the data which confirms that eq 16 fits the data best. Table II-5 presents the parameter values and some related regression information for the fit of eq 16 to the data from this study. The parameters $a$ and $b$ of eq 16 are highly statistically significant at both 220 and $240^{\circ} \mathrm{C}$. The substantially higher value of $b$ at $220^{\circ} \mathrm{C}$ is as would be expected from inhibition by adsorption of $\mathrm{CO}$.

A further test of eq 16 could in principle be obtained by casting $a$ and $b$ into exponential form and calculating the effect of temperature on the exponent. With data from a temperature range of only $20^{\circ} \mathrm{C}$, it was not reasonable to do in the present case. However, an apparent activation energy was calculated from rate data for two sets of values of $\mathrm{P}_{\mathrm{H}_{2}}$ and $\mathrm{P}_{\mathrm{CO}}$ that were nearly the same at 220 and $240^{\circ} \mathrm{C}$. The apparent activation energies were 92.7 and $94.5 \mathrm{~kJ} / \mathrm{mol}$ which are very close to apparent activation energies reported previously: $102 \mathrm{~kJ} / \mathrm{mol}$ calculated by Anderson ${ }^{2}$ (p.266) from data of Fischer and Pichler ${ }^{19}, 103 \mathrm{~kJ} / \mathrm{mol}$ reported by Storch et al. ${ }^{10}$ (p.530), $96 \mathrm{~kJ} / \mathrm{mol}$ calculated by Anderson ${ }^{2}$ (p.266) from data of Gibson and $\mathrm{Hall}^{20}$, and $84 \mathrm{~kJ} / \mathrm{mol}$ reported by Anderson ${ }^{2}(p .265)$. These apparent activation energies were calculated from the slope 
of plots of the logarithm of the rate of reaction versus the reciprocal of absolute temperature for data collected at similar pressures, feed rates and feed compositions. Yang et al. $^{3}$ report an apparent activation energy of $100 \mathrm{~kJ} / \mathrm{mol}$ for their constant a in eq 5 which was regressed from their data.

Five of the six studies, including the present one, yield apparent activation energies within the close limits of 93 to $103 \mathrm{~kJ} / \mathrm{mol}$. This is perhaps surprising considering the wide range of conditions that were studied.

Figure II-8 shows the fit of eq 16 to the data from this study in the form of a parity plot. Within the scatter in the data, the two-parameter model fits the data well. Data points not included in the regression taken at $230^{\circ} \mathrm{C}$ are also well predicted by the rate equation, indicating that the estimates of the parameters $a$ and $b$ are reasonably good at both 220 and $240^{\circ} \mathrm{C}$.

\section{E. Comparison to Literature Data}

Data from three of the studies listed in Table II-1 are available in the literature $\mathrm{e}^{5,6,8}$. Having developed a two-parameter model that was different from any of those recommended by these researchers, we decided to fit their data to eq 16 . The linearized form, eq 21 , is used to examine goodness-of-fit and to look for outlying data points.

Figure II-9 shows the data of Rautavuoma and van der Baan', Figure II-10 the data of Wang ${ }^{6}$ (pp.100-101), and Figure II-11 the data of Sarup and Wojiechowski. All three sets of data fit the linear relationship of eq 21 well and have positive slopes and intercepts, as would be expected. 


\section{F. Conclusions}

Data for the rate of synthesis gas consumption on a cobalt catalyst were obtained over a wide range of industrially-relevant conditions. Five different two-parameter rate models were examined for fit to the data by three methods: visual examination of linearized forms of the rate models, regression of these linearized expressions, and nonlinear regression of the expressions. Eq 16 is found to provide the best fit to our data. Data from three previous kinetic studies are also well fit by this kinetic expression. Apparent activation energies for five of six studies, including the present one, all fall within the narrow range of 93 to $103 \mathrm{~kJ} / \mathrm{mol}$. 


\section{II.G. Nomenclature}

a

b

c

d

$P_{i}$

$-R$

$-\mathrm{R}_{\mathrm{H}_{2}}+\mathrm{CO}$

$-\mathrm{R}_{\mathrm{CO}}$ -temperature-dependent constant, the product of a surface rate constant and adsorption constants (equation specific).

-temperature-dependent adsorption constant (equation specific).

-temperature-dependent adsorption constant (equation specific).

-temperature-dependent adsorption constant (equation specific).

-partial pressure of component $i, \mathrm{MPa}$.

-rate of disappearance of either hydrogen plus carbon monoxide or carbon monoxide, mmol/min/g of catalyst (unreduced basis).

-rate of disappearance of hydrogen plus carbon monoxide, $\mathrm{mmol} / \mathrm{min} / \mathrm{g}$ of catalyst (unreduced basis).

-rate of disappearance of carbon monoxide, $\mathrm{mmol} / \mathrm{min} / \mathrm{g}$ of catalyst (unreduced basis). 


\section{II.H. Literature Cited}

(1) Brötz, W. Z. Elektrochem. 1949, 53, 301.

(2) Anderson, R.B. In Catalysis; Emmett, P.H., Ed., Reinhold: New York, 1959; Vol. IV, pp. 257-283.

(3) Yang, C.-H.; Massoth, F.E.; Oblad, A.G. Adv, Chem. Ser 1979, 178, 35.

(4) Pannell, R.B.; Kibby, C.L.; Kobylinski, T.P. Proc. 7th Int. Cong on Catal. Tokyo, 1980, p. 447.

(5) Rautavuoma, A.O.I.; van der Baan, H.S. Appl. Catal, 1981, 1, 247.

(6) Wang, J., Ph.D. Thesis, Brigham Young University, Provo, Utah, 1987, p. 99.

(7) Sarup, B.; Wojiechowski, B.W. Can. J. Chem. Eng. 1989, 67, 62.

(8) Wojiechowski, B.W. Catal. Rev.Sci.Eng. 1988, 30, 629.

(9) Newsome, D.S. Catal. Rev.Sci. Eng 1980, 21, 275.

(10) Storch, H.H.; Golumbic, N.; Anderson, R.B. The Eischer-Tropsch and Related Syntheses, Wiley, New York, 1951, p. 529.

(11) Huff, G.A., Jr.; Satterfield, C.N. Ind.Eng. Chem. Fundam. 1982, 21, 479.

(12) Huff, G.A., Jr., Sc.D. Thesis, M.I.T., Cambridge, Massachusetts, 1982.

(13) Huff, G.A., Jr.; Satterfield, C.N. Ind. Eng. Chem. Process Des. Dev 1984, 23 , 696.

(14) Satterfield, C.N., Mass Transfer in Heterogeneous Catalysis, reprint edition, Krieger Publishing Company, Inc., Malabar, Florida, 1981.

(15) Donnelly, T.J.; Yates, I.C.; Satterfield, C.N. Energy_Fuels 1988, 2, 734. 
(16) Huff, G.A., Jr.; Satterfield, C.N.; Wolf, M.H. Ind. Eng Chem. Fund 1983, 22 , 258.

(17) Yates, I.C.; Satterfield, C.N. Ind. Eng. Chem. Res, 1989, 28, 9.

(18) Vannice, M.A. Catal. Rev_-Sci. Eng 1976, 14, 153.

(19) Fischer, F.; Pichler, H. Brennstoff-Chem. 1939, I, 97.

(20) Gibson, E.J.; Hall, C.C. J.Appl. Chem. 1954, 4, 49. 


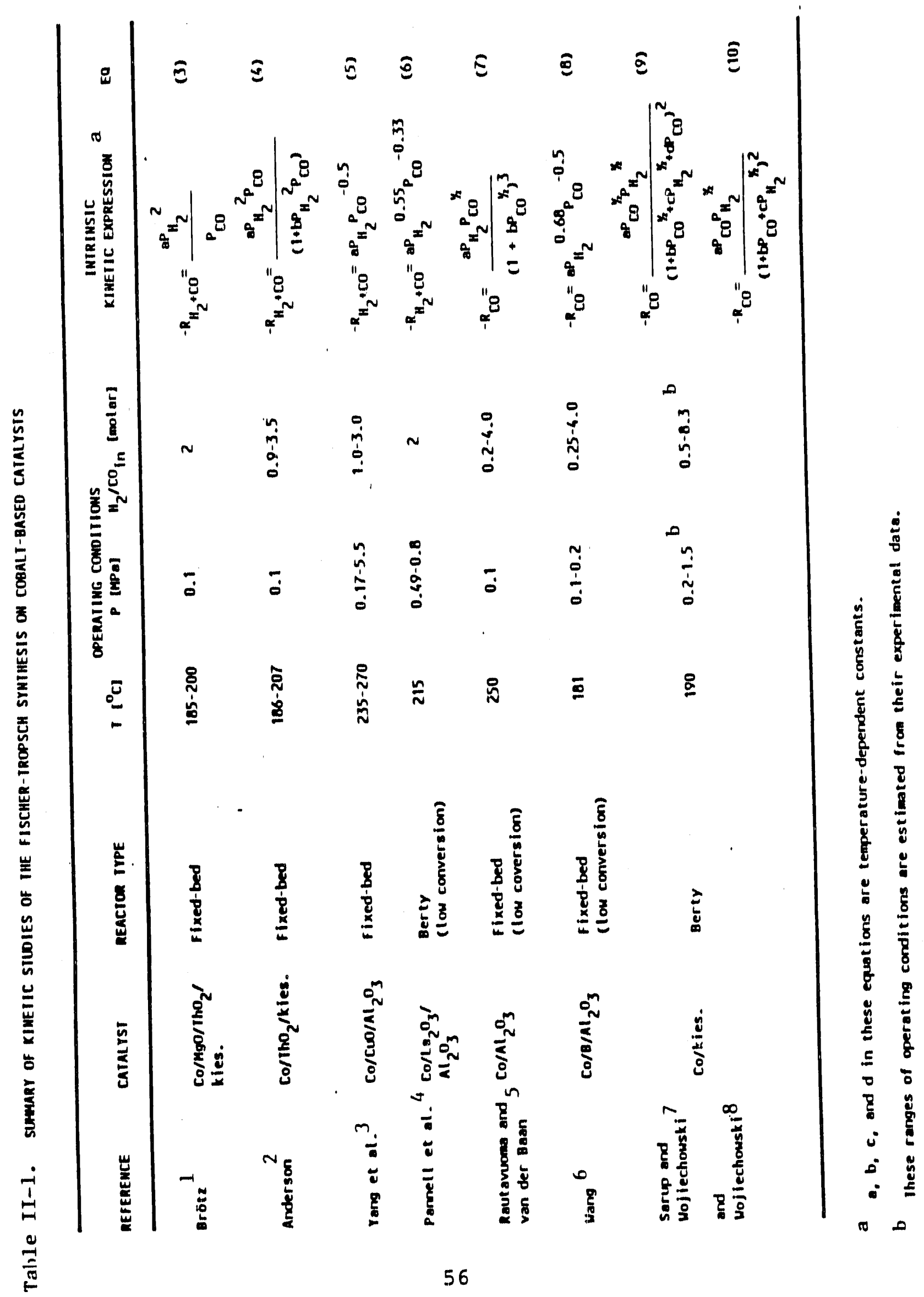


Table II-2.

ACTIVITY FOR REPEATED CONDITIONS OF $240^{\circ} \mathrm{C}, 0.79 \mathrm{MPa}_{3} \mathrm{H}_{2} / \mathrm{CO}=2$, AND SYNTHESIS GAS FEED RATE OF $0.067 \mathrm{Nl} / \mathrm{min} / \mathrm{g}$ of catalyst ${ }^{\dagger}$

\begin{tabular}{lccll}
\hline $\begin{array}{l}\text { Time-On- } \\
\begin{array}{c}\text { Stream } \\
{[\mathrm{h}]}\end{array}\end{array}$ & $\begin{array}{c}\text { Oxygen Closure } \\
{[\% \text { molar }]}\end{array}$ & $\begin{array}{c}-\mathbf{R}_{\mathrm{H}_{2}+\mathrm{CO}} \\
{[\mathrm{mmol} / \mathrm{min} / \mathbf{g c a t}]}\end{array}$ & $\begin{array}{c}\mathbf{P}_{\mathrm{B}_{2}} \\
{[\mathrm{MPa}]}\end{array}$ & $\begin{array}{l}\mathbf{P}_{\mathrm{CO}} \\
{[\mathrm{MPa}]}\end{array}$ \\
\hline 257.5 & 97.06 & 0.678 & 0.48 & 0.25 \\
617.0 & 101.23 & 0.680 & 0.48 & 0.24 \\
$1073.0+$ & 100.21 & 0.594 & 0.45 & 0.25 \\
2176.5 & 99.89 & 0.694 & 0.47 & 0.24 \\
& & & & \\
\hline
\end{tabular}

+ Flow is calculated at standard conditions; grams of catalyst are on an unreduced basis.

$+\mathrm{H}_{2} / \mathrm{CO}$ and feed rate were slightly lower for this material balance at 1.95 and 0.066 standard $1 / \mathrm{min} /$ gcah, respectively. 


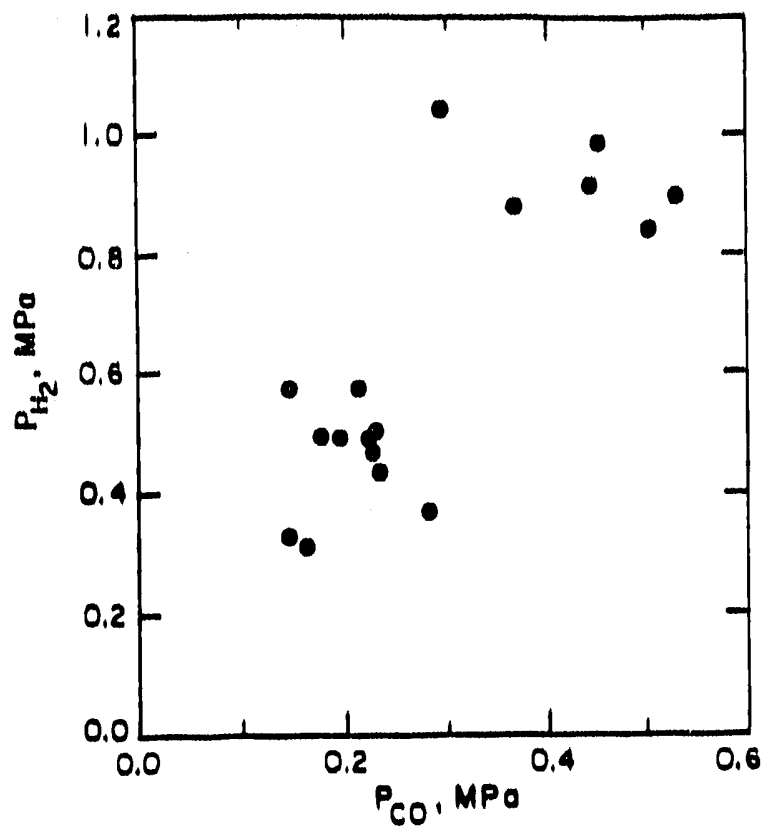

Fig. II-1 Plot showing lack of covariance between $\mathrm{P}_{\mathrm{H}_{2}}$ and $\mathrm{P}_{\mathrm{CO}}$ at $220^{\circ} \mathrm{C}$.

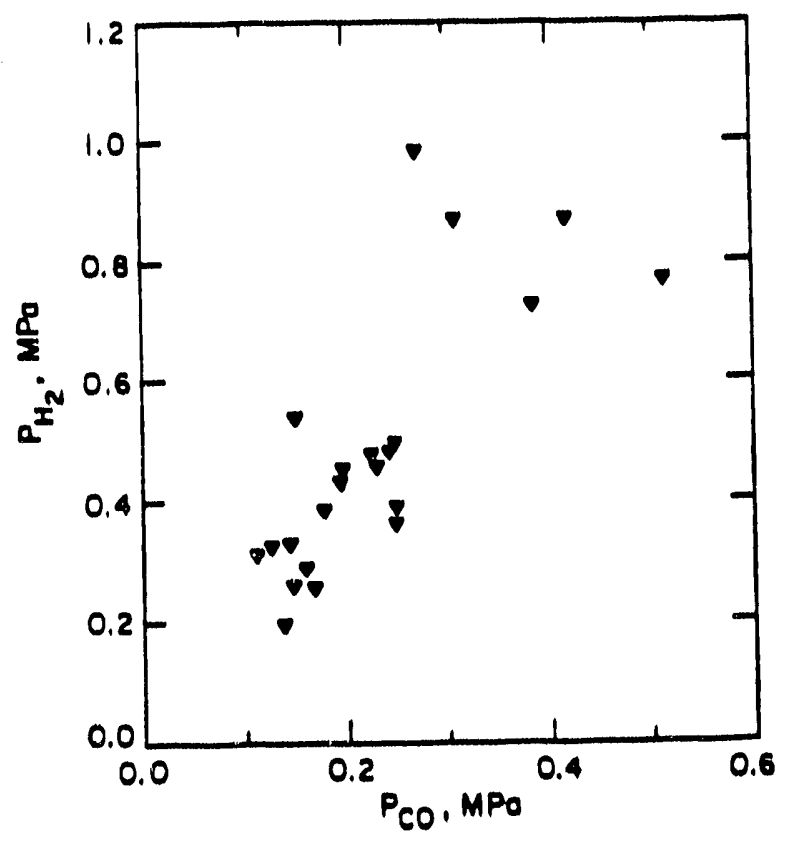

Fig. II-2 Plot showing lack of covariance between $P_{\mathrm{H}_{2}}$ and $\mathrm{P}_{\mathrm{CO}}$ at $240^{\circ} \mathrm{C}$. 
Table II-3. $\quad R^{2}$ for Linearized Expressions

\begin{tabular}{cccccc}
\hline eq & $T,{ }^{\circ} \mathrm{C}$ & $R^{2}$ & eq & $T,{ }^{\circ} \mathrm{C}$ & $R^{2}$ \\
\hline 17 & 220 & 0.954 & 20 & 220 & 0.970 \\
& 240 & 0.909 & & 240 & 0.886 \\
18 & 220 & 0.938 & 21 & 220 & 0.968 \\
& 240 & 0.945 & & 240 & 0.984 \\
19 & 220 & 0.927 & & & \\
& 240 & 0.590 & & &
\end{tabular}

Table II-4. Nonlinear Regression Statistical Analyses

\begin{tabular}{rcrc}
\hline eq & [sum of squared errors] & $F$ ratio & $R^{2}$ \\
\hline 4 & 0.340 & 42.06 & 0.663 \\
7 & 0.072 & 303.27 & 0.929 \\
14 & 0.245 & 85.82 & 0.758 \\
15 & 0.214 & 101.61 & 0.788 \\
16 & 0.062 & 361.22 & 0.938
\end{tabular}

Table II-5. Results of Nonlinear Fit of Data from This Study at 220 and $240^{\circ} \mathrm{C}$ to $\mathrm{Eq} 16$

\begin{tabular}{ccccccc}
\hline $\begin{array}{c}\text { reactor } \\
\text { teinp, } \\
{ }^{\circ} \mathrm{C}\end{array}$ & $a^{a}$ & $\begin{array}{c}\text { std } \\
\text { error } \\
\text { of } a^{a}\end{array}$ & $\begin{array}{c}t \text { value }^{b} \\
\text { of } a\end{array}$ & $b^{c}$ & $\begin{array}{c}\text { std } \\
\text { error } \\
\text { of } b^{b}\end{array}$ & $\begin{array}{c}t \text { value } \\
\text { of } b\end{array}$ \\
\hline 240 & 75.76 & 9.20 & 8.23 & 11.61 & 0.97 & 12.02 \\
220 & 53.11 & 1.38 & 38.63 & 22.26 & 3.63 & 6.62
\end{tabular}

${ }^{a}$ In mmol/(min.g of catalyst. $\left.\mathrm{MPa}^{2}\right) .{ }^{b}$ There were 23 data points collected at $240^{\circ} \mathrm{C}$ and 17 at $220^{\circ} \mathrm{C}$. Critical $t$ values for $99 \%$ confidence that the parameters are statistically significant are $t_{0.995,21}=2.831$ for $240^{\circ} \mathrm{C} ; t_{0.995,15}=2.947$ for $220^{\circ} \mathrm{C}$. $t$ values above these critical values indicate that one can be $99 \%$ confident that the parameters are significant. ' In $1 / \mathrm{MPa}$. 


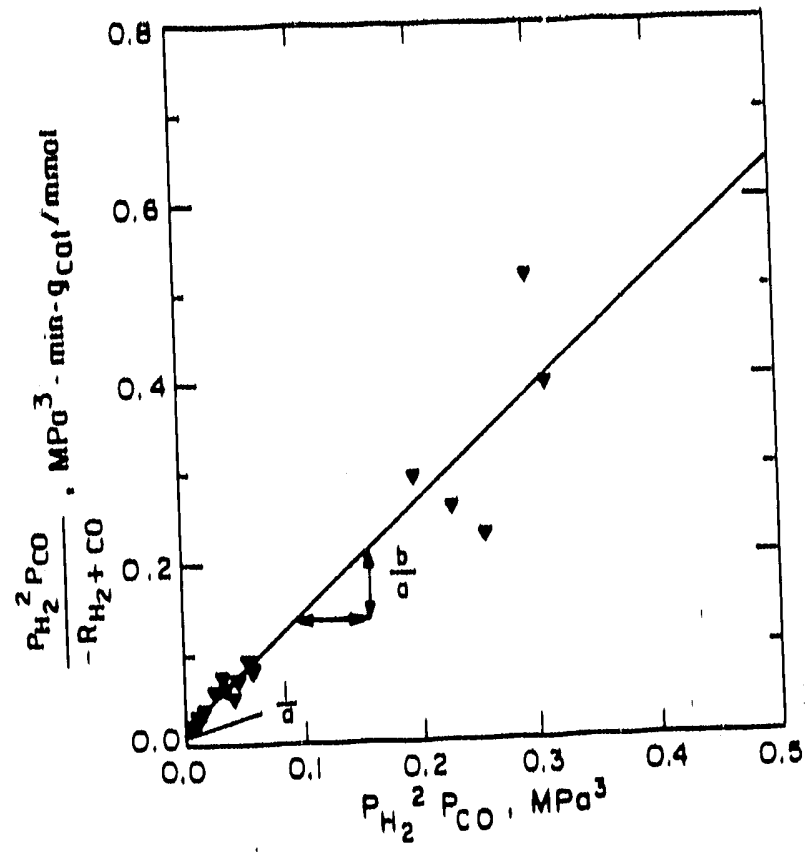

Fig. ${ }^{-5}$ Test of eq 17 with experimental results at $240^{\circ} \mathrm{C}$. Solid line is best fit linear regression line.

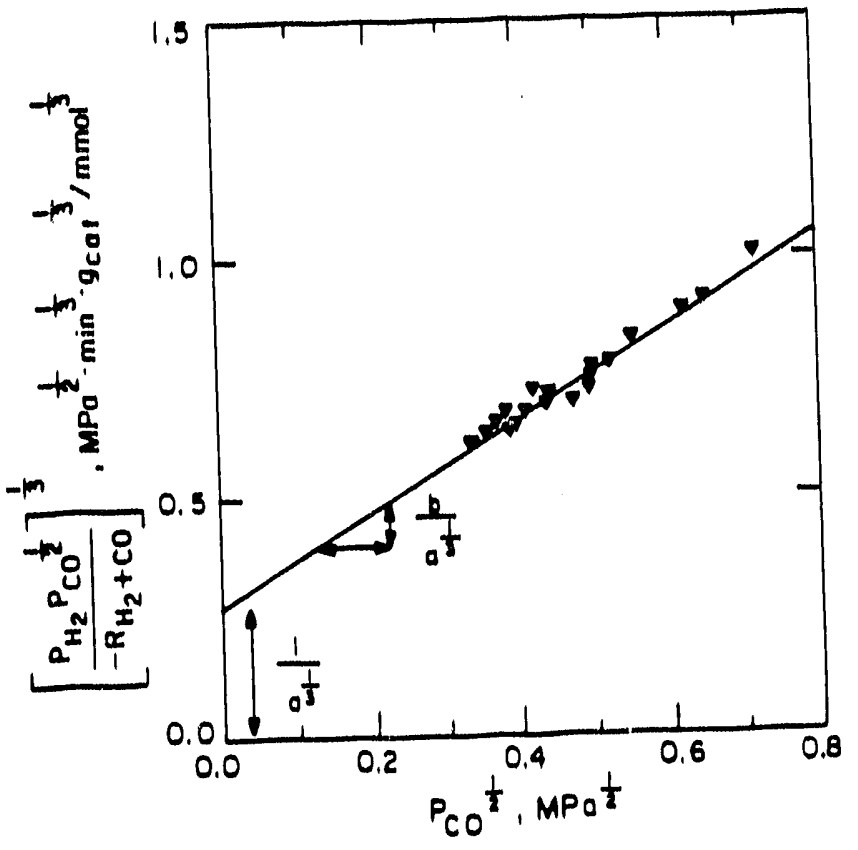

Fig. II-4 Test of eq 18 with experimental results at $240^{\circ} \mathrm{C}$. Solid line is best fit linear regression line. 


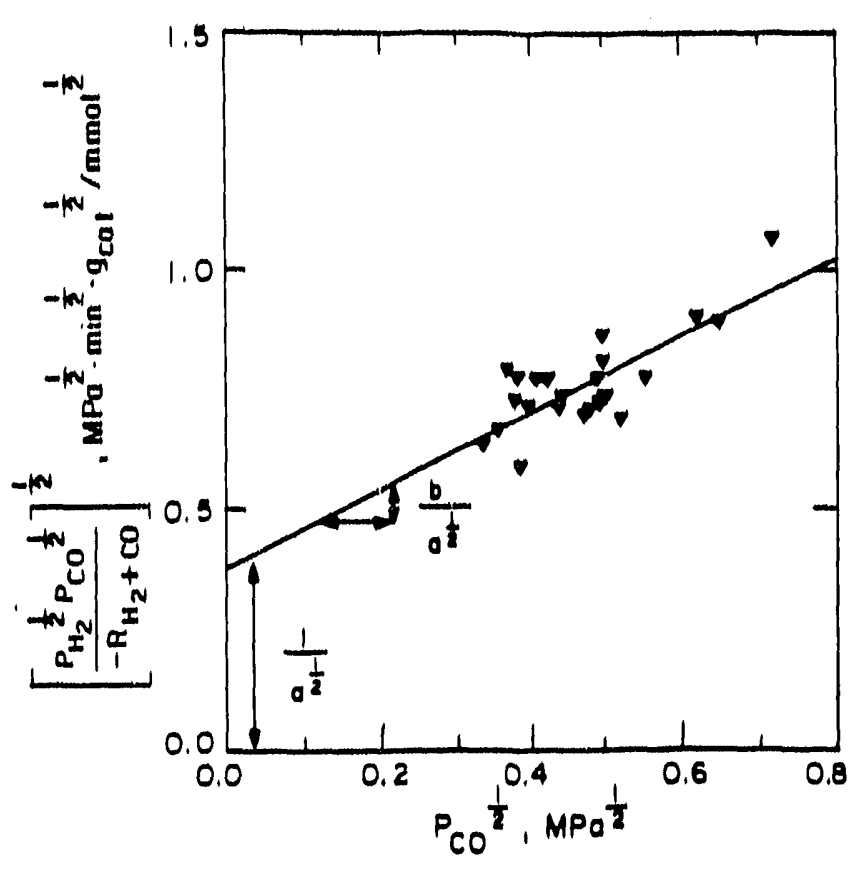

Fig. II-5 Test of eq 19 with experimental results at $240^{\circ} \mathrm{C}$. Solid line is best fit linear regression line.

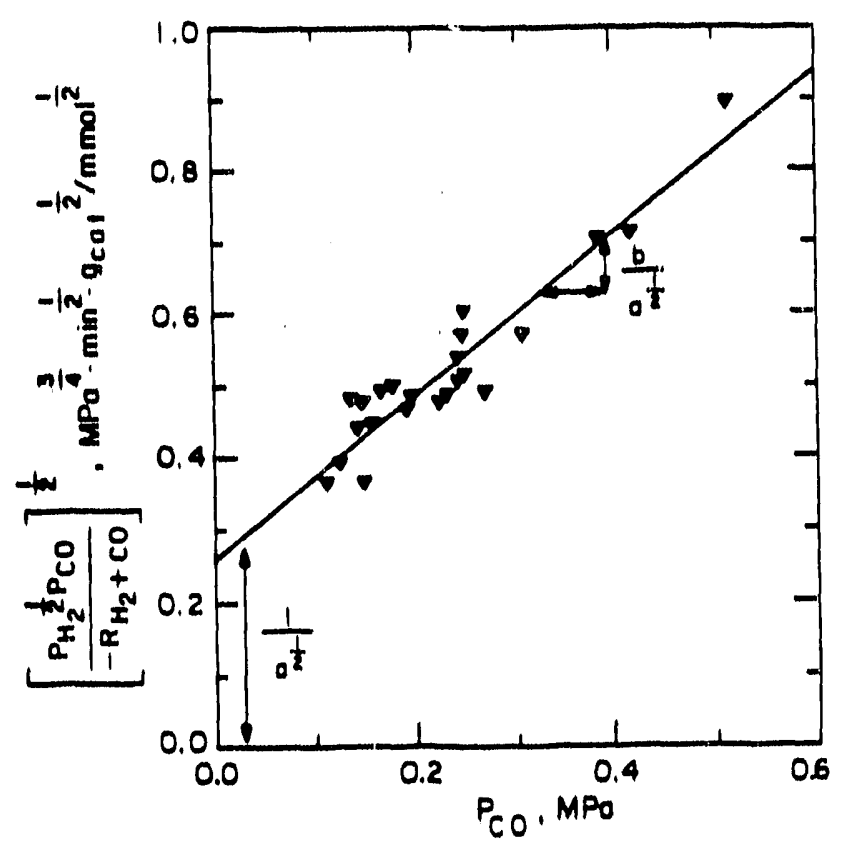

Fig. II-6 Test of eq 20 with experimental results at $240^{\circ} \mathrm{C}$. Solid line is best fit linear regression line. 


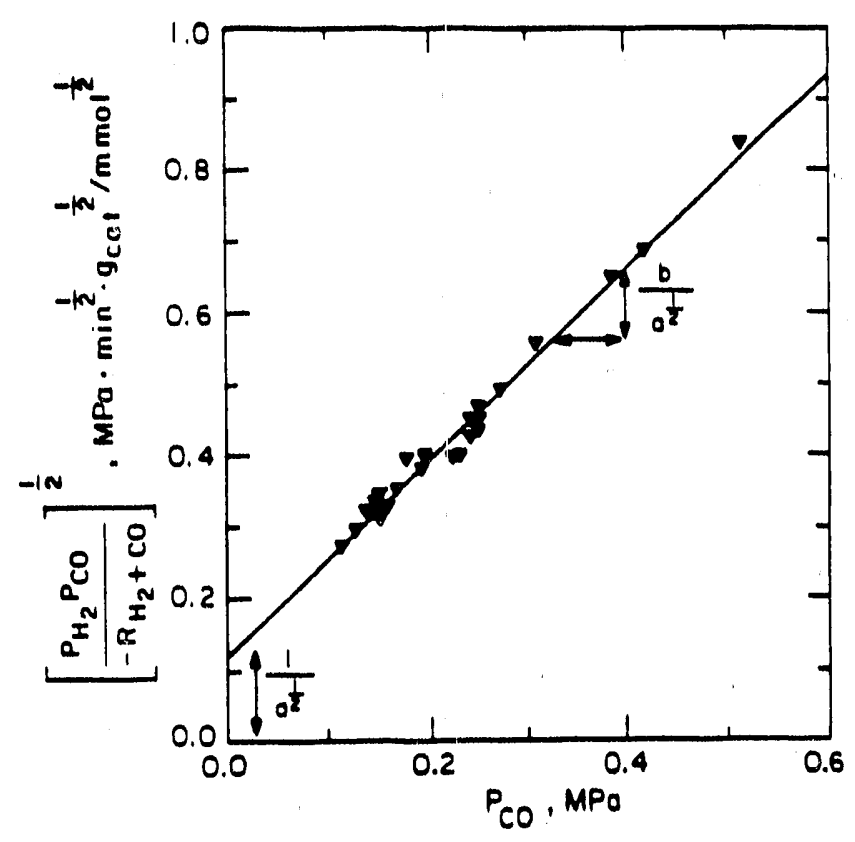

Fig. II-7 Test of eq 21 with experimental results at $240^{\circ} \mathrm{C}$. Solid line is best fit linear regression line.

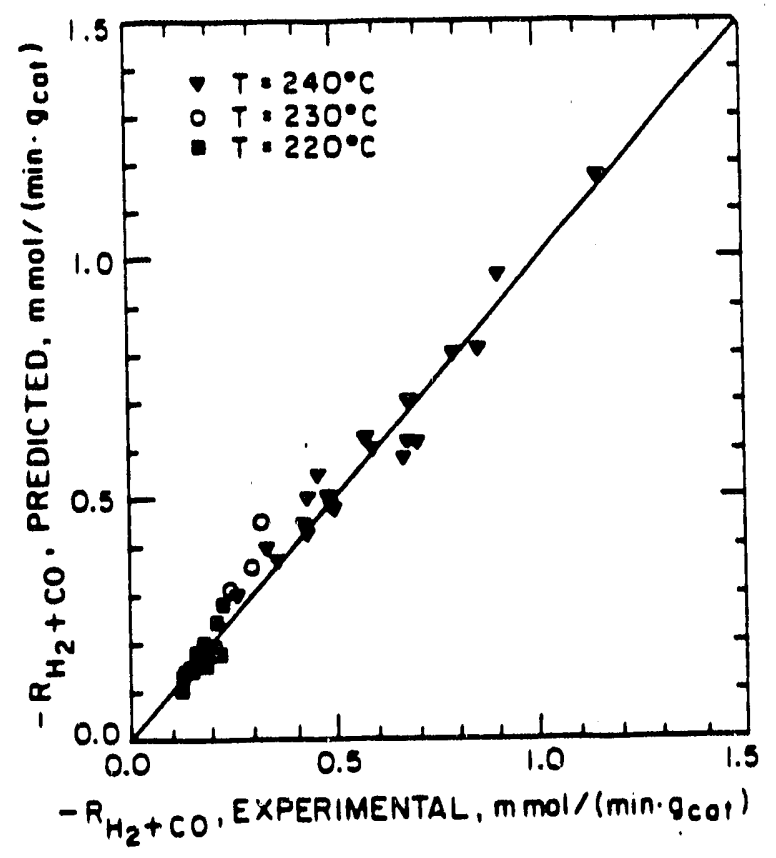

Fig. II-8 Parity plot comparison of data with prediction from eq. 16. Solid line gives predicted yalues. 


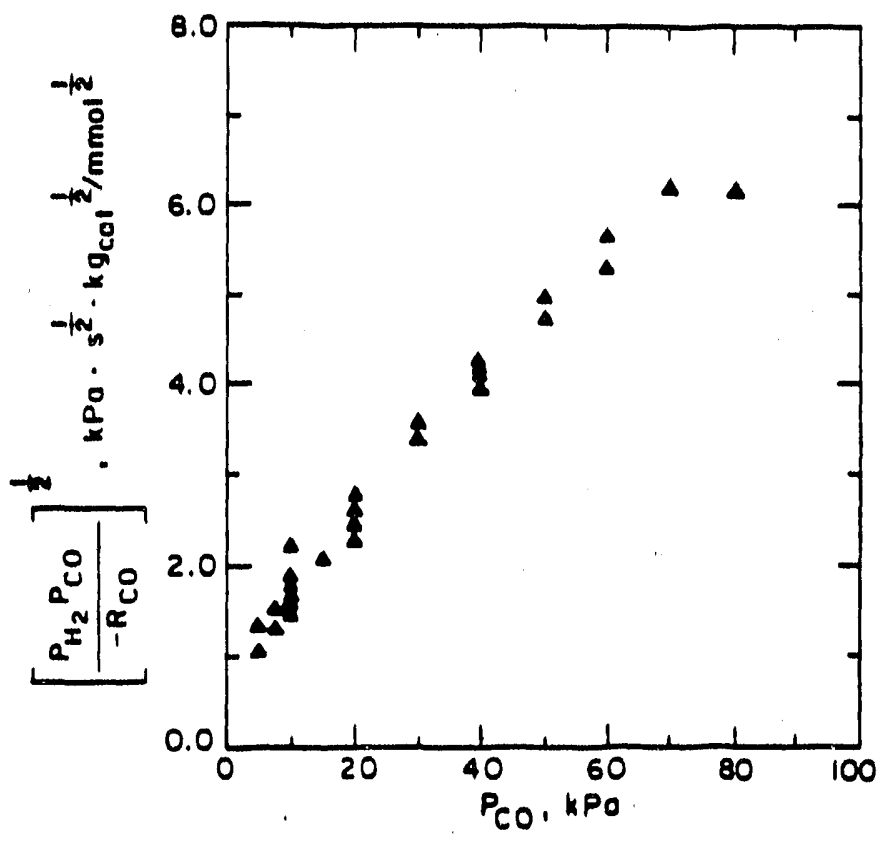

Fig. II-9 Test of eq 21 with data from Rautavuoma and van der Baan. ${ }^{5}$

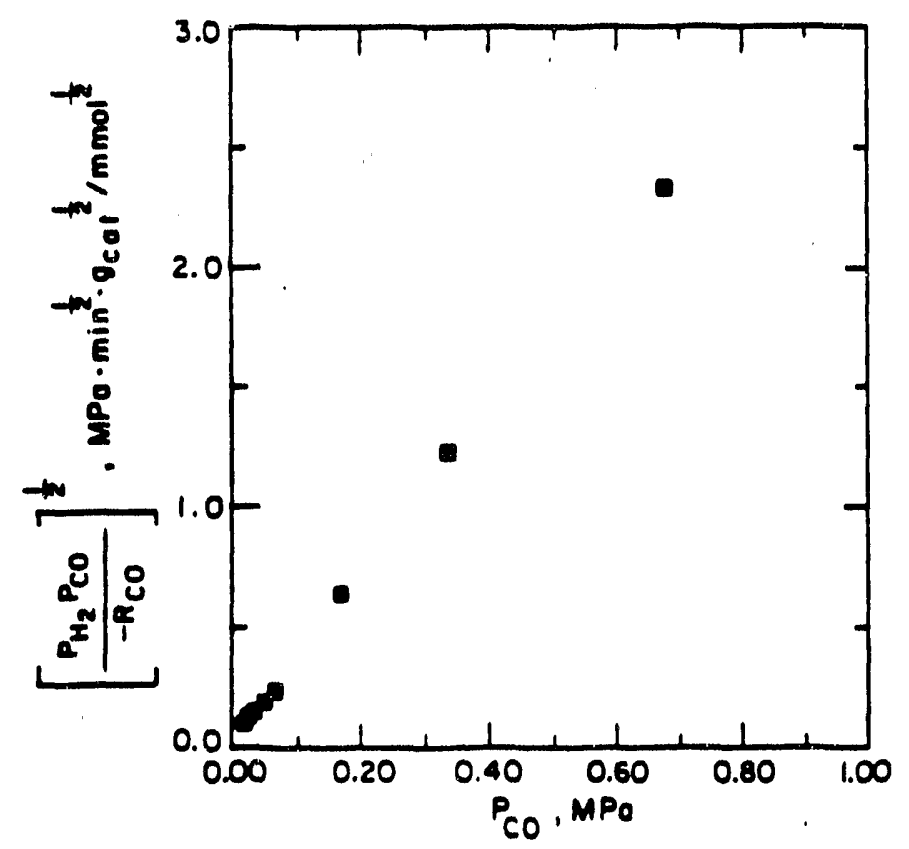

Fig. II-10 Test of eq 21 with data from Wang ${ }^{6}$ (pp 100-101). 


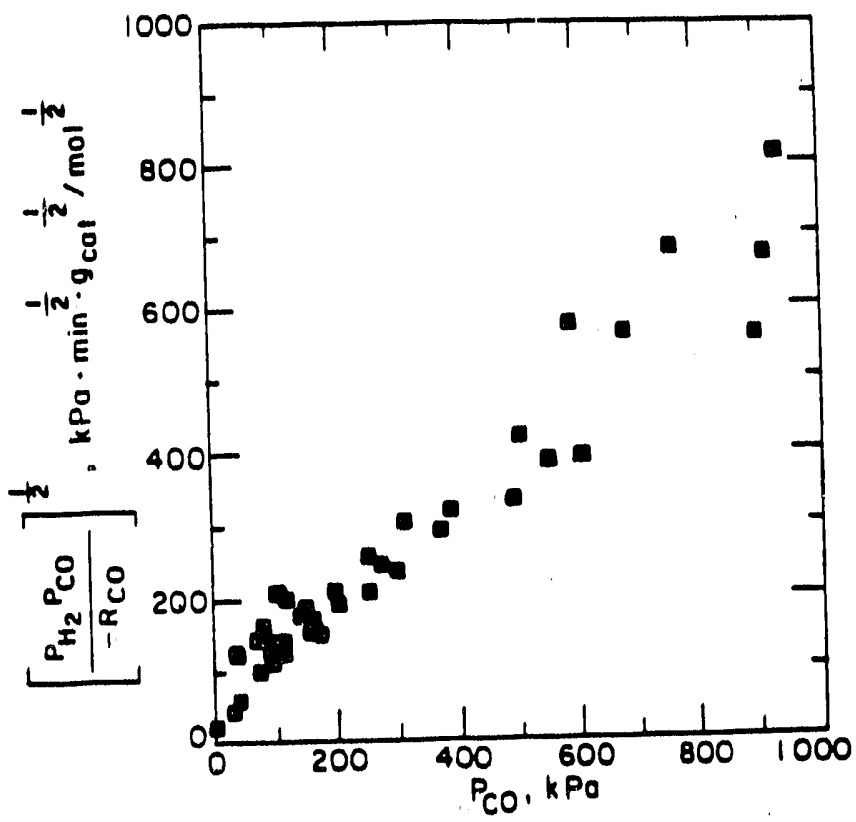

Fig. II-11 Test of eq 21 with data from Sarup and Wojciechowski. ${ }^{7}$ 


\title{
III. The Hydrocarbon Selectivity of Cobalt Fischer-Tropsch Catalysts
}

\begin{abstract}
Increasing space velocity (decreasing conversion) or decreasing reactor $\mathrm{H}_{2} / \mathrm{CO}$ ratio decreased the yield of (undesired) $C_{1}$ products and increased the yield of (desired) $\mathrm{C}_{10}+$ products. Reactor temperature and pressure had little effect on the carbon number distribution. These findings are interpreted in terms of the extent of the readsorption of 1-alkenes into growing chains on the catalyst surface. The relative selectivity to 1 -alkenes by the primary synthesis and secondary reaction of 1 -alkenes to nalkanes and 2-alkenes depends on reactor $\mathrm{H}_{2} / \mathrm{CO}$ ratio and $\mathrm{CO}$ concentration.
\end{abstract}




\section{A. Introduction}

The chemistry of the Fischer-Tropsch synthesis can be described as the polymerization of single-carbon units on a catalytic site. ${ }^{1-3}$ The distribution of products may be characterized by a parameter $\alpha$, the Schulz-Flory chain growth probability; in its simplest formulation $\alpha$ is the likelihood that a $C_{n}$ species on the catalyst surface will add another carbon and become a $C_{n+1}$ species, rather than desorb as a product. More than one chain growth probability may exist. The existence of product distributions with two chain growth probabilities, $\alpha_{1}$ for low carbon numbers and $\alpha_{2}$ for high carbon numbers, has been observed experimentally on iron catalysts by many investigators ${ }^{47}$ and has been reported also for cobalt in a study by Schulz. ${ }^{8}$

On iron-based Fischer-Tropsch catalysts, a sharp "break" from $\alpha_{1}$, with a value usually near 0.6 , to $\alpha_{2}$, having a higher value, usually near 0.9 , occurs on a semilogarithmic plot of mole fraction versus carbon number, typically at about $C_{10}$. The double- $\alpha$ and its mathematical development are discussed in detail by Donnelly et al. ${ }^{3}$ Data from previous studies indicate that the break from $\alpha_{1}$ to $\alpha_{2}$ may be less pronounced on cobalt catalysts than on iron catalysts.

The objective of this part of the study was to characterize the hydrocarbon selectivity on a cobalt Fischer-Tropsch catalyst as a function of process variables over a wide range of industrially-relevant conditions. Particular attention was paid to understanding the effects of process variables on the yield of desired high-molecular weight products.

The secondary reactions of 1-alkenes can have a significant effect on the observed product distributions on cobalt. 1-Alkenes can incorporate into growing chains, the 
extent of which is affected by competitive reactions, largely alkene hydrogenation and isomerization to the 2-alkene. The effects of 1-alkenes deliberately added during synthesis on the product distribution on cobalt catalysts will be discussed in an accompanying paper, ${ }^{9}$ together with relevant literature.

\section{B. Literature Review}

Reports on hydrocarbon distributions from cobalt catalysts date back to the early days of the Fischer-Tropsch synthesis in Germany, in which cobalt was used in industrial plants during World War II. Results from this early German work and other studies immediately following World War $\mathrm{II}$ are summarized by Storch et al. ${ }^{10}$ On the $\mathrm{Co} / \mathrm{TbO}_{2} / \mathrm{MgO} /$ kieselguhr catalysts studied, the selectivity to heavy products increased with decreasing $\mathrm{H}_{2} / \mathrm{CO}$ ratios, and reportedly went through a maximum with respect to pressure between 0.5 and $0.85 \mathrm{MPa}$ and remained unaffected by conversion. From a considerable number of more recent studies, we comment only on those most closely related to our work. Product distributions can be affected by many variables such as operating pressure, temperature, degree of conversion, $\mathrm{H}_{2} / \mathrm{CO}$ ratio, catalyst composition, and nature of reactor, such as integral fixed bed versus a well-mixed flow reactor. Thus some reported results may seem to be contradictory.

Borghard and Bennett ${ }^{11}$ studied a $34 \mathrm{wt} . \% \mathrm{Co} / \mathrm{SiO}_{2}$ catalyst at $2.03 \mathrm{MPa}$ and $250^{\circ} \mathrm{C}$ with a $\mathrm{H}_{2} / \mathrm{CO}$ feed ratio of 2 in a fixed bed reactor and compared the product distribution with that from several iron catalysts. In differential reactor studies performed at $250^{\circ} \mathrm{C}$, atmospheric pressure, and conversions below $2 \%$ on a Co/ $\mathrm{Al}_{2} \mathrm{O}_{3}$ catalyst, Rautavuoma and van der Baan ${ }^{12}$ report data on the $C_{1}-C_{1}$ hydrocarbon 
distribution. Values of $\alpha$ varied from 0.49 to 0.82 . Beuther et al. ${ }^{13}$ describe FischerTropsch synthesis on $100 \mathrm{Co}: 18 \mathrm{ThO}_{2}: 200 \mathrm{Al}_{2} \mathrm{O}_{3}$ and $21.9 \% \mathrm{Co:} 0.5 \%$ Ru: $2.2 \% \mathrm{ThO}_{2}$ : 74.5\% $\mathrm{Al}_{2} \mathrm{O}_{3}$ catalysts. The data are somewhat difficult to interpret, but the selectivity to higher hydrocarbons can be inferred to decrease with increasing temperature.

The most extensive results are from a variety of studies by Schulz and co-workers. Some of these appear in rather inaccessible sources and frequently work with cobalt is discussed in conjunction with more extensive studies on iron. The most extensive studies were apparently obtained by Schulz $z^{8}$ on five different cobalt compositions, all containing $\mathrm{ThO}_{2}$ and a silica gel support. Three also contained $\mathrm{MgO}$. Reaction conditions were varied from 0.1 to $3.3 \mathrm{MPa}, 175$ to $210^{\circ} \mathrm{C}$ and $\mathrm{H}_{2} / \mathrm{CO}$ ratios usually of 1.8 to 2.0 , utilizing a fixed bed reactor. A double $\alpha$ product distribution is reported, breaking at about $C_{10}$, attributed to incorporation of olefinic primary products. The carbon number distribution of products varied substantially with operating conditions.

From this study and a later report summarizing much of his work, Schulz et al. ${ }^{14}$ drew a number of generalizations. The ratio of alkenes to alkanes decreased with increasing carbon number, increased with increasing pressure and decreased with increasing space velocity (lower conversion). These are basically trends in alkene hydrogenation. Higher molecular weight alkenes are postulated to be more strongly adsorbed, the reduction in hydrogenation at higher pressures is attributed to inhibition of alkene adsorption by increased adsorption of $\mathrm{CO}$. At high space velocities (low conversion) increased hydrogenation is attributed to higher hydrogen pressure. Hydrogenation increased with increasing temperature, which can also be interpreted in terms of competitive adsorption of $\mathrm{CO}$, that would be expected to decrease at higher 
temperatures. Methane selectivity was reported to be in the range of 7 to 14 carbon\% (\% of total $\mathrm{C}$ in hydrocarbon products, qualitatively very similar to wt.\%) and increased with increasing temperature. The formation of 2-alkenes was lower at low conversions, and decreased with increasing pressure and temperature. The isomerization of 1-alkenes to 2-alkenes increased with increasing carbon numbers, possibly as a result of longer residence times of higher-molecular weight 1-alkenes.

Operating with a Berty reactor at $250^{\circ} \mathrm{C}$, Sarup and Wojciechowski ${ }^{15}$ examined the effect of $\mathrm{H}_{2} / \mathrm{CO}$ ratio on product distribution over a $\mathrm{Co} / \mathrm{SiO}_{2}$ catalyst Products from $\mathrm{C}_{1}$ to $C_{30}$ were identified as predominantly linear alkanes, monomethyl isomers and some 1 and 2-alkenes. The $\mathrm{C}_{3}+$ products were reported to follow a single- $\alpha$ Schulz-Flory distribution. However, graphs of the data taken after a significant time-on-stream show a possible second $\alpha$ beginning in the $C_{10}$ range. The chain growth probability decreased with increasing $\mathrm{H}_{2} / \mathrm{CO}$ ratio.

Fu et al. ${ }^{16}$ studied 10 and 15 wt.\% Co on $\mathrm{Al}_{2} \mathrm{O}_{3}$ at $0.1 \mathrm{MPa}$ in a differential reactor. Temperature was varied from $200^{\circ} \mathrm{C}$ to $235^{\circ} \mathrm{C}, \mathrm{H}_{2} / \mathrm{CO}$ ratios from 0.5 to 3 , and a four-fold range of space velocities was examined. Selectivities are reported in terms of $\mathrm{C}$-number ranges, the highest being $\mathrm{C}_{12}+$. The resulting $\alpha_{1}$ values varied from about 0.6

to 0.8 . Chain growth probability decreased with increasing inlet $\mathrm{H}_{2} / \mathrm{CO}$ ratio and increasing temperature.

\section{C. Hydrocarbon Carbon Number Distributions}

Cobalt catalysts form mostly straight chain hydrocarbons. In the range of $C_{10}$ to $\mathrm{C}_{20,}$, such products are of value as diesel and jet fuels. Heavier waxy products in the 
$\mathrm{C}_{20}+$ range can be hydrocracked back to lower molecular weight fuels. The results presented here focus on the effects of process variables on the hydrocarbon product distributions of the synthesis. Particular attention was paid to the selectivity to the desired $\mathrm{C}_{10}+$ fraction and the undesired $\mathrm{C}_{1}$ fraction. Because incorporation or secondary reactions of alkenes may be responsible for the sensitivity of the product distributions to operating conditions, the secondary reactions of synthesized 1-alkenes were also examined.

III. C. 1. Representative Product Distributions. Figures III-1 and III-2 show representative Schulz-Flory diagrams of products volatilized from the reactor. The $\mathrm{C}_{3}+$ data are well described by a double- $\alpha$ Schulz-Flory model. The solid line in Figures MI-1 and III-2 is the best-fit nonlinear regression of a double- $\alpha$ model as developed by Donnelly et al..$^{3}$ Above about $\mathrm{C}_{15}-\mathrm{C}_{20}$, the overhead product distribution deviates increasingly from that actually formed because of retention of heavy products in the reactor.

This model was used as a basis for comparison of the data from this study with data from previous studies on iron catalysts. For the two material balances shown, $\alpha_{1}$ is calculated to be about 0.54 and $\alpha_{2}$ near 0.89 . The "break" carbon number, the carbon number at which the contributions of both $\alpha_{1}$ and $\alpha_{2}$ are equal, is near 5 , which is lower than is typically observed on iron catalysts. ${ }^{20,21,22}$ For a description of this two-site interpretation of the double- $\alpha$, see ${ }^{4,20,22}$.

Figure III-3 shows a Schulz-Flory diagram of a wax sample taken from the reactor slurry at the end of the run. The value of $\alpha_{2}$ estimated by linear regression of the data 
between $\mathrm{C}_{30}$ and $\mathrm{C}_{53}$ was 0.87 . Although this sample represents the sum of all product distributions from the entire run, note that this value of $\alpha_{2}$ is close to that calculated by the nonlinear regression from the overhead products. The asymptotic linear relationship holds over a wide range of carbon numbers, indicating that chain growth probability reaches a constant value at high carbon numbers.

III. C. 2. The Effect of Operating Parameters. A useful method of reporting results on product distributions is to report $\alpha_{1}, \alpha_{2}$, and either $Q$, the breakpoint between the two distributions, or $x_{1}$, the product fraction formed by the $\alpha_{1}$ distribution. In addition, we determine respective $95 \%$ confidence intervals or standard deviation of parameter estimate. However, $Q$ or $x_{1}$ is difficult to estimate precisely from regression of experimental data and therefore, an additional method of reporting selecivity data is useful. Because of low volatility, products at kigher carbon numbers tend to remain in the slurry liquid. Therefore, to develop a complete distribution of the products being synthesized, the mole fractions above $\mathrm{C}_{15}$ must be estimated.

The recommended method used here is as follows. First, the data from $C_{3}$ to $C_{1}$ are fit and estimates of $\alpha_{1}, \alpha_{2}$, and $Q$ made. Second, the mole fractions from $C_{N}$ to $C_{100}$ are extrapolated and used to generate estimates of the "data" in terms of weight fractions. Assuming that all products above $C_{N}$ have the molecular weight of alkanes is generally reasonable; however, if more precise estimates about the within-carbon-number selectivity are known, these can be included also. Third, the actual weight of products produced at $C_{1}$ and $C_{2}$ are included and the data are then expressed in terms of weight classes. Weight classes which are industrially-relevant are $C_{1}, C_{2}-C_{4}$ (light gas), $C_{5}-C_{9}$ 
(gasoline), and $\mathrm{C}_{10}+$ (diesel and wax). Finally, to check that the estimate of the weight classes is reasonable, the closure on carbon, including the extrapolated hydrocarbons, is estimated and required to fall between 95 and $105 \%$.

By expressing the data in terms of these weight classes, minor differences in the nonlinear regression results will have less tendency to mislead interpretation of the data and selectivity correlation. For example, in some analyses $\alpha_{2}$ may seem slightly high, while $\Omega$ may be also be high; thus, it is impossible to determine which conditions are better by examining the effect of process conditions on $\alpha_{2}$ only. To simplify presentation of the results here, only $\mathrm{C}_{1}$ and $\mathrm{C}_{10}+$ products are reported. These two product classes are representative of undesirable and desirable products, respectively.

III. C. 3. Space Velocity. Figure III-4 shows the effect of space velocity on the yield of products at $0.79 \mathrm{MPa}, 240^{\circ} \mathrm{C}$, and $\mathrm{H}_{2} / \mathrm{CO}$ feed ratio of 2 . This $\mathrm{H}_{2} / \mathrm{CO}$ feed ratio is near the usage ratio of cobalt and therefore varying space velocity has little effect on reactor $\mathrm{H}_{2} / \mathrm{CO}$. Increasing space velocity (decreasing conversion) increases the fraction of $\mathrm{C}_{10}+$, while decreasing the yield of $\mathrm{C}_{1}$ products.

One possible interpretation is that at higher conversions, a product, such as water, might readsorb onto the surface of the catalyst and increase chain termination. However, the effect seems to be related rather to the extent of chain incorporation of 1alkenes relative to being hydrogenated or isomerized to 2-alkenes. At higher space velocity (lower residence time), 1-alkenes are hydrogenated or isomerized less than at lower space velocities because of the decrease in residence time of the 1-alkenes. 
III. C. 4. Pressure. Figure III-5 shows that, at $220^{\circ} \mathrm{C}$ and $0.017-0.018 \mathrm{Nl} / \mathrm{min} / \mathrm{gcat}$ (unreduced basis) of $\mathrm{H}_{2} / \mathrm{CO}=2$ synthesis gas, the selectivity to $\mathrm{C}_{1}$ and $\mathrm{C}_{10}+$ products remained constant over a range of total reactor pressure of 0.5 to $1.5 \mathrm{MPa}$. In a study at $175^{\circ} \mathrm{C}$, and pressures of 0.12 to $3.3 \mathrm{MPa}$, using a $\left(\mathrm{H}_{2} / \mathrm{CO}\right)$ inlet ratio of 1.8 , Schulz ${ }^{8}$ reported that methane selectivity decreased with increasing pressure. The $\mathrm{C}_{10}+$ product distribution scattered considerably with pressure. The $\left(\mathrm{H}_{2} / \mathrm{CO}\right)$ exit ratio was nearly constant, in the range of 1.6 to 1.7 .

III. C. 5. Temperature. Figure III-6 shows the dependence of the weight fractions of $C_{1}$ and $C_{10}+$ for total synthesis gas conversions between 31 and $33 \%$ at 220 and $240^{\circ} \mathrm{C}$. Data are presented at comparable conversion, rather than equivalent space velocities, because the ratio of product to reactant concentration appears to have a marked effect. No trend is observed over this limited temperature range. In a study at 1:7 $\mathrm{MPa}$ and 170 to $190^{\circ} \mathrm{C}$, using a $\left(\mathrm{H}_{2} / \mathrm{CO}\right)$ inlei ratio of 1.0 , Schulz $z^{8}$ reported that methane formation increased with temperature but there was little effect of temperature on the $\mathrm{C}_{10}+$ distribution. However the exit $\left(\mathrm{H}_{2} / \mathrm{CO}\right)$ ratio varied substantially through the reactor. The exit value decreased from 0.65 at $170^{\circ} \mathrm{C}$ to 0.24 at $190^{\circ} \mathrm{C}$.

III. C. 6. Reactor $\mathrm{H}_{2} / \mathrm{CO}$ Ratio. Figure III-7 shows the effect of reactor $\mathrm{H}_{2} / \mathrm{CO}$ ratio on the relative yield of $\mathrm{C}_{1}$ products at $220^{\circ} \mathrm{C}$. Similar plots were generated showing the analogous trends at 230 and $240^{\circ} \mathrm{C}^{23}$ but are not shown here. Increasing reactor $\mathrm{H}_{2} / \mathrm{CO}$ ratios increases the relative weight fraction of $\mathrm{C}_{1}$ at all temperatures, although the trend is more apparent at lower temperatures. Methane may be formed by a mechanism separate from chain growth, which may have a positive dependence on the 
$\mathrm{P}_{\mathrm{H}_{2}} / \mathrm{P}_{\text {CO }}$ ratio, as is examined below.

Figure III-8 shows the effect of reactor $\mathrm{H}_{2} / \mathrm{CO}$ ratio on the fractional yield of products in the $\mathrm{C}_{10}+$ range at $220^{\circ} \mathrm{C}$. Again, similar plots were generated showing the analogous trends at 230 and $240^{\circ} \mathrm{C}^{23}$ but are not shown here. Increasing reactor $\mathrm{H}_{2} / \mathrm{CO}$ ratio decreases the yield of high-molecular weight products relative to total bydrocarbons synthesized. This decrease can be primarily attributed to the increase in rate of production of low-molecular weight products, particularly methane. This general trend has also been reported by others. ${ }^{8,11,16}$

\section{D. Selectivity to Various Product Classes}

Figures III-9 and III-10 show component Schulz-Flory diagrams including the distribution of three major product classes, n-alkanes, 1-alkenes, and n-alcohols. Three other components were observed in much lower concentrations than these at each carbon number; in order of relative abundance, they were 2-alkenes, branched alkanes, and aldehydes (only at $C_{2}$ and $C_{3}$ and in very low concentrations). Methane lies above the line that would be predicted by a double- $\alpha$ Schulz-Flory mechanism, while $C_{2}$ products lie below, as is characteristic of most Schulz-Flory diagrams of hydrocarbon products. ${ }^{3}$ The observed $C_{2}$ concentration on cobalt is generally less than on iron. ${ }^{8}$

Both the n-alkanes and n-alcohols exhibit a double- $\alpha$ type distribution; that is, at low carbon numbers, the mole fraction of products drops off quickly, while, at higher carbon numbers, the mole fraction drops off more slowly. Above $\mathrm{C}_{3}$, the fraction of synthesized products which are hydrogenated increases with increasing carbon number.

In contrast to $n$-alkanes and $n$-alcohols, 1 -alkenes appear to follow a single- $\alpha$ type 
distribution in Figures III.9 and II-10. The extent to which observed products represent $t^{2}$ - primary synthesis versus secondary reactions varies depending on reactor conditions. 1.dikenes, presumed to be the primary product of the synthesis by Schulz et al., ${ }^{14}$ may be hydrogenated to n-alkanes or isomerized to 2 -alkenes. The ratio of 1 -alkene/n-alkane and 1-alkene/2-alkene both decrease with increasing carbon number, as was also observed by Schulz ${ }^{8}$ and Rautavuoma and van der Baan. ${ }^{12}$ As shown below, a large fraction of $n$-alkanes appear to be produced by the bydrogenation of 1 -alkenes. Therefore, assuming independent mechanisms for the production of 1-alkenes and alkanes, based on differences in component Schulz-Flory diagrams, may be incorrect.

Since the formation of $C_{1}$ products appeared markedly different from the formation of other components, we examined the fit of the rate expression developed elsewhere for the consumption of synthesis gas to the formation of $C_{1}$ and $C_{2}+$ products as two separate groups. The expression is ${ }^{24}$ :

$$
-R_{H_{2}+C O}=\frac{a P_{C O} P_{H_{2}}}{\left(1+b P_{C O}\right)^{2}}
$$

Figure III-11 shows that the rate of $C_{1}$ formation is well fit by the linearized form of equation 1. Figure III-12 shows that the rate of $C_{2}+$ formation is also well fit by equation 1. Thus, the decrease in yield of higher molecular weight products with increasing $\mathrm{H}_{2} / \mathrm{CO}$ does not seem to result from competing rate mechanisms for formation of $C_{1}$ versus $C_{2}+$ products. 


\section{E. Secondary Reactions of 1-Alkenes}

In characterizing secondary reactions, the rate of formation of ethane, n-butane, and 2-butene were studied. Ethane represents hydrogenation only; the behavior of the $\mathrm{C}_{4}$ compounds is taken as representative of that of the $\mathrm{C}_{3}+$ products. As discussed by Hanlon and Satterfield, ${ }^{25}$ and Donnelly and Satterfield, ${ }^{7} \mathrm{C}_{4}$ products are the highest molecular weight products which do not split between vapor and liquid phases in our traps and therefore are the least subject to experimental error.

III. E. 1. Rate of Ethane Formation from Ethene. Figure 13 shows the dependence of the rate of formation of ethane on the ratio of $\mathrm{P}_{\mathrm{C}_{2} \mathrm{H}_{4}} \mathrm{P}_{\mathrm{H}_{2}} / \mathrm{P}_{\mathrm{CO}}$ in the reactor; data at $220^{\circ} \mathrm{C}$ are shown as representative. This assumes that ethane formation is a cimple hydrogenation process inhibited by adsorbed $\mathrm{CO}$. While the data scatter somewhat, much of the variation in the rate of ethane formation can be explained by such a simple model. The vertical axis intercept of this figure represents the amount of ethane produced as primary product. Over most of the range of operating variables studied, the amount of ethane produced by primary synthesis is less than half of the total amount synthesized.

III. E. 2. Rate of $\mathbf{n}$-Butane Formation from 1-Butene. Figures 14 shows the dependence of the rate of formation of n-butane on the ratio of $\mathrm{P}_{\mathrm{C}_{4} \mathrm{H}_{8}} \mathrm{P}_{\mathrm{H}_{2}} / \mathrm{P}_{\mathrm{CO}}$ in the reactor; data at $220^{\circ} \mathrm{C}$ are shown as representative. Again, a simple hydrogenation process inhibited by adsorbed $\mathrm{CO}$ is assumed. While there is considerable scatter in the data in Figure 14, the rate of n-butane formation clearly increases with increasing $\mathrm{P}_{\mathrm{C}_{4} \mathrm{H}_{8}} \mathrm{P}_{\mathrm{H}_{2}} / \mathrm{P}_{\mathrm{CO}}$. The vertical axis intercept of this figure is related to the amount of $n$ - 
butane produced in the primary synthesis; over the range of operating variables studied, the amount of $n$-butane produced by primary synthesis is generally less than half of the total amount synthesized.

The behavior of these two simple hydrogenation models is consistent with the observations of Schulz $z^{8,14}$ and Rautavuoma and van der Baan ${ }^{12}$ on cobalt and Donnelly and Satterfield ${ }^{7}$ on iron that increasing hydrogen to carbon monoxide ratio decreases the 1-alkene/n-alkane ratio.

III. E. 3. Rate of 2-Butene Formation trom 1-Butene. 2-alkenes are not considered to be a primary product, but are assumed to be produced solely by isomerization of 1-alkenes. ${ }^{14}$ Thus a model was developed which accounts for all of the production of 2-butene in terms of 1-butene isomerization. A Langmuir-Hinshelwoodtype relationship of the following form is proposed:

$$
R_{2-1000}=\frac{k P_{1-b e c}}{\left(1+K_{\infty} P_{\infty}\right)}
$$

Equation 2 assumes that the rate of 2-butene formation is simply proportional to the concentration of 1-butene and inhibited by carbon monoxide. Equation 2 can be linearized, yielding

$$
\frac{P_{1-b e c o c}}{R_{2-b e c}}=\frac{1}{k}+\frac{R_{\infty O} P_{\infty}}{k}
$$


Following the relationship of equation 3, Figures III-15a and III-15b depict the dependence of the rate of formation of $\mathrm{P}_{1 \text {-butenc }} / \mathrm{R}_{2 \text {-butene }}$ on $\mathrm{P}_{\mathrm{CO}}$ at 220 and $240^{\circ} \mathrm{C}$ respectively. Both figures show that increasing $\mathrm{P}_{\mathrm{CO}}$ will decrease the rate of 1-butene isomerization. Data from two temperatures are shown here in order to justify the added complexity of the proposed two-parameter 2-alkene production model.

The conclusion of Schulz et al. ${ }^{14}$ that the ratio of 1 -alkenes/total alkenes increases with increasing total pressure is consistent with equation 2 since the range of values of $\left(\mathrm{H}_{2} / \mathrm{CO}\right)$ through his fixed bed reactor was within the range of 1.8 to 1.6 throughout his wide range of pressure.

III. E. 4. Swetmary. Three interesting conclusions can be drawn. First, a large fraction of the alkanes and all 2-alkenes appear to be produced by secondary reactions. Second, increasing the reactor $\mathrm{H}_{2} / \mathrm{CO}$ ratio increases the ratio of alkane to 1-alkene at each carbon number. If 1-alkenes readsorb onto the catalyst surface and incorporate into growing chains, then the decrease in 1-alkene concentration, relative to $\mathrm{n}$-alkane concentration, at increased $\mathbf{P}_{\mathrm{H}_{2}} / \mathrm{P}_{\mathrm{CO}}$ may explain the decrease in high-molecular weight products at high $\mathbf{P}_{\mathrm{H}_{2}} / \mathrm{P}_{\mathrm{CO}}$. Finally, increasing the concentration of carbon monoxide may decrease the amount of 2-alkene formation. If 1-alkene incorporation plays a role in hydrocarbon production, then again the decrease in 1-alkene concentration, relative to 2 alkene concentration, at low values of $\mathrm{P}_{\mathrm{CO}}$ may explain the decrease in high-molecular weight products at high values of $\mathrm{P}_{\mathrm{H}_{2}} / \mathrm{P}_{\mathrm{CO}}$. Studies of the extent to which 1-alkene incorporation is affected by process variables such as temperature and total pressure may 
provide fundamental insight into the effects of process variables on the selectivity of the synthesis.

\section{F. Conclusions}

The relative production of $\mathrm{C}_{10}+$ on a weight basis increased with increasing space velocity and decreasing reactor $\mathrm{H}_{2} / \mathrm{CO}$, but was independent of reactor pressure or temperature. Conversely, the relative yield $C_{1}$ on a weight basis decreased with increasing space velocity and decreasing reactor $\mathrm{H}_{2} / \mathrm{CO}$, and was also relatively insensitive to reactor pressure or temperature.

Above $\mathrm{C}_{3}$, the 1-alkene/n-alkane ratio decreased with increasing carbon number. Hydrogenation modelling indicates that a large fraction of the n-alkanes were synthesized by hydrogenation of 1-alkenes, a primary synthesis product. Increasing the reactor $\mathrm{H}_{2} / \mathrm{CO}$ ratio decreased the 1-alkene/n-alkane ratio, while increased concentrations of $\mathrm{CO}$ in the reactor inhibited the isomerization of 1-alkenes to 2-alkenes. 
III. G. Literature Cited

(1) Herington, E.F.G. Chemistry and Industry 1946, 65, 346.

(2) Anderson, R.B. The Fischer-Tropsch Synthesis; Harcourt, Brace \& Jovanovich: New York, 1984.

(3) Donnelly, T.J.; Yates, I.C.; Satterfield, C.N. Energy \& Fuels 1988, 2, 734.

(4) König, L.; Gaube, J. Chem.-Ing Tech, 1983, 55, 14.

(5) Huff, G.A., Jr.; Satterfield, C.N. L. Catal, 1984, 85, 370.

(6) Dictor, R.A.; Bell, A.T. L.Catal. 1986, $27,121$.

(7) Donnelly, T.J.; Satterfield, C.N. Appl. Catal, 1989, 52, 93.

(8) Schulz, H. Report to the Bundesministerium für Forschung und Technologie, "Katalysatoren und Selektivitätslenkung bei der Fischer-Tropsch-Synthese," BMFT-FB-T 80-124, Nov., 1980.

(9) Yates, I.C.; Satterfield, C.N. to be submitted.

(10) Storch, H.H.; Golumbic, N.; Anderson, R.B. The Fischer-Tropsch and Related Syntheses; John Wiley and Sons: New York, 1951.

(11) Borghard, W.G.; Bennett, C.O. Ind. Eng Chem. Process Res, and Dev, 1979, 18, 18.

(12) Rautavuoma, A.O.I.; van der Baan, H.S. Appl. Cat, 1981, 1, 247.

(13) Beuther, H.; Kibby, C.L.; Kobylinski, T.P.; Pannell, R.B. United States Patent 4,399.234, August 16, 1983.

(14) Schulz, H.; Rosch, S.; Gokcebay, H. Proceedings $64^{\text {th }}$ CIC Coal SymposiumA.M. Al Taweel, ed., C.S.Ch.E., Ottawa (1982).

(15) Sarup, B.; Wojciechowski, B.W. Can. J. Chem. Eng, 1984, 62, 249. 
(16) Fu, L; Rankin, 'J.L.; Bartholomew, C.H. C1 Mol. Chem., 1986, 1, 369.

(17) Huff, G.A., Jr.; Satterfield, C.N. Ind. Eng, Chem. Fund, 1982, 21, 479.

(18) Donnelly, T.J.; Satterfield, C.N. Appl. Catal 1989, 56, 231.

(19) Huff, G.A., Jr.; Sittherfield, C.N. Ind. Eng, Chem. Process Des, Dev, 1984, 23, 696 .

(20) Huff, G.A., Jr. Eischer-Tropsch Synthesis in a Slurry Reactor. Sc.D. Thesis, Massachusetts Institute of Technology, Cambridge, Massachusetts, 1982.

(20a) Huff, G.A., Jr.; Satterfield, C.N.; M.H. Wolf, Ind. Eng, Chem. Fund, 1983, 22, 258.

(21) Matsumoto, D.K., The Effects of Selected Process Variables on the Performance of an Iron Fischer-Tropsch Catalyst, Sc.D. Thesis, Massachusetts Institute of Technology, Cambridge, Massachusetts, 1987.

(22) Donnelly, T.J., Product Distributions of the Fischer-Tropsch Synthesis, Ph.D. Thesis, Massachusetts Institute of Technology, Cambridge, Mass., 1989.

(23) Yates, I.C., The Slurry-Phase Fischer-Tropsch Synthesis, Ph.D. Thesis, Massachusetts Institute of Technology, Cambridge, Massachusetts, 1990.

(24) Yates, I.C.; Satterfield, C.N. Energy_\& Fuels, 1991, 5, 168.

(25) Hanlon, R.T.; and Satterfield, C.N. Energy \& Fuels, 1988, $2,196$. 


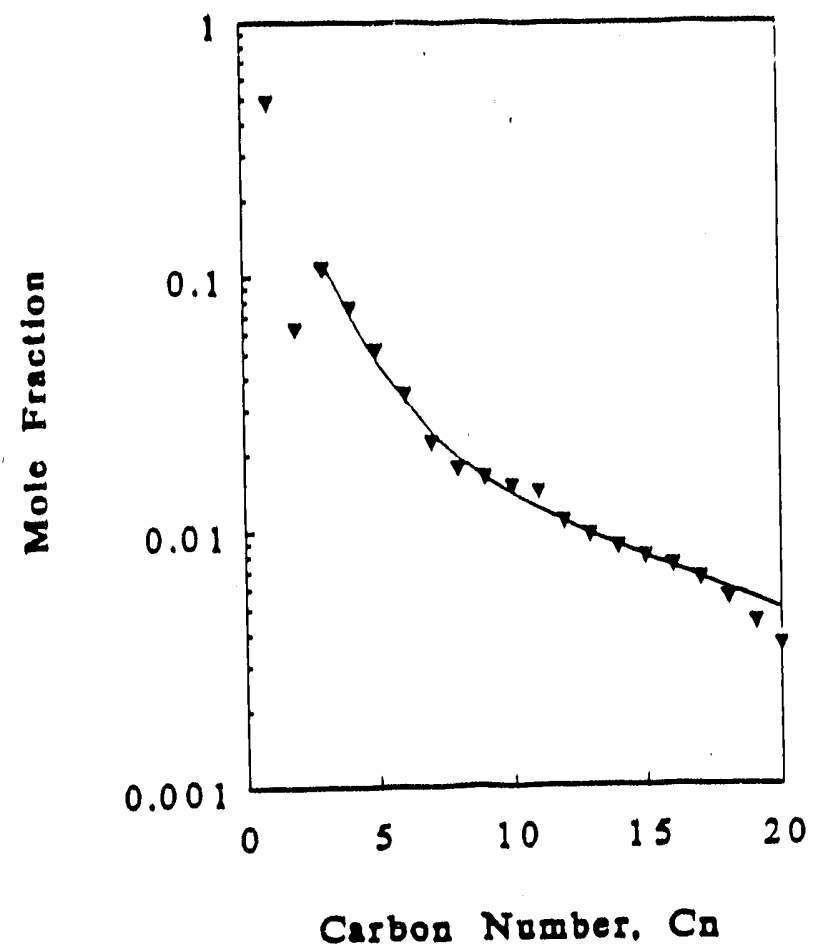

Fig.III-1 Representative Schulz-Flory Diagram showing a double- $\alpha$-type distribution $\left(220^{\circ} \mathrm{C}, 1.48 \mathrm{MPa}\right.$, feed rate $=0.032 \mathrm{Nl} / \mathrm{min} /$ gcat $)$. $\left(\mathrm{H}_{2} / \mathrm{CO}\right)_{\text {in }}=1.64$. $\left(\mathrm{H}_{2} / \mathrm{CO}\right)$ in reactor $=1.65 . \alpha_{1}=0.54, \alpha_{2}=0.91$, and $Q=5.4$.

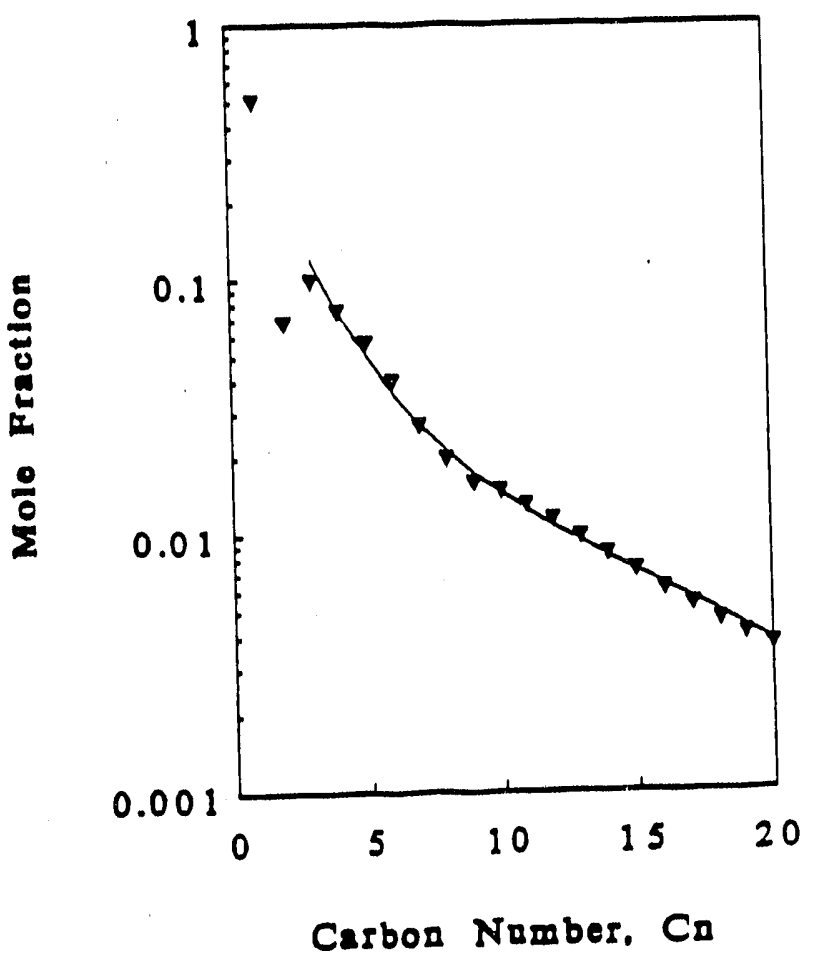

Fig. III-2 Representative Schulz-Flory Diagram showing a double- $\alpha$-type distribution $\left(230^{\circ} \mathrm{C}, 0.79 \mathrm{MPa}\right.$, feed rate $=0.020 \mathrm{Nl} / \mathrm{min} /$ gcat $)$. $\left(\mathrm{H}_{2} / \mathrm{CO}\right)$ in reactor $=1.39 .\left(\mathrm{H}_{2} / \mathrm{CO}\right)_{\text {in }}=1.55 . \alpha_{1}=0.54, \alpha_{2}=0.88$, and $\mathrm{Q}=5$. 


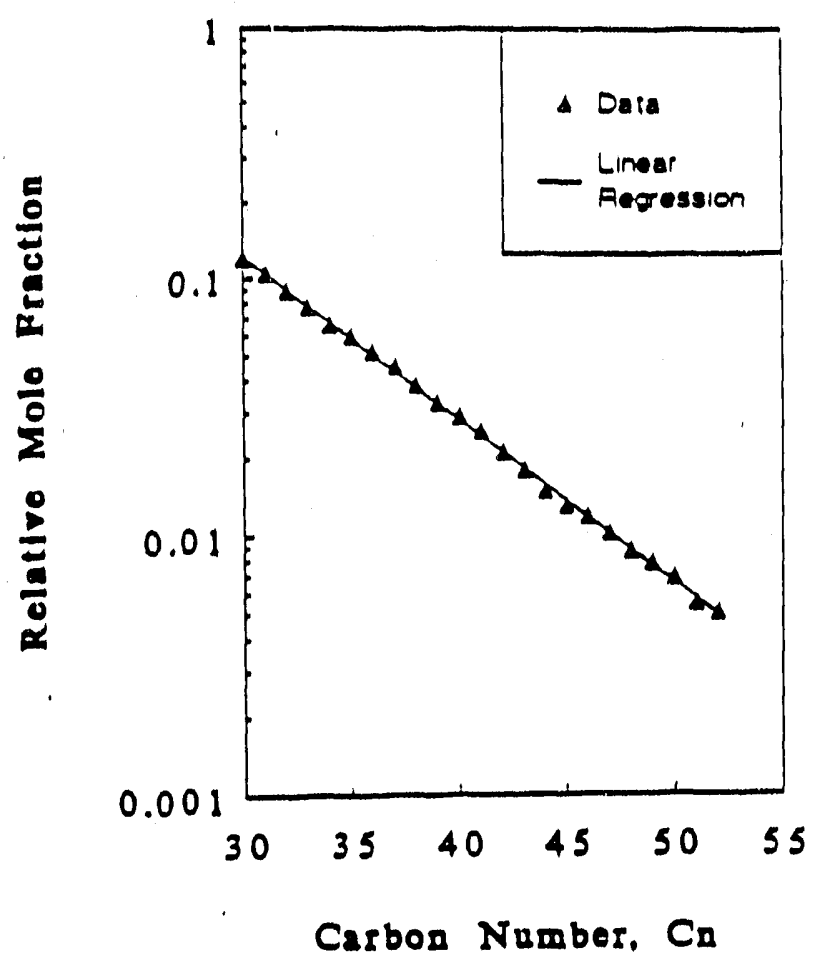

Fig. III-3 Schulz-Flory diagram for reactor liquid at completion of run. $\alpha_{2}=0.87$.

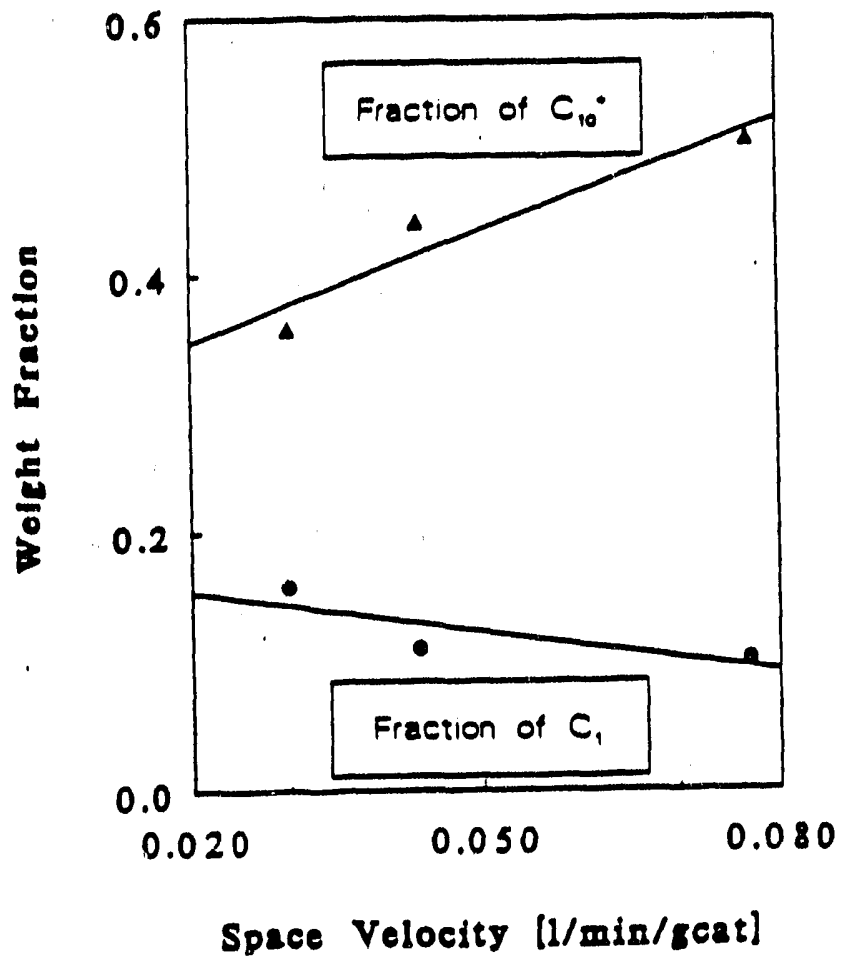

Fig. III-4 The $\mathrm{C}_{10}+$ yield is greater at higher space velocities. Data at $240^{\circ} \mathrm{C}$, $0.79 \mathrm{MPa}$, and $\left(\mathrm{H}_{2} / \mathrm{CO}\right)_{\text {in }}=2$. 


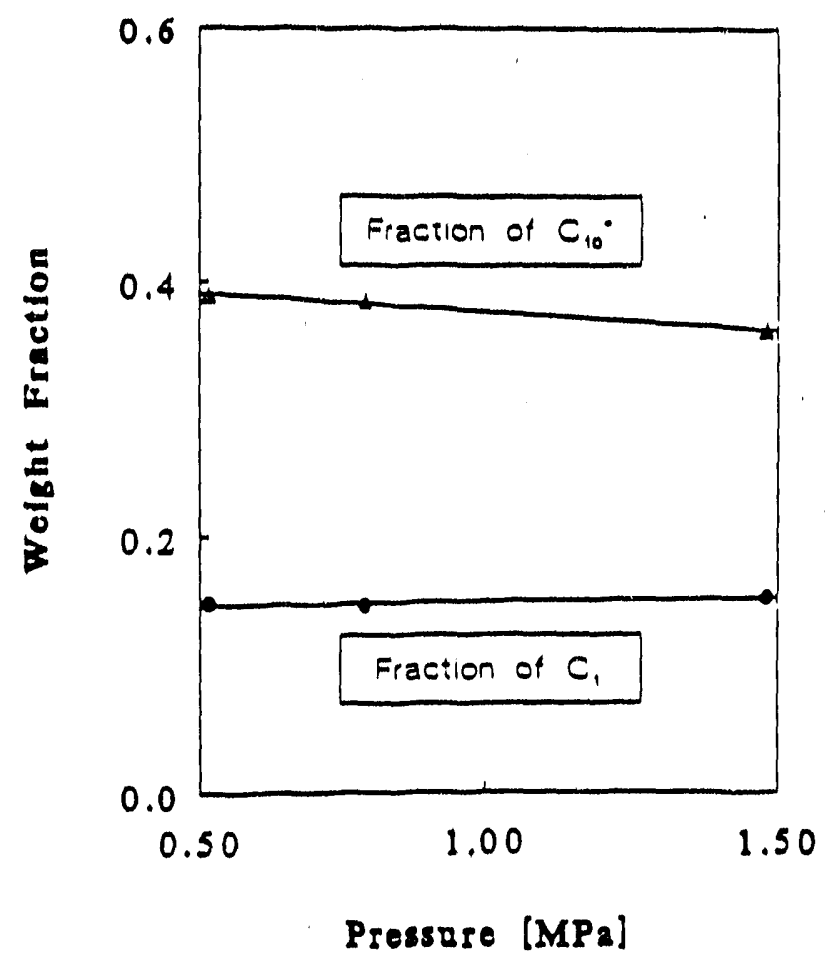

Fig. III-5 Pressure has no noticeable effect on product distribution. Data at $220^{\circ} \mathrm{C}$ and feed rate of $0.017-0.018 \mathrm{Nl} / \mathrm{min} / \mathrm{gcat}$. $\left(\mathrm{H}_{2} / \mathrm{CO}\right)_{\text {in }}=2$.

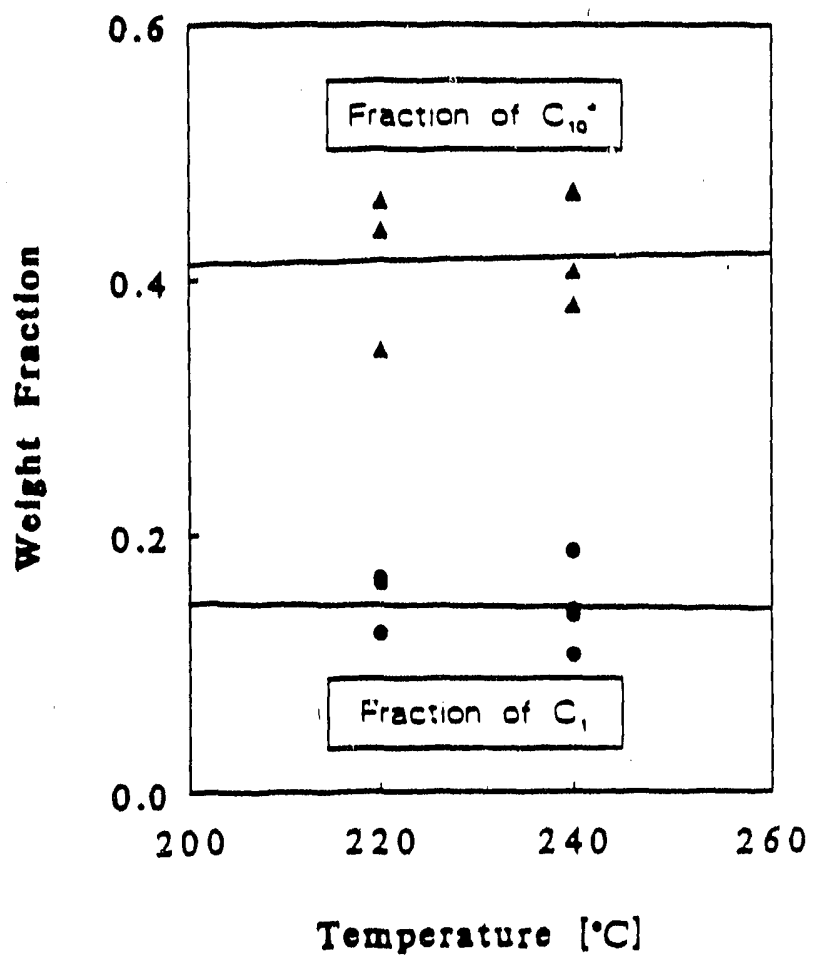

Fig. III-6 Temperature has no effect on product distributions. Total synthesis gas conversions are between 31 and 33\%, allowing comparison of similar product to reactant ratios. 


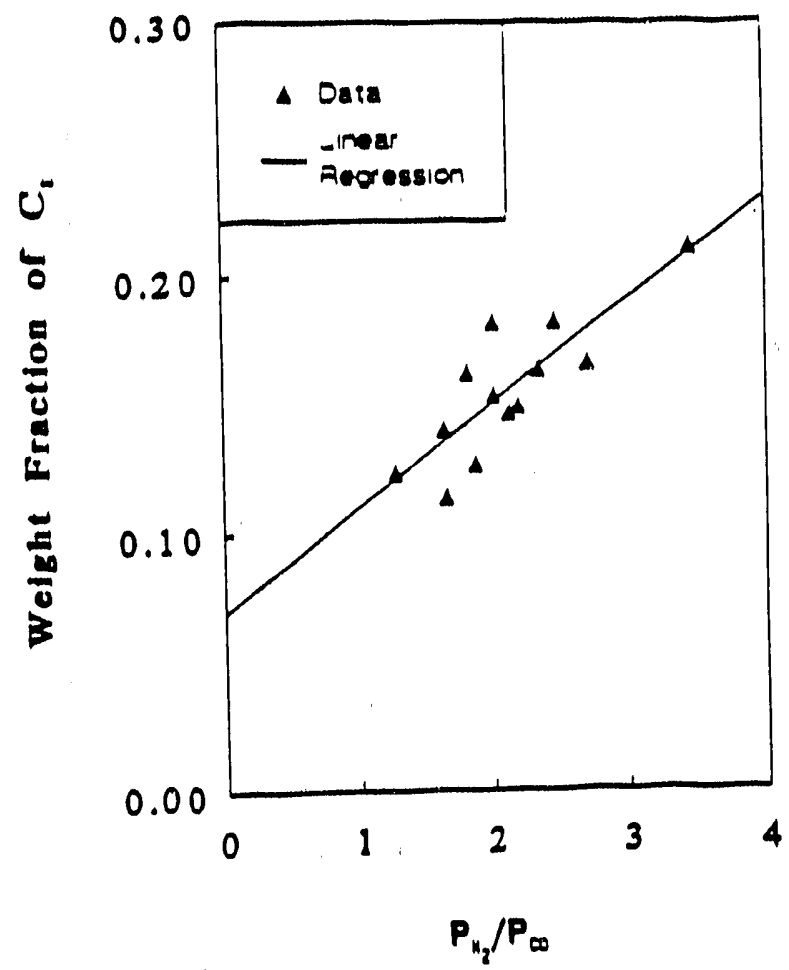

Fig. III-7 Weight fraction of $\mathrm{C}_{1}$ increases with increasing $\mathrm{H}_{2} / \mathrm{CO}, 220^{\circ} \mathrm{C}$.

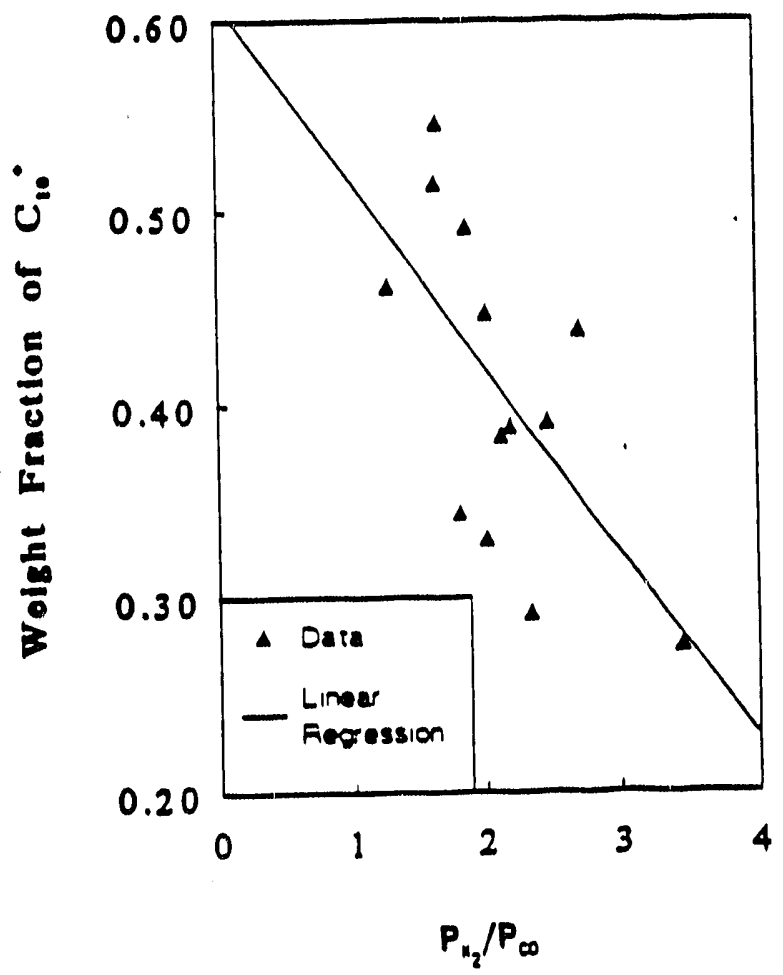

Fig. III-8 Weight fraction of $\mathrm{C}_{10}+$ decreases with increasing $\mathrm{H}_{2} / \mathrm{CO}, 220^{\circ} \mathrm{C}$. 


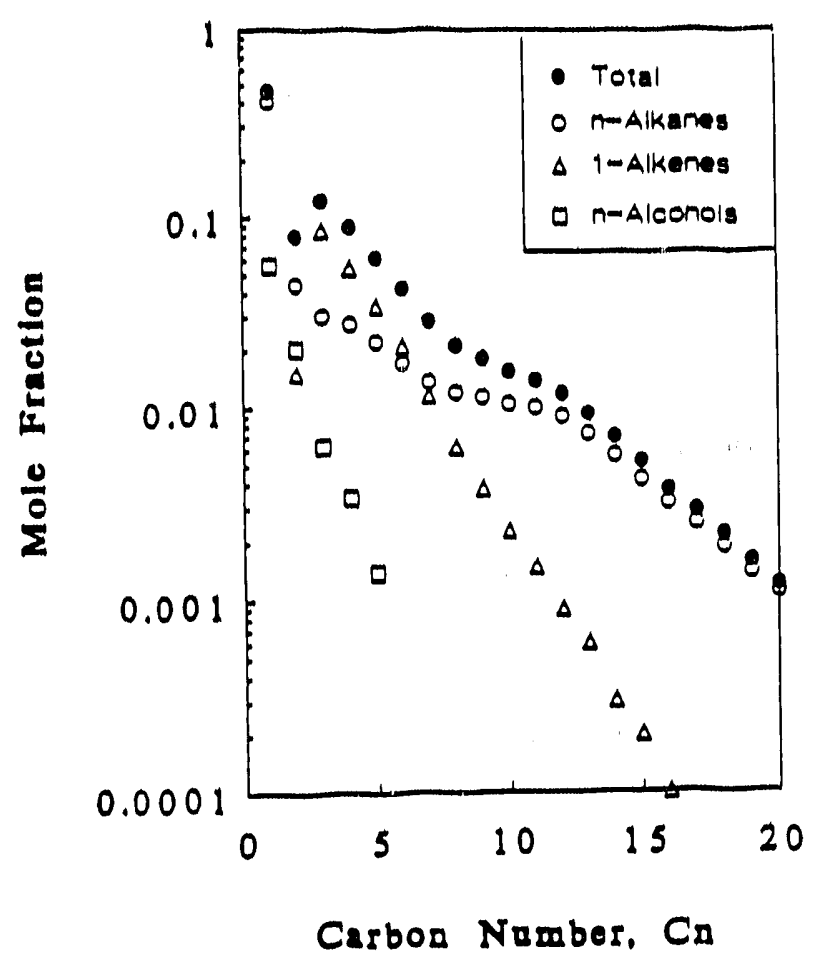

Fig. III-9 Component product distribution showing primary products, n-alkanes, 1-alkenes, and n-alcohols $\left(220^{\circ} \mathrm{C}, 1.48 \mathrm{MPa}\right.$, and feed rate of 0.015 $\mathrm{Nl} / \mathrm{min} /$ gcat $) .\left(\mathrm{H}_{2} / \mathrm{CO}\right)_{\text {in }}=1.66$.

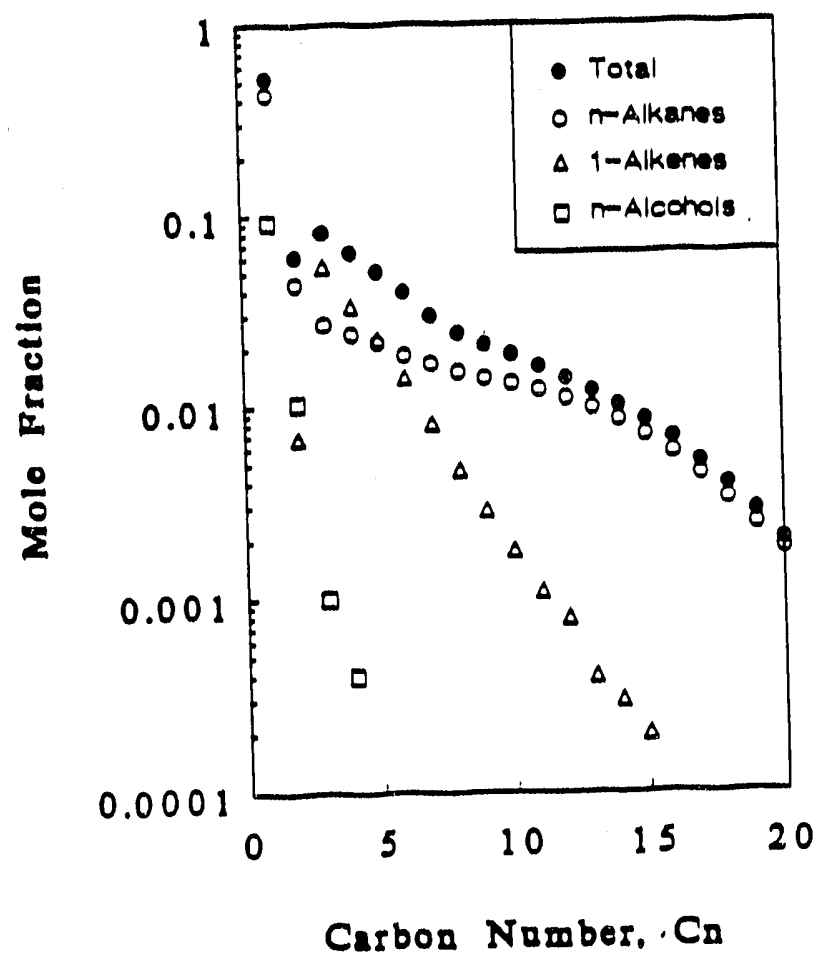

Fig. III-10 Component product distribution showing primary products, nalkanes, 1-alkenes, and $\mathrm{n}$-alcohol $\left(240^{\circ} \mathrm{C}, 0.79 \mathrm{MPa}\right.$, and feed rate of $0.035 \mathrm{Nl} / \mathrm{min} / \mathrm{gcat}) .\left(\mathrm{H}_{2} / \mathrm{CO}\right)_{\text {in }}=2.15$. 


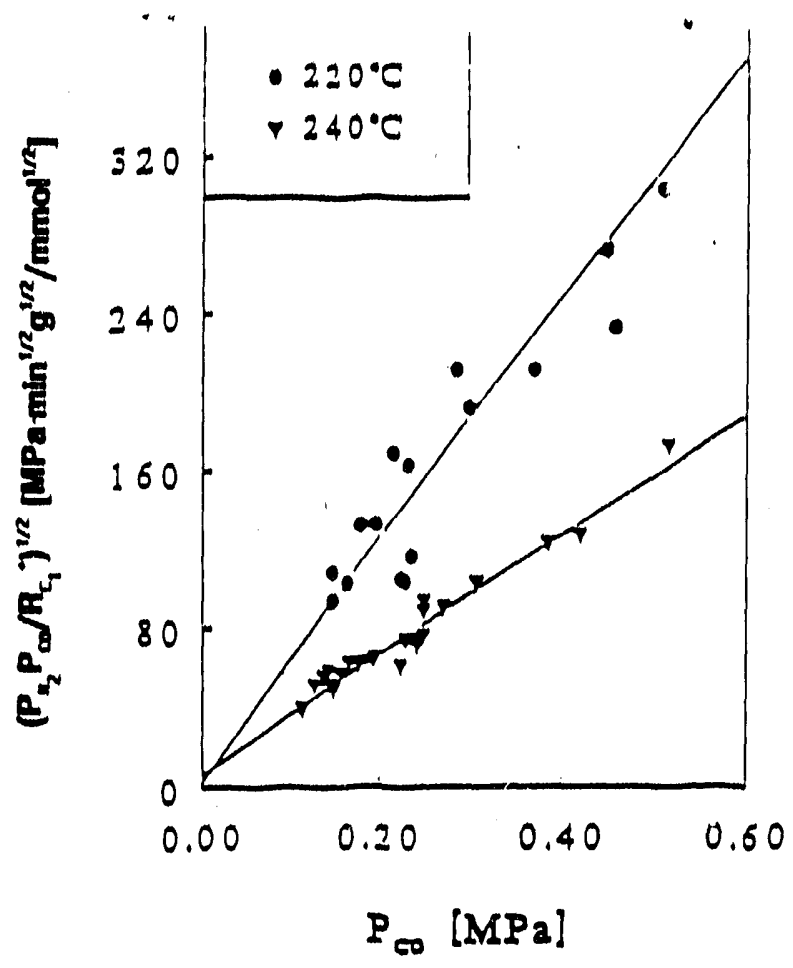

Fig. III-11 The rate of methane plus methanol formation is well fitted by equation 1.

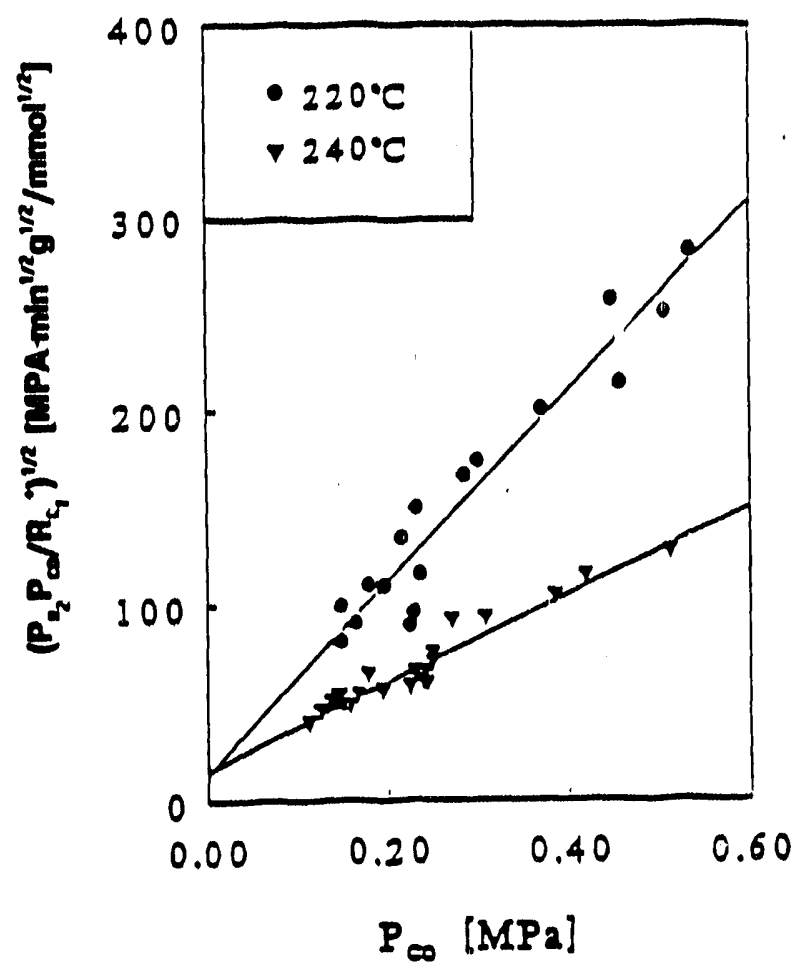

Fig. III-12 Rate of formation of $\mathrm{C}_{2}+$ compounds is well fitted by equation 1 . 


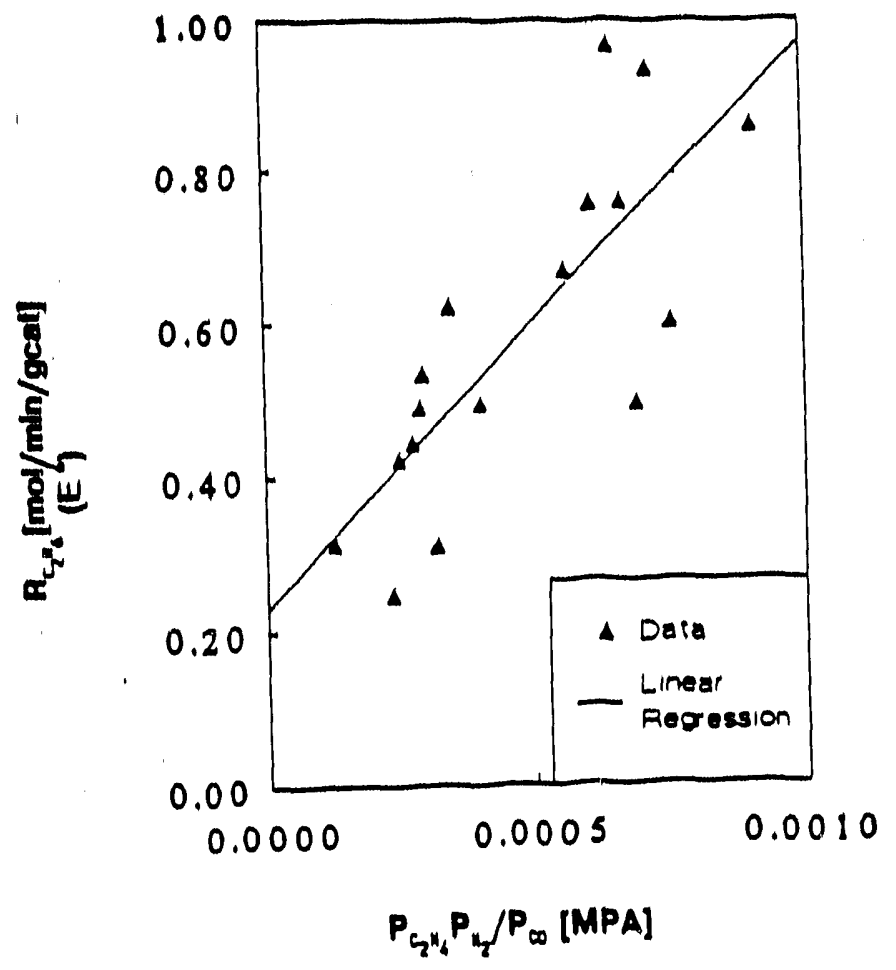

Fig. III-13 Most ethane is produced from ethene, according to a simple hydrogenation model, data at $220^{\circ} \mathrm{C}$.

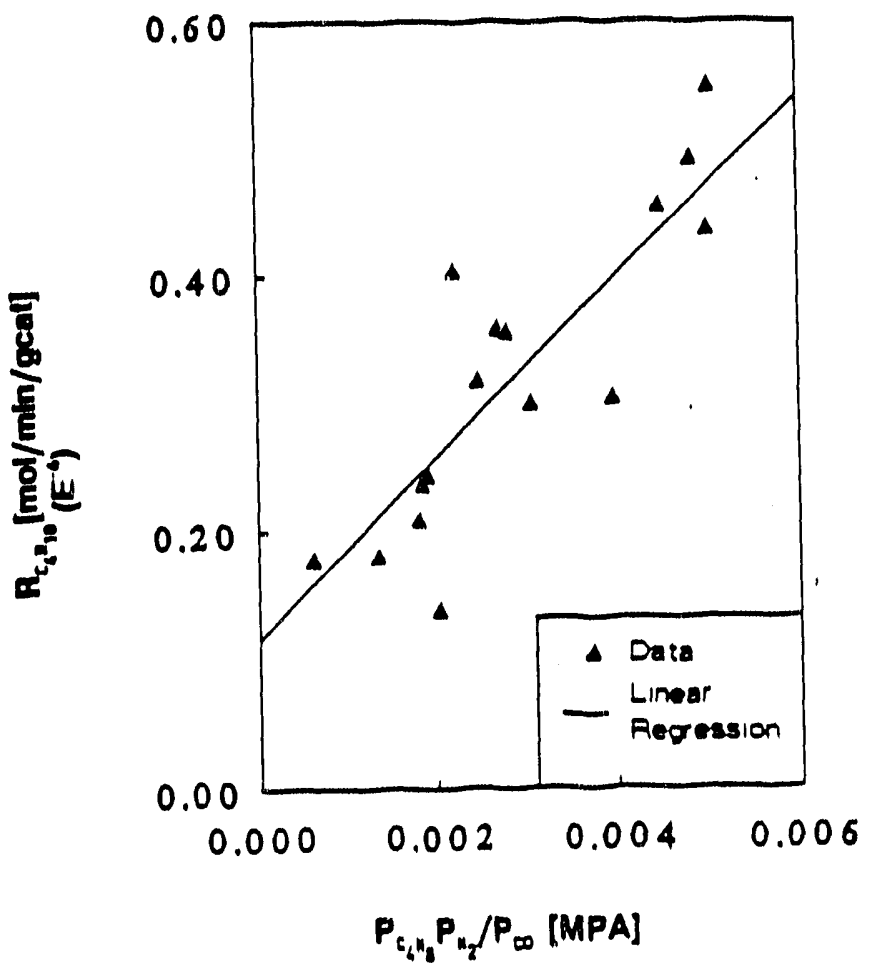

Fig. III-14 Most n-butane is produced from 1-butene, according to a simple hydrogenation model, data at $220^{\circ} \mathrm{C}$. 


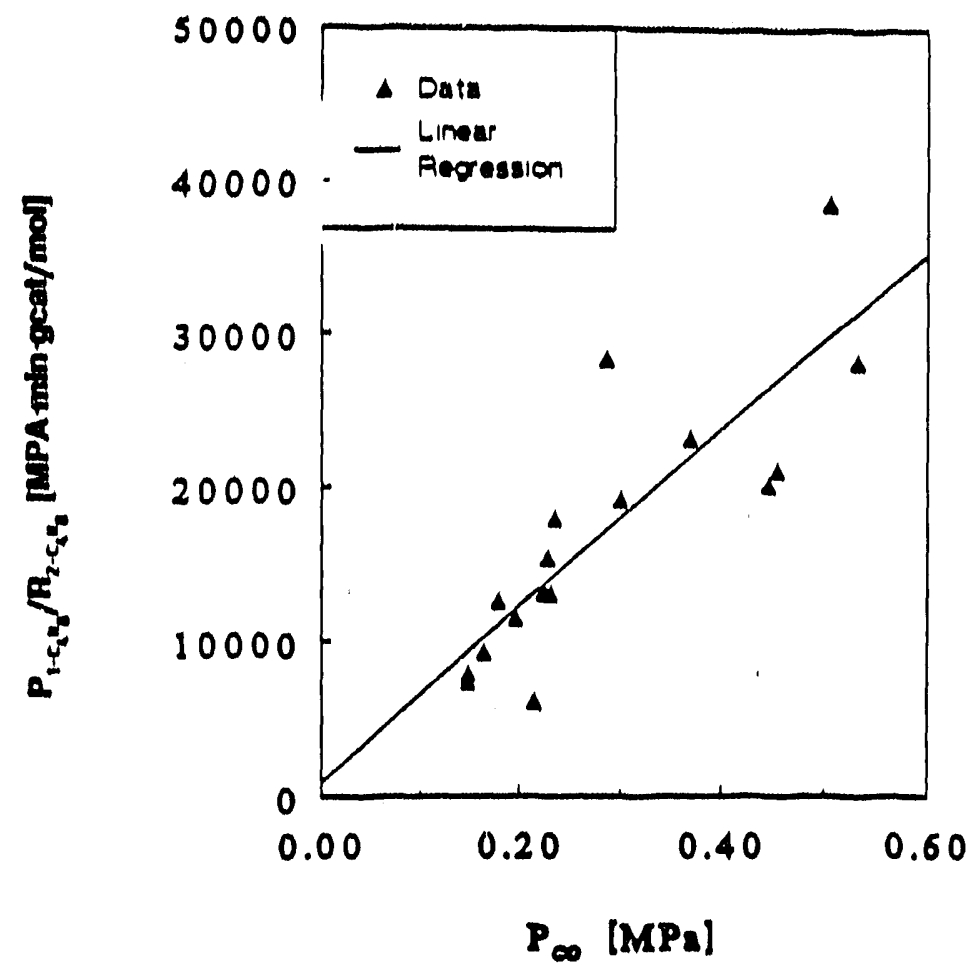

Fig. III-15a Most 2-butene is produced from 1-butene, according to simple isomerization model (see equation 2 ), $220^{\circ} \mathrm{C}$.

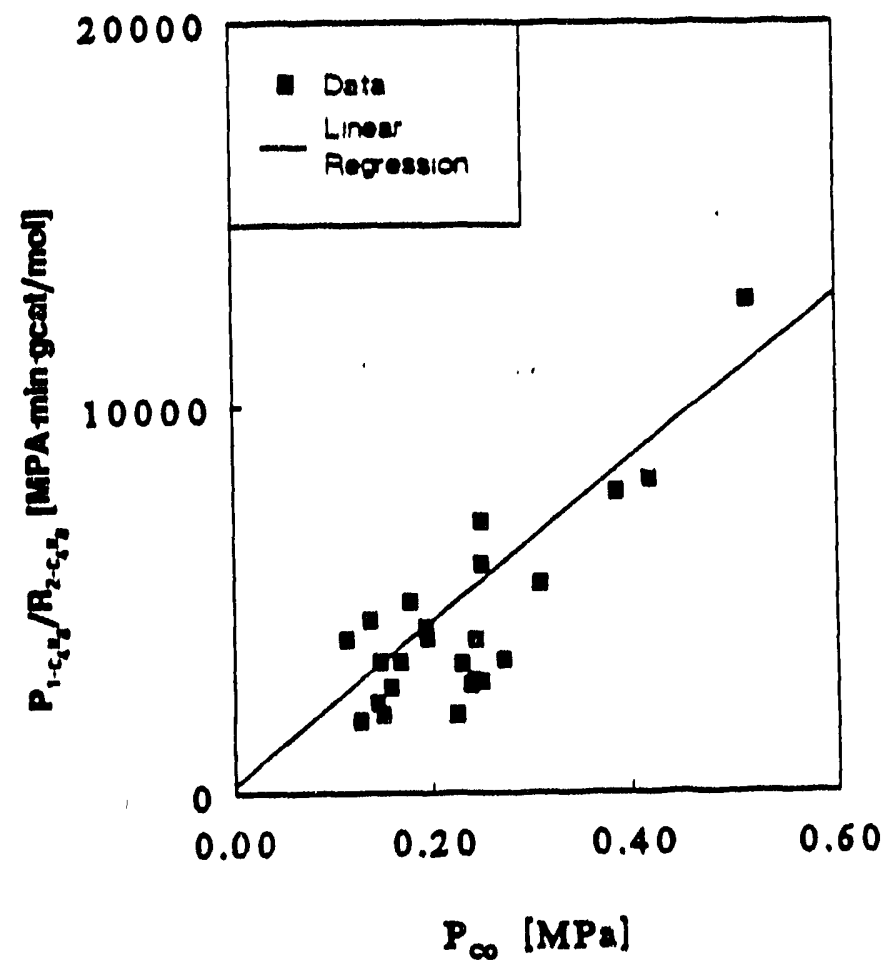

Fig. III-15b Most 2-butene is produced from 1-butene, according to simple isomerization model (see equation 2 ), $240^{\circ} \mathrm{C}$. 


\title{
IV. The Efrect of 1-Alkene Addition on \\ Hydrocarbon Product Distribution \\ on a Cobalt Catalyst
}

\begin{abstract}
The cobalt-catalyzed reactions of $\mathrm{C}_{2} \mathrm{H}_{4}, \mathrm{C}_{3} \mathrm{H}_{6}$, or $1-\mathrm{C}_{4} \mathrm{H}_{8}$ added to synthesis gas in concentrations ranging from 0.5 to $1.2 \mathrm{~mol} . \%$ of total feed were studied at $220^{\circ} \mathrm{C}$, and 0.45 to 1.48 $\mathrm{MPa} . \mathrm{H}_{2} / \mathrm{CO}$ feed ratios were varied between 1.45 to 2.25 and $\mathrm{H}_{2}+\mathrm{CO}$ conversions between 5 and $30 \%$ were observed.

1-Alkenes incorporate into growing chains on the catalyst surface, probably by initiating and/or terminating the chain growth process. Only ethene may propagate chain growth significantly. The propensity of the 1-alkenes to incorporate decreases with increasing carbon number of the 1-alkene and is affected by the extent of competitive reactions, notably hydrogenation to the alkene and isomerization to the 2-alkene. Incorporation is most evident in products above about $\mathrm{C}_{10}+$.

The double- $\alpha$ behavior exhibited by most Fischer-Tropsch catalysts can be interpreted as the sum of two growth processes, one a stepwise single-carbon growth process and the other a 1-alkene incorporation process. Many of the effects of process variables on the hydrocarbon selectivity of Fischer-Tropsch catalysts are consistent with this theory.
\end{abstract}




\section{A. Introduction}

Section III describes the effect of process variables on the product composition and carbon number distribution of a cobalt catalyst. The sensitivity of the hydrocarbon distribution to process variables seems to be greater than that encountered with iron catalysts. Therefore, secondary reactions of 1 -alkenes formed by the primary synthesis may be important in determining the final product composition. These reactions are primarily chain incorporation, hydrogenation, and isomerization of a 1-alkene to the 2-alkene. The objective of this part of the study was to develop a more fundamental understanding of the role of 1-alkenes in the hydrocarbon chain growth process on Fischer-Tropsch catalysts.

A large number of studies have been published on the effects observed upon addition of 1-alkenes to synthesis gas in contact with iron catalysts, but relatively little on effects observed on cobalt. Summaries of the literature, focussing on iron, have been published recently. ${ }^{2-5}$ In most cases, with either iron or cobalt catalysts, the possibility of chain incorporation has been examined with respect to light hydrocarbon products. There is general agreement that ethene is much more reactive than propylene or butene, but the extent of incorporation is dependent on many variables. Incorporation into light products on iron typically appears to be minor.

Our two previous studies with reduced fused magnetite catalysts in which we added light l-alkenes to synthesis gas indicated that chain incorporation could be observed but was minor in amount. Then we were focussing on carbon products mostly of $\mathrm{C}_{10}$ and less. A new feature from our present study is the observation that effects are much more noticeable for higher molecular weight products. In agreement with earlier 
work, we conclude that incorporation occurs more readily on cobalt than on iron catalysts. The following summarizes the literature on cobalt.

In early work, Gibson and Clarke ${ }^{6}$ fed 5.1 mol.\% labelled ${ }^{14} \mathrm{CO}, 49.1$ mol.\% $\mathrm{C}_{2} \mathrm{H}_{4}$, and $45.8 \mathrm{~mol} . \% \mathrm{H}_{2}$ to a $100 \mathrm{Co}: 5 \mathrm{ThO}_{2}: 8 \mathrm{MgO}: 200$ kieselguhr catalyst. Operating conditions of their fixed-bed reactor were $185^{\circ} \mathrm{C}, 0.1 \mathrm{MPa}$, and they achieved about $50 \%$ $\mathrm{C}_{2} \mathrm{H}_{4}$ conversion. The average radioactivity at each carbon atom within the $\mathrm{C}_{6}$ and $\mathrm{C}_{7}$ 1alkenes was determined. Because the radioactivity was significantly lower nearer the end of the $\mathrm{C}_{6}$ and $\mathrm{C}_{7}$ chains, they concluded that ethene both initiates and terminates the chain growth process. They were unable to determine if ethene propagates chain growth.

Schulz et al. ${ }^{7}$ performed the most complete study of the effects of adding selected labelled compounds during synthesis on cobalt. They added ethene $\left({ }^{14} \mathrm{C}\right)$, propene $\left(1-{ }^{14} \mathrm{C}\right.$ and $\left.2 \cdot{ }^{14} \mathrm{C}\right)$, butane $\left(1 \cdot{ }^{14} \mathrm{C}\right), 2$-methylpentadecane $\left(15 \cdot{ }^{14} \mathrm{C}\right)$, and 1-hexadecene $\left(1 \cdot{ }^{14} \mathrm{C}\right)$ at concentrations ranging from 0.10 to 0.78 vol.\% of total synthesis gas feed. They ran their fixed-bed reactor at $185-190^{\circ} \mathrm{C}, 0.1 \mathrm{MPa}$, with $\mathrm{H}_{2} / \mathrm{CO}=2$ synthesis gas at a space velocity of $75 \mathrm{~N} /$ /min/liter of catalyst (unreduced basis). For the 1-alkenes studied, hydrogenation to alkanes was the predominant reaction, with 67 mol.\% of the added ethene hydrogenated, $51 \mathrm{~mol} . \%$ of the propene, and $79 \mathrm{~mol} . \%$ of the 1 -hexadecene. Of the added 1-alkene which was not hydrogenated, they found that 88 mol.\% of the ethene was incorporated into growing chains, $63 \mathrm{~mol} . \%$ of the propene, and $31 \mathrm{~mol} . \%$ of the 1 hexadecene, thus producing higher molecular weight products.

Schulz and coworkers also examined the radioactivity of products at carbon numbers greater than the added component and noted two different behaviors, one for ethene and one for both propene and 1-hexadecene. Adding ethene, products at even 
carbon numbers had higher radioactivity than those at odd carbon numbers, indicating that ethene can propagate growing hydrocarbon chains; the levels of radioactivity at odd carbon numbers were consistent with the hypothesis that ethene can terminate and/or initiate growing chains. In contrast, propene was found to propagate growing chains only slightly, producing monomethyl branched compounds. Schulz and coworkers conclude that $C_{3}+1$-alkenes must be involved predominantly in chain termination and initiation. The added alkanes underwent negligible reaction at the process conditions studied. No data on the effect of process variables on the rate of incorporation were presented.

In a report to the German government, Schulz ${ }^{7 a}$ reported the results of extensive studies on five cobalt catalysts, all containing $\mathrm{ThO}_{2}$ on aerosil (a silica gel). Three contained $\mathrm{MgO}$ in addition. Reaction conditions were 175 to $185^{\circ} \mathrm{C}$ and 9 bar. The compositions containing $\mathrm{MgO}$ showed a much more pronounced double $\alpha$ than those without and gave a considerably higher fraction of $\mathrm{C}_{10}+$. In the presence of $\mathrm{MgO}$, the $\mathrm{C}_{2} \mathrm{H}_{4}$ in the product was substantially less than when $\mathrm{MgO}$ was absent. Although this was not commented on by the author, this seems to be additional evidence that $\mathrm{C}_{2} \mathrm{H}_{4}$ was being incorporated into $\mathrm{C}_{10}+$ product and by a mechanism influenced by $\mathrm{MgO}$.

Kibby et al. ${ }^{8}$ co-fed ethene or propene at 10 vol.\% with a $\left(\mathrm{H}_{2} / \mathrm{CO}\right)$ in of 1 and 2 to a reduced 30 wt.\% Co, 5 wt.\% $\mathrm{ThO}_{2}$, on 65 wt.\% $\mathrm{Al}_{2} \mathrm{O}_{3}$ catalyst in an internal recycle reactor operated at $195^{\circ} \mathrm{C}$ and $0.79 \mathrm{MPa}$. To calculate yields to various product classes, Kibby et al. measured the composition of the light gases $\left(C_{1}-C_{4}\right)$ and determined the yield to $C_{5}+$ as the difference between the $C O$ consumption and the $C_{1}-C_{4}$ yield. Present analysis of their data at $\left(\mathrm{H}_{2} / \mathrm{CO}\right)_{\text {in }}=2$ indicates that the wt.\% of $\mathrm{C}_{5}+$ hydrocarbons increased to $62.5 \mathrm{wt} . \%$ with ethene addition and $54.7 \mathrm{wt} . \%$ with propene 
addition, as compared with 44.6 wt.\% with no added 1-alkenes. With ethene addition the wt.\% of $\mathrm{C}_{5}+$ hydrocarbons increased to $85.4 \mathrm{wt} . \%$ at $\left(\mathrm{H}_{2} / \mathrm{CO}\right)_{\text {in }}=1$ from $62.5 \mathrm{wt} . \%$ at $\left(\mathrm{H}_{2} / \mathrm{CO}\right)_{\text {in }}=2$. This effect of decreasing incorporation with increasing $\mathrm{H}_{2} / \mathrm{CO}$ ratio is consistent with a set of reaction pathways for alkenes in which hydrogenation and incorporation both consume alkenes competitively; thus, at higher $\mathrm{H}_{2} / \mathrm{CO}$, more alkenes are hydrogenated and consequently less are incorporated in growing chains. In separate experiments at feed conditions similar to Gibson and Clarke, ${ }^{7}$ Kibby et al. also observed "hydropolymerization" of ethene, propene, and 1-butene.

Most alkene addition studies on cobalt by various researchers were performed in conjunction with a more extensive study of feed additions to iron catalysts; as a result, cobalt catalysts were studied at only a few different process conditions. Although 1alkenes appear to be incorporated into growing chains on cobalt, there is little agreement as to the extent to which incorporation affects the product distribution; further, no studies exist which cover a wide range of process conditions, for example only Kibby and co-workers performed experiments at above atmospheric pressure.

\section{B. Experimental Procedure}

Catalyst composition, reduction procedure and experimental methods are described in previous sections. After reduction, the catalyst was allowed to achieve stable activity and selectivity. Process variables were then manipulated to provide data over a broad operating range, during the course of a single run that lasted over several hundred hours. Data were obtained at $220^{\circ} \mathrm{C}, 0.45$ to $1.48 \mathrm{MPa}$ and synthesis gas flow rate between 0.015 and $0.030 \mathrm{Nl} / \mathrm{gcat} / \mathrm{min}$ with inlet $\mathrm{H}_{2} / \mathrm{CO}$ ratios of 1.45 to 2.25 yielding $\mathrm{H}_{2}+\mathrm{CO}$ conversions between 5 and $30 \%$. 
The 1-alkenes were co-fed with the synthesis gas feed in about. 2 mol.\% of a single 1-alkene in CP Grade CO (Matheson and MedTech Gases, Inc.); each of three 1alkenes, $\mathrm{C}_{2} \mathrm{H}_{4}, \mathrm{C}_{3} \mathrm{H}_{6}$, and 1- $\mathrm{C}_{4} \mathrm{H}_{8}$, were added in quantities to comprise from 0.5 to 1.2 mol.\% of total feed. At these feed rates, the added 1-alkenes are present in concentrations ranging from 2 to 10 times those observed during normal synthesis. These light 1-alkenes were chosen because they are not condensed to any significant extent in either our hot or cold traps ${ }^{10,11}$ and, therefore, analysis of these light 1 -alkenes is less subject to error. 15 material balances were performed adding $\mathrm{C}_{2} \mathrm{H}_{4}$, six adding $\mathrm{C}_{3} \mathrm{H}_{6}$, and eight adding $\mathrm{C}_{4} \mathrm{H}_{8}$.

For each material balance in which 1-alkenes were added, a material balance was performed at similar process conditions without 1-alkenes added, so that comparison of hydrocarbon selectivity with and without alkene addition could be made directly.

\section{C. Evidence for Incorporation on Cobalt}

Figures IV-1a, IV-1b, and IV-1c show Schulz-Flory diagrams comparing ethene, propene, and 1-butene additions to material balances at similar process conditions without added alkenes. To avoid presenting dilution effects in these results, data are normalized to remove the "added" carbon number, according to equation 1:

$$
\operatorname{Normalized}\left(M_{n}\right)=\frac{\operatorname{Observed}\left(M_{n}\right)}{\left(1-\operatorname{Observed}\left(M_{\text {addes }}\right)\right)}
$$

In equation 1, Observed $\left(M_{n}\right)$ are the actual mole fraction data and the Observed( $\left.M_{\text {added }}\right)$ is the mole fraction at the carbon number added. Thus, for Figure IV-1a, the actual mole fraction data are divided by $\left(1-\mathrm{M}_{2}\right)$; the normalized $\mathrm{M}_{2}$ are removed from the plot 
and thus the normalized data, the first 20 carbon numbers of which are shown on the plot, sum to unity. The figures show that 1-alkenes incorporate into growing chains on the catalyst surface, as evidenced by the increase in products at higher carbon numbers. This increase in products predominantly in the $\alpha_{2}$ region of the Schulz-Flory plot will be discussed in detail below.

A measure of the extent to which the $C_{n}$ added alkene incorporated was determined by comparing the $\mathrm{C}_{\mathrm{n}+1} / \mathrm{C}_{\mathrm{n}-1}$ of the material balance with added alkene to the base case material balance. If $C_{n}$ alkene incorporates, then the $C_{n+1}$ hydrocarbon is affected most dramatically, while the $C_{n-1}$ hydrocarbon yield remains unchanged, assuming negligible cracking. Thus, the higher this $C_{n+1} / C_{n-1}$ ratio is relative to the base case, the more the $C_{b}$ alkene can be inferred to incorporate.

Figures IV-2a through IV-2c show the ratio of $C_{n+1} / C_{n-1}$ for the $C_{n}$ addition material balance divided by the $C_{n+1} / C_{n-1}$ for the base case versus $P_{H_{l}} / P_{C O}$ for ethene, propene, and 1-butene additions respectively. Although the data scatter, ethene can be inferred to incorporate more than propene, which incorporates more than 1-butene. Similar trends upon co-feeding 1-alkenes with synthesis gas were reported on cobalt ${ }^{7,8}$ and on iron. ${ }^{7}$ Increasing $\mathrm{H}_{2} / \mathrm{CO}$ ratio decreases incorporation, seen most readily in Fig. IV-2a. This is consistent with the observation that the rate of bydrogenation of alkenes is approximately proportional to the $\mathrm{H}_{2} / \mathrm{CO}$ ratio. ${ }^{1}$ In using the $\mathrm{C}_{\mathrm{n}+1} / \mathrm{C}_{\mathrm{n}-1}$ criterion with respect to ethylene addition, it should be recalled that methane formation occurs by a mechanism that does not involve a carbon species polymerization.

In most previous studies with olefin addition, either radioactive tracers were used or relatively high concentrations of olefin were added, e.g., 5 to $10 \mathrm{~mol} \%$ of the synthesis 
gas feed, to magnify reaction effects and make possible overall material balances to search for the fate of the added olefin. The approach here was to use much lower added olefin concentrations that were closer to those formed by the normal synthesis, so that the results might be more representative of ordinary practice. This gain was purchased at the loss of being able to make useful material balances on the added component. To verify that added alkenes were not undergoing cracking to any significant extent, Figure IV-3 shows that the rate expression for the rate of production of methane ${ }^{9}$ fits the data collected here, even when alkenes are added to the feed. There are reports from studies on iron that added ethene may have an inhibiting effect on methanation, but these seem to have occurred only with much higher ethene concentrations. Adesima et al..$^{s}$ in a study on a cobalt catalyst at $0.11 \mathrm{MPa}$ and $200^{\circ} \mathrm{C}$ report that methane production rates were unchanged upon addition of 1 to $2 \%$ ethene. Figure IV -4 shows a Schulz-Flory diagram for two material balances performed without added alkene and 1850 hours-on-stream apart. Within the scatter of the data, the hydrocarbon selectivity is unchanged with time. 


\section{D. Mathematical Modelling of Incorporation}

To develop a fundamental understanding of the effect of incorporation on product distributions, mathematical models for incorporation were developed. These models are complex, but their mathematical behavior closely parallels that of a single- $\alpha$ distribution. The double- $\alpha$ is postulated to be the sum of two growth processes, one a stepwise singlecarbon growth process, represented by $\alpha_{1}$, and the other a 1-alkene incorporation process, represented by $\alpha_{2}$.

Alkene incorporation adds mathematical complexity to the mathematical models of the chain growth process and introduces a number of adjustable parameters. Alkenes can be assumed to either initiate and terminate hydrocarbon chains only or initiate, terminate, and propagate chains. These two behaviors are treated separately below.

All formulations for alkene incorporation are somewhat complex, have a large number of parameters, and require knowledge of relative rates of surface reaction that cannot be measured directly. To develop a useful model, the limiting behavior of these different models is shown to match that of a most probable, single- $\alpha$ distribution, except at very low carbon numbers. This single- $\alpha$ chain growth probability is therefore essentially a lumped parameter which accounts for contributions to the chain growth process from the incorporation reactions of the entire series of alkenes.

IV. D. 1. Initiation and Termination by 1-Alkenes. If 1-alkenes initiate and terminate growing chains, then the mole fraction of products observed at a given carbon number $\left(M_{n}\right)$ depends not only on the mole fraction one carbon number before it $\left(M_{n-1}\right)$, but also on the mole fractions of all the carbon numbers before it, $\left(M_{n-2}, M_{n-3}\right.$, etc.). 
Equation 2 shows how the simple, no-incorporation chain growth process represents the dependence of mole fraction at carbon number $\mathrm{n}$ on the mole fraction at carbon number $\mathrm{n}-1$, as

$$
M_{n}=p_{1} M_{(n-1)}
$$

In equat on 2, $p_{1}$ is analogous to a Schulz-Flory chain growth probability, $\alpha$.

To develop an equation for 1-alkene incorporation, only ethene and propene are assumed to initiate and terminate alkenes, for the pu-.-'oses of illustration. This analysis can be casily extended by analogy to include initiatio: or termination by any number of alkenes, however, for simplicity, only this model is presented.

If ethene and propene can initiate or terminate growing chains, then the mole fractiont for $\mathrm{C}_{4}+$ is given by:

$$
M_{n>3}=p_{1} M_{(n-1)}+p_{2} M_{(n-2)}+p_{3} M_{(n-3)}
$$

In equation $3, p_{1}$ is the probability of $C_{1}$ addition, $p_{2}$ is the probability of $C_{2}$ initiation or termination, and $p_{3}$ is the probability of $C_{3}$ initiation or termination.

To develop a closed-form expression for the mole fraction at all carbon numbers, it is noted that, since only initiation or termination can occur, a $C_{n}$ can only be formed by either all $C_{1}$ growth (like equation 2), all $C_{1}$ growth except for having incorporated one $C_{2}$, or all $C_{1}$ growth except for having incorporated one $C_{3}$. Thus, the mole fractions of all components can be expressed in terms of an arbitrary constant, $M_{0} . M_{0}$ can be thought of as the hypothetical mole fraction at carbon number zero. Equations 4-7 show the mole fraction in terms of this arbitrary constant, $M_{0}$. In equation 7 , the first term is the stepwise growth process adding $C_{1}$ units one-at-a-time, 


$$
\begin{gathered}
M_{1}=p_{1}\left(1-p_{1}\right) M_{0} \\
M_{2}=p_{1}^{2}\left(1-p_{1}\right) M_{0} \\
M_{3}=p_{1}^{3}\left(1-p_{1}\right) M_{0}+p_{2} p_{1}\left(1-p_{1}\right) M_{0} \\
M_{n>3}=p_{1}^{n}\left(1-p_{1}\right) M_{0}+p_{2} p_{1}^{(n-2)}\left(1-p_{1}\right) M_{0}+p_{3} p_{1}^{(n-3)}\left(1-p_{1}\right) M_{0}
\end{gathered}
$$

the second term accounts for $C_{2}$ initiation or termination, and the last term accounts for $\mathrm{C}_{3}$ initiation or termination.

To remove the arbitrary constant, the mole fractions are summed from $n=1$ to $\infty$ and equated to 1 . Thus, the constant is found to be,

$$
M_{0}=\frac{1}{p_{1}\left(1+p_{2}+p_{3}\right)}
$$

Substituting equation 8 into equations 4-7, the complete distribution can be described in terms of $p_{1}, p_{2}$, and $p_{3}$, by the following equations:

$$
\begin{gathered}
M_{1}=\frac{\left(1-p_{1}\right)}{\left(1+p_{2}+p_{3}\right)} \\
M_{2}=\frac{p_{1}\left(1-p_{1}\right)}{\left(1+p_{2}+p_{3}\right)} \\
M_{3}=\frac{\left(p_{1}^{2}\left(1-p_{1}\right)+p_{2}\left(1-p_{1}\right)\right)}{\left(1+p_{2}+p_{3}\right)}
\end{gathered}
$$




$$
\mathbf{M}_{\mathrm{n}>3}=\frac{\left(p_{1}^{(n-1)}\left(1-p_{1}\right)+p_{2} p_{1}^{(n-3)}\left(1-p_{1}\right)+p_{3} p_{1}^{(n-4)}\left(1-p_{1}\right)\right)}{\left(1+p_{2}+p_{3}\right)}
$$

Figure IV-5 shows a theoretical product distribution for $p_{1}=0.7, p_{2}=0.3$, and $p_{3}=0.1 . p_{2}$ $>\mathrm{p}_{3}$ matches the experimental evidence, presented in Figures IV-2a through IV-2c, which show that ethene incorporates more than propene. The multiparameter initiation and termination model appears to be very similar to a single- $\alpha$ model at carbon numbers above 3. $C_{2}$ and $C_{3}$ hydrocarbons are produced in lower quantities than would be observed by a Schulz-Flory mechanism; this behavior of $C_{2}$ lying below the line predicted by Schulz-Flory mathematics has been observed previously on a number of catalysts operated over a wide range of conditions. ${ }^{12}$

IV. D. 2. Initiation, Termination, and Propagation by 1-Alkenes. The above model for the hydi Jcarbon products of the Fischer-Tropsch synthesis describes the product distribution if only initiation or termination by alkenes occurs; however, on cobalt catalysts, Schulz et al. ${ }^{7}$ have observed propagation by ethene and, to a lesser extent, propene.

Novak et al. ${ }^{13}$ developed a model to predict carbon number distribution by $C_{1}$ chain growth combined with independent $\mathrm{C}_{2}$ addition. Their model has four parameters, $\alpha$ (a stepwise chain growth probability), $\Gamma$ (a reactivity ratio of $C_{2}$ to $C_{1}$ addition processes), $\boldsymbol{\theta}_{1}$ (the mole fraction of $C_{1}$ ), and $\boldsymbol{\theta}_{2}$ (the mole fraction of $C_{2}$ ). The product distribution is derived to be: 


$$
\begin{gathered}
M_{n>2}=\frac{\left(\left(\theta_{2}-\theta_{1} f_{2}\right) f_{1}^{(n-1)}+\left(\theta_{1} f_{1}-\theta_{2}\right) f_{2}^{(n-1)}\right)}{\left(f_{1}-f_{2}\right)} \\
\text { where } f_{1,2}=\frac{\alpha}{2(1+\Gamma \alpha)} \pm\left[\left(\frac{\alpha}{2(1+\Gamma \alpha)}\right)^{2}+\frac{\Gamma \alpha}{(1+\Gamma \alpha)}\right]^{1 / 2}
\end{gathered}
$$

$f_{1,2}$ are the roots of the quadratic equation; $M_{1}$ is the same as $\theta_{1}$, and $M_{2}$ is the same as $\boldsymbol{\theta}_{2}$.

Equation 13 appears qualitatively similar to the double- $\alpha$ formulation typically used to describe Fischer-Tropsch product distributions; however, $f_{2}$ in equation 13 is negative (see equation 14), causing oscillation of the product distribution. Schulz et al. ${ }^{7}$ present data from ethene additions to cobalt which show oscillating levels of radioactivity, with even carbon numbers higher than odd carbon numbers; such behavior is consistent with this type of formulation.

Oscillations are not observed in experimental carbon number distributions for at least two reasons. First, if the ratio of $C_{2}$ propagation to $C_{1}$ is low (i.e. $\Gamma$ is almost zero), then the oscillations are observed at only very low carbon numbers. Second, there can be a great deal of "scatter" in experimentally-obtained hydrocarbon distributions which causes subtleties, such as minor oscillations, to be masked.

Figure IV-6 shows a theoretical product distribution based on ethene both initiating, terminating, and propagating chains on the catalyst surface, for $\boldsymbol{\theta}_{1}=0.5, \boldsymbol{\theta}_{2}=0.1$, $\alpha=0.62$, and $\Gamma=0.2$. As with the model which accounts for only initiation and termination, the model is similar to a single- $\alpha$ distribution at high carbon numbers.

Thus, in summary, both multiparameter incorporation behaviors can be well represented by a lumped parameter, single- $\alpha$ chain growth process, shown in equation 2 . 
This lumped parameter is the probability that a $C_{n}$ hydrocarbon will become a $C_{n+1}$ hydrocarbon by any alkene incorporation process and, therefore, represents the sum of all alkene incorporation processes.

Using sophisticated models that account for a large number of surface processes is inappropriate, because experimentally-obtained hydrocarbon data do not provide the resolution necessary to determine these models' parameters accurately. For example, accounting for $C_{1}, C_{2}$, and $C_{3}$ initiation and termination and $C_{1}$ and $C_{2}$ propagation, all of which have been observed experimentally, requires a model with at least seven adjustable parameters; this many adjustable parameters should not be estimated from Fischer-Tropsch product distribution data.

\section{E. A Model for the Double- $\alpha$ Distribution}

A double- $\alpha$ model has been developed to describe the mole fraction of products at carbon number $\mathrm{n}$ for the $\mathrm{C}_{3}+$ products. $^{12}$ This can be expressed as ${ }^{9,14}$ :

$$
M_{n}=x_{1}\left(1-\alpha_{1}\right) \alpha_{1}^{(n-1)}+\left(1-x_{1}\right)\left(1-\alpha_{2}\right) \alpha_{2}^{(n-1)}
$$

In equation $15, x_{1}$ can be visualized as the mole fraction of products synthesized by the " $\alpha_{1}{ }^{\prime}$ mechanism; therefore, $\left(1-x_{1}\right)$ is the mole fraction of products synthesized by the " $\alpha_{2}$ " mechanism.

In Figures IV-1a through IV-1c, the difference in the Schulz-Flory diagrams between alkene addition runs and base case runs is most notable at higher carbon numbers. Based on this observation, the " $\alpha_{1}$ " site is postulated to be the site on which normal stepwise addition of $C_{1}$ units occurs and the " $\alpha_{2}$ " process is assumed to be the site which accounts for the incorporation processes. As discussed above, the sum of all 
incorporation processes can be approximated by a single chain growth probability, in this case $\alpha_{2}$. In this theory, $x_{1}$ represents the mole fraction of products synthesized by the simple stepwise growth process of $C_{1}$ units and $\left(1-x_{1}\right)$ is the mole fraction of procicts synthesized by the sum of all incorporation processes.

This model is not catalyst-specific, and the results of the alkene addition experiments can be well interpreted in its terms. When alkenes are added to the feed, only the mole fraction of products synthesized by alkene incorporation should change relative to the base case material balance without alkenes added; thus, adding alkenes should decrease $x_{1}$, while $\alpha_{1}$ and $\alpha_{2}$ should remain constant.

Figure IV-7 shows the Schulz-Flory diagrams of the ethene addition and base case material balances. The solid line is the fit of the double- $\alpha$ model to the base-case data. To fit the data from the ethene addition studies, the values of $\alpha_{1}$ and $\alpha_{2}$ are retained, and only the value of $x_{1}$ is changed. The resulting fit is shown as the dashed line. More heavy products are produced by alkene incorporation processes when alkenes are added to the feed; thus, the value of $x_{1}$ decreases.

Figure IV- 8 shows the ratio of products with ethene addition to the ratio of products from base case material balances. The change in the normalized mole fractions is well predicted by the model.

\section{F. Explanations of Selectivity Trends}

IV. F. 1. Cobalt. Process variable effects observed during normal synthesis ${ }^{1}$ can be explained by the effects of the process variables on the concentration of 1-alkenes and 
thus on the rate of incorporation. Table IV-1 shows the observed process variable effect on selectivity and the postulated explanation, based on incorporation being an important mechanism for chain growth. Figure IV-9 shows the effect of space velocity on the yield of $C_{1}$ (undesired) and $C_{10}+$ (desired). Data labels show the in situ ethene to ethane ratio. At higher space velocities (lower total conversions) less hydrogenation of alkenes occurs, as indicated by the increase in ethene to ethane ratio; thus, more high molecular weight products are synthesized via the " $\alpha_{2}$ " mechanism. Figure IV-10 shows the effect of in situ $\mathrm{H}_{2} / \mathrm{CO}$ on the yield of $\mathrm{C}_{10}+$. Data labels show the in situ ethene to ethane ratio. At higher $\mathrm{H}_{2} / \mathrm{CO}$ ratios, a greater fraction of ethene is hydrogenated, reducing the fraction of products synthesized by the " $\alpha_{2}$ " mechanism. Figures IV-9 and IV-10 provide experimental evidence that the theory is consistent with actual behavior of a cobalt catalyst. 
IV. F. 2. Iron. Many of the effects of process variables on the product distribution on iron catalysts can be interpreted in terms of their effects on the concentration of 1 alkenes and their degree of adsorption onto the catalyst, and thus on the degree of their incorporation into the product. Thus increased potassium loading increases the yield of heavy products, but it also decreases secondary hydrogenation and isomerization, thereby increasing 1-alkene concentration and the probability of chain incorporation. Increasing the $\mathrm{H}_{2} / \mathrm{CO}$ ratio decreases the yield of heavy products by increasing the hydrogenation of 1-alkenes and thereby decreasing incorporation.

Sorting out these and other effects in detail is complex since most data available are from fixed bed reactors in which composition varies with position. For example, competitive adsorption between 1-alkenes and CO can cause markedly different effects at low and high degrees of conversion with $\mathrm{H}_{2}$-rich gas, and these effects are integrated in the exit product. Further, pressure and temperature can affect competing reactions differently.

\section{G. Conclusions}

The cobalt-catalyzed reactions of light 1-alkenes added to synthesis gas feed have been studied. Reaction conditions were $220^{\circ} \mathrm{C}, 0.45$ to $1.48 \mathrm{MPa}$ utilizing a synthesis gas flow rate between 0.015 and $0.030 \mathrm{Nl} / \mathrm{gcat} / \mathrm{min}$, with $\mathrm{H}_{2} / \mathrm{CO}$ ratios of 1.45 to 2.25 . $\mathrm{C}_{i,} \mathrm{H}_{4}, \mathrm{C}_{3} \mathrm{H}_{6}$, and $1-\mathrm{C}_{4} \mathrm{H}_{8}$ were added to the synthesis gas feed in concentrations ranging from 0.5 to 1.2 mol.\% of total feed. For each material balance in which 1-alkenes were added, a "base case" material balance was performed at similar process conditions without 1-alkenes added. Material balances without added 1-alkenes were also repeated 
to verify catalyst selectivity stability.

1-Alkenes are found to incorporate into growing chains on the catalyst surface and are thought to initiate and terminate the chain growth process. The relative reactivity of the 1-alkenes decreases with increasing carbon number. On the basis of data in the literature, only ethene is believed to propagate chain growth.

A theory is presented which postulates that the double- $\alpha$ is the sum of two growth processes, one a stepwise single-carbon growth process (the $\alpha_{1}$ mechanism) and the other the sum of the 1-alkene incorporation processes (the $\alpha_{2}$ mechanism). Many of the effects of process variables on the hydrocarbon selectivity of Fischer-Tropsch catalysts are consistent with this model. 


\section{IV.H. Nomenclature}

$f_{1,2} \quad$ - parametric constants for ethene propagation model.

$\mathrm{M}_{\mathrm{added}}$ - mole fraction of products at carbon number of added alkene.

$M_{0} \quad$ - constant, the mole fraction of products at carbon number "zero".

$M_{n}$ - mole fraction of products at carbon number $n$.

n - carbon number.

Normalized $\left(M_{\mathfrak{n}}\right) \quad$ - normalized mole fraction, with $\mathrm{M}_{\text {added }}$ removed.

Observed $\left(M_{n}\right) \quad$ - mole fraction data, observed experimentally.

$\mathrm{p}_{1} \quad$ - the probability of $\mathrm{C}_{1}$ addition.

$\mathrm{p}_{2} \quad$ - the probability of $\mathrm{C}_{2}$ initiation or termination.

$\mathrm{p}_{3} \quad$ - the probability of $\mathrm{C}_{3}$ initiation or termination.

$x_{1} \quad$ - mole fraction of products produced by $\alpha_{1}$ mechanism.

Greek

$\alpha \quad$ - single chain growth probability.

$\alpha_{1} \quad$ chain growth probability for stepwise addition of $C_{1}$.

$\alpha_{2} \quad$ - chain growth probability for incorporation of alkenes.

$\Gamma \quad$ ratio of reactivity of $C_{2} / C_{1}$.

$\theta_{1}$ - mole fraction of $C_{1}$.

$\theta_{2} \quad-$ mole fraction of $\mathrm{C}_{2}$. 


\section{IV.1. Literature Cited}

(1) Yates, I.C.; Satterfield, C.N. "Hydrocarbon Selectivity of Cobalt FischerTropsch Catalysts," Energy \& Fuels, submitted.

(2) Snel, R.; Espinoza, R.L. L.Mol_Cat. 1987, 43, 237.

(3) Boelee, J.H.; Cüsters, J.M.G.; van der Wiele, K. Appl. Catal 1989, 53, 1.

(4) Tau, L-M.; Dabbagh, H.A.; Davis, B.H. Eneroy \& Fuels, 1990, 4, 94.

(5) Adesima, A.A.; Hudgins, R.R.; Silveston, P.L. Appl. Catal 1990, 62, 295.

(6) Gibson, E.J.; Clarke, R.W. L.Appl. Chem 1961, 11, 293.

(7) Schulz, H.; Rao, B.R.; Elstner, M. Erdol und Koble 1970, 23, 651.

(7a) Schulz, H. Report to the Bundesministerium für Forschung und Technologie, "Katalysatoren und Selektivitätslenkung bei der Fischer-Tropsch Synthese," BMFT-FB-T80-124, November 1980.

(8) Kibby, C.L.; Pannell, R.B.; Kobylinski, T.P. A.C.S. Pet. Chem. Preprints 1984, 29(4), 1113.

(9) Yates, I.C. The Slumy-Phase Fischer-Tropsch Synthesis, Ph.D. Thesis, Massachusetts Institute of Technology, Cambridge, Massachusetts, 1990.

(10) Hanlon, R.T.: Satterfield, C.N. Energy \& Fuels, 1988, 2, 196.

(10a) Chanenchuk, C.A.; Yates, I.C.; Satterfield, C.N. Energy \& Fuels, submitted. 
(11) Matsumoto, D.K., The Effects of Selected Process Variables on the Performance of an Iron Fischer-Tropsch Catalyst, Sc.D. Thesis, Massachusetts Institute of Technology, Cambridge, Mass., 1987.

(12) Donnelly, T.J.; Yates, I.C.; Satterfield, C.N. Energy \& Fuels 1988, 2, 734.

(13) Novak, S.; Madon, R.T.; Suhl, H. L.Chem. Phys, 1981, 74, 6083.

(14) Huff, G.A., Jr., Eischer-Tropsch Synthesis in a Slurry Reactor, Sc.D. Thesis, Massachusetts Institute of Technology, Cambridge, Mass., 1982. 
TABLE IV-1

\section{INTERPRETATION OF OBSERVED PROCESS VARIABLE EFFECTS ON COBALT}

$\begin{array}{lll}\begin{array}{l}\text { Process } \\ \text { variable }\end{array} & \begin{array}{l}\text { Effect on yield to } \\ \text { desired products }\end{array} & \begin{array}{l}\text { Postulated explanation based on } \\ \text { incorporation of 1-alkenes }\end{array} \\ \begin{array}{l}\text { Decreasing } \\ \text { space velocity } \\ \text { (increasing conversion) }\end{array} & \begin{array}{l}\text { Decreases yield of } \\ \text { desired heavy products }\end{array} & \begin{array}{l}\text { At low space velocities, 1-alkenes are } \\ \text { converted to n-alkanes and 2-alkenes } \\ \text { more readily. }\end{array} \\ \begin{array}{l}\text { Increasing } \\ \mathrm{H}_{2} / \mathrm{CO} \text { ratio }\end{array} & \begin{array}{l}\text { Decreases yield of } \\ \text { desired heavy products }\end{array} & \begin{array}{l}\text { At high } \mathrm{H}_{2} / \mathrm{CO} \text { ratio, 1-alkenes are } \\ \text { more readily hydrogenated and therefore } \\ \text { less are incorporated. }\end{array} \\ \text { Pressure } & \text { No effect } & \begin{array}{l}\text { 1-alkene reactions are affected } \\ \text { predominantly by the ratio of reactant } \\ \text { pressures, not total pressure. }\end{array} \\ & \text { No effect } & \begin{array}{l}\text { The rate of incorporation and of } \\ \text { competing reactions such as }\end{array} \\ & & \begin{array}{l}\text { hydrogenation and isomerization are } \\ \text { affected by temperature similarly. }\end{array}\end{array}$




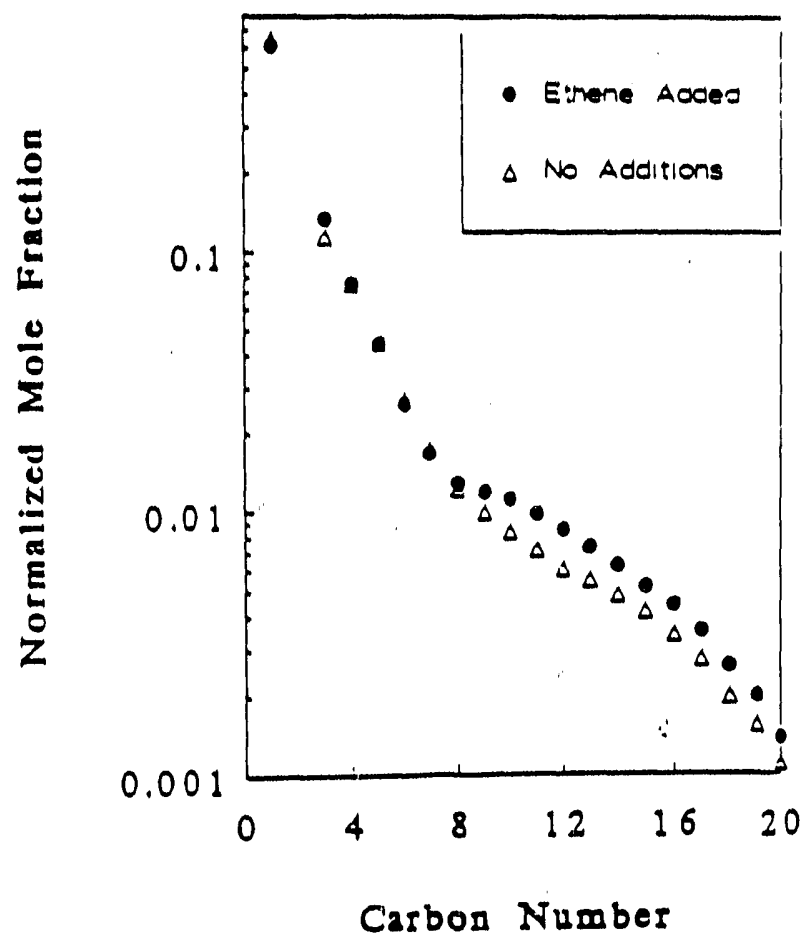

Fig. IV-1a Ethene incorporates into growing chains on cobalt. Ethene added to comprise $0.64 \mathrm{~mol} . \%$ of feed $\left(220^{\circ} \mathrm{C}, 1.48 \mathrm{MPa}\right.$. Entering $\mathrm{H}_{2} / \mathrm{CO}=2.15,\left(\mathrm{H}_{2} / \mathrm{CO}\right)$ in reactor $\sim 2.2$. Feed rate $=0.030 \mathrm{Nl} / \mathrm{min} /$ gcat (unreduced basis)).

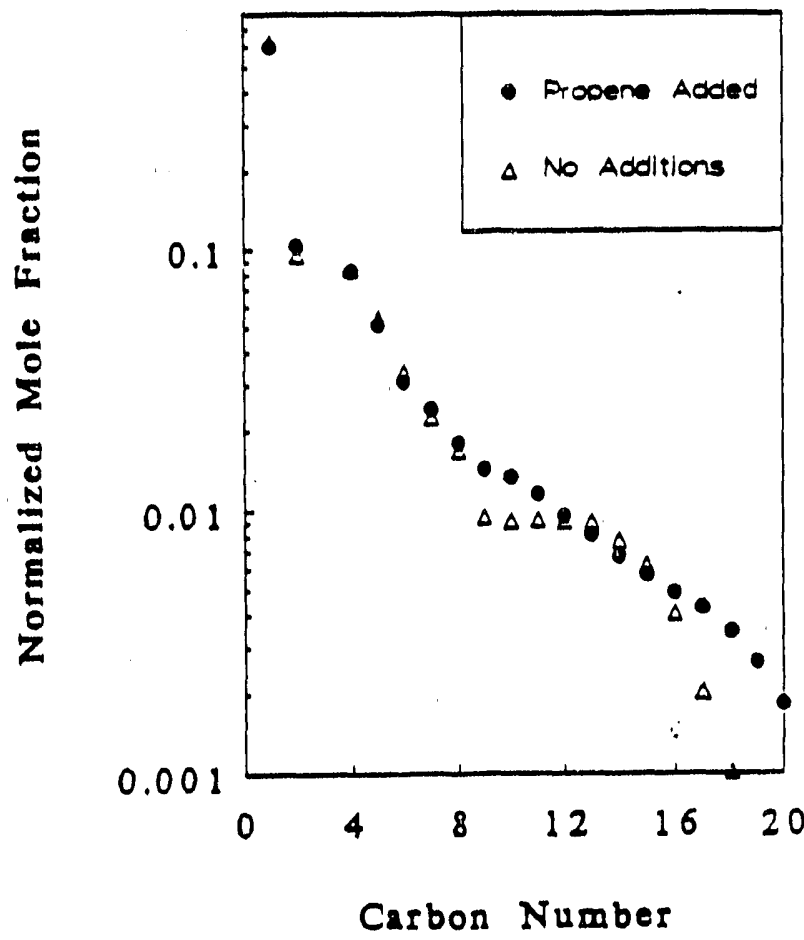

Fig. IV-1b Propene incorporates into growing chains on cobalt. Propene added to comprise $0.70 \mathrm{~mol} . \%$ of feed $\left(220^{\circ} \mathrm{C}, 1.48 \mathrm{MPa}\right.$. Entering $\left(\mathrm{H}_{2} / \mathrm{CO}\right)=1.61$, $\left(\mathrm{H}_{2} / \mathrm{CO}\right)$ in reactor -1.59 . Feed rate $=0.029 \mathrm{Nl} / \mathrm{min} /$ gcat (unreduced basis)). 


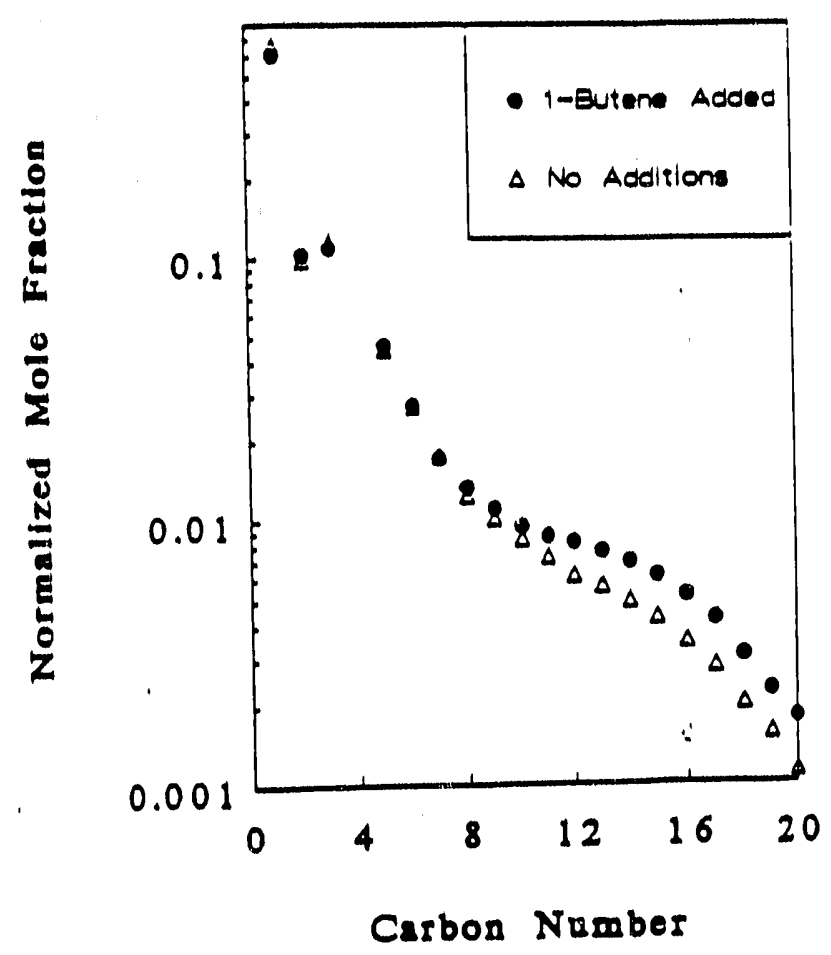

Fig. IV-1c 1-butene incorporates into growing chains on cobalt. 1-butene added to comprise 0.64 mol. \% of feed $\left(220^{\circ} \mathrm{C}, 1.48 \mathrm{MPa}\right.$. Entering $\left(\mathrm{H}_{2} / \mathrm{CO}\right)=$ 2.15 , $\left(\mathrm{H}_{2} / \mathrm{CO}\right)$ in reactor -2.17 . Feed rate $=0.030 \mathrm{Nl} / \mathrm{min} / \mathrm{gcat}$ (unreduced basis)).

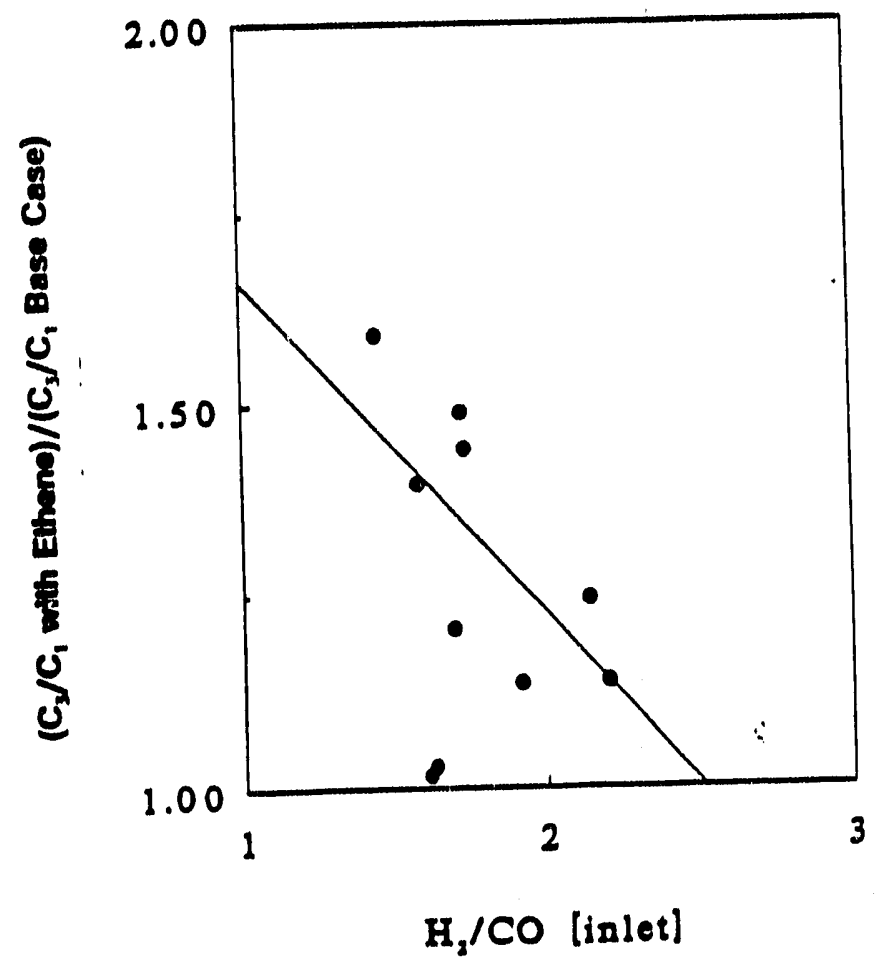

Fig. IV-2a Hydrogenation decreases incorporation of ethene. Comparing the vertical axis values for this plot with Figures $2 b$ and $2 c$ indicates that ethene incorporates more than propene or 1-butene. 


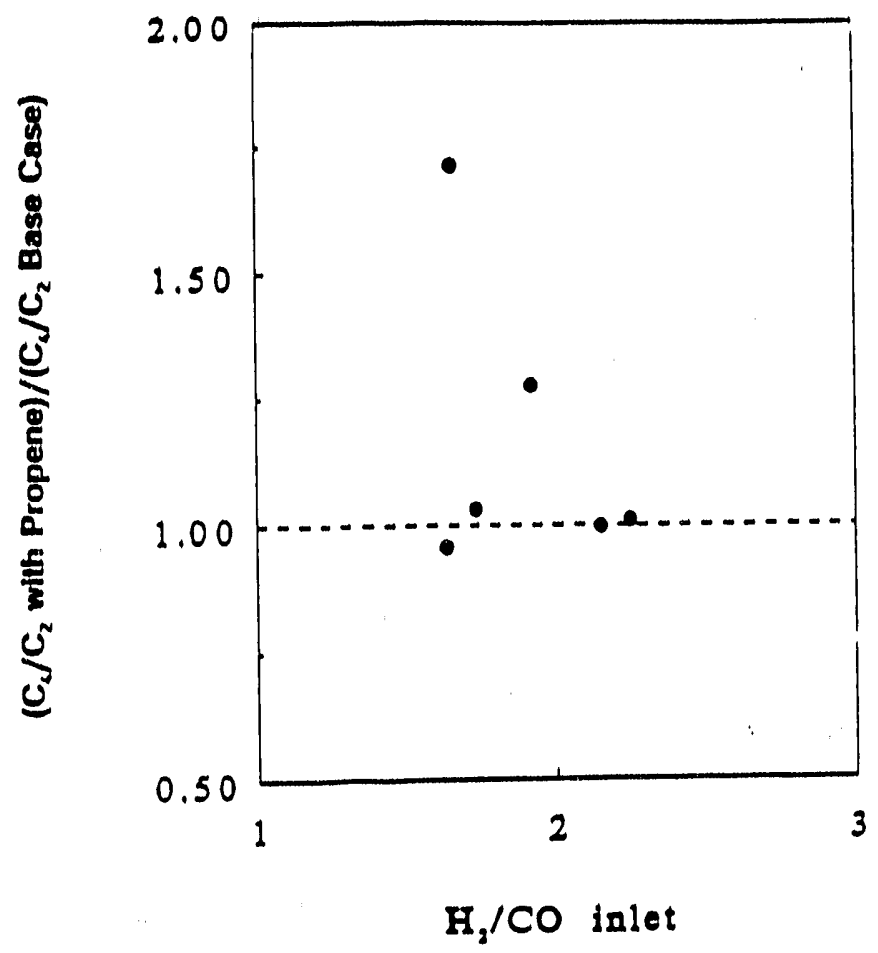

Fig. IV-2b Propene incorporates into growing chains. Propene incorporates less than ethene, but more than 1-butene (see Figure $2 a$ and $2 c$ ).

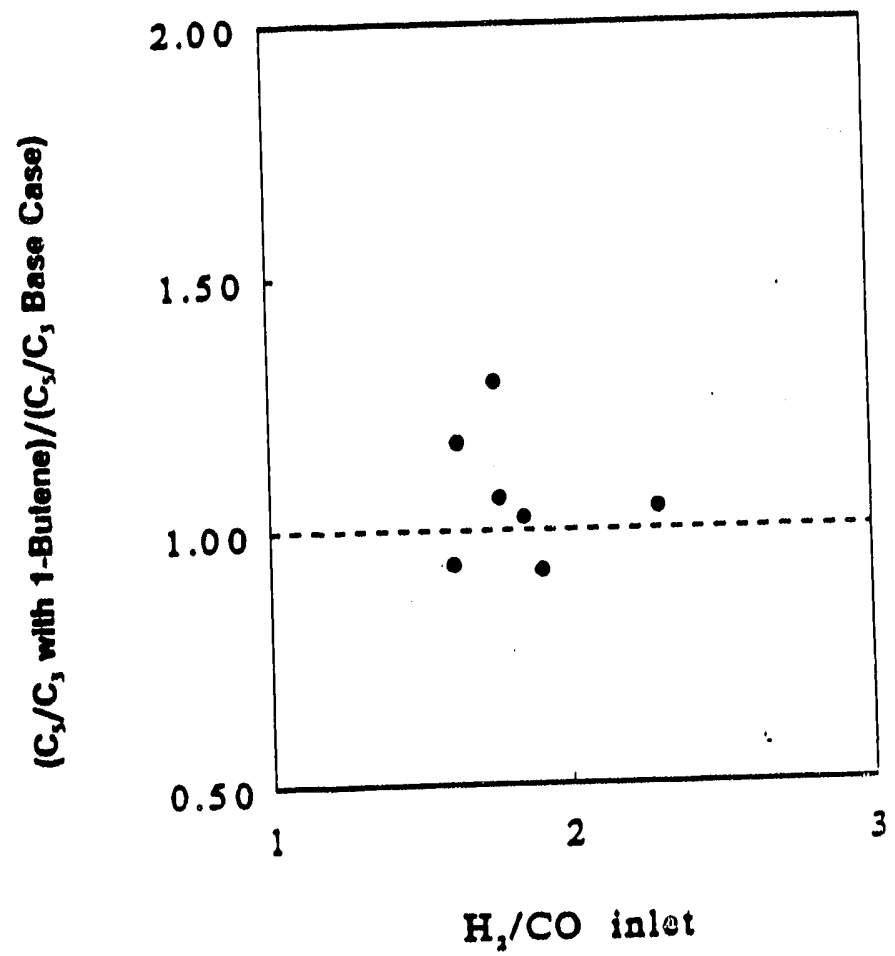

Fig. IV-2c 1-butene incorporates into growing chains. 1-butene incorporates less than either ethene or propene (see Figure $2 a$ and $2 b$ ). 


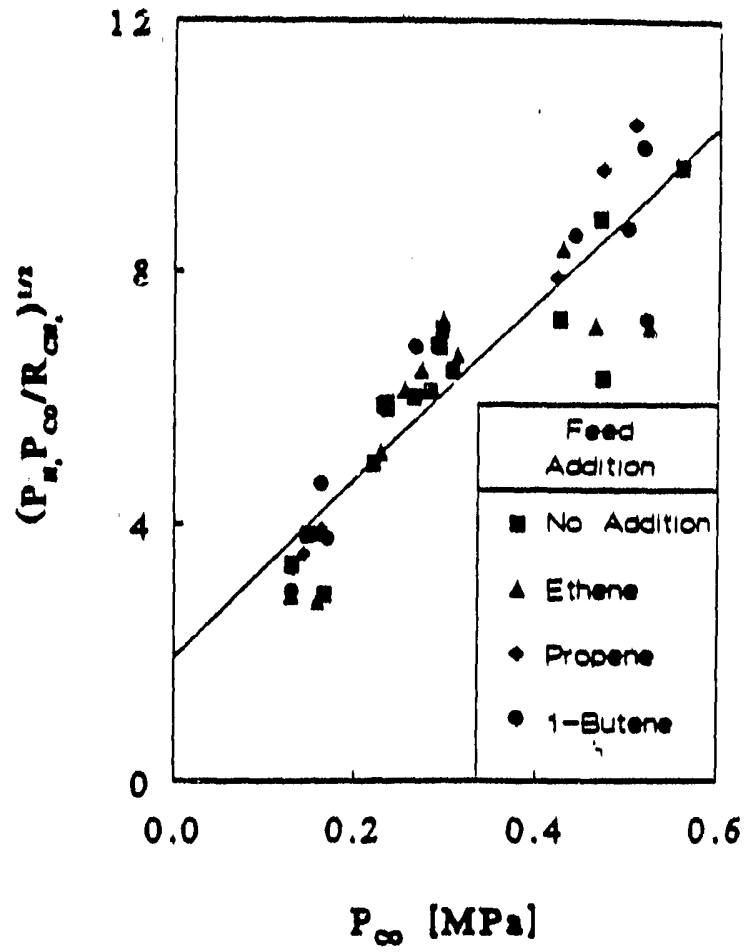

Fig. IV-3 Methanation rate is unaffected by alkene additions. $\left(220^{\circ} \mathrm{C}, 0.5\right.$ to $1.5 \mathrm{MPa}$.)

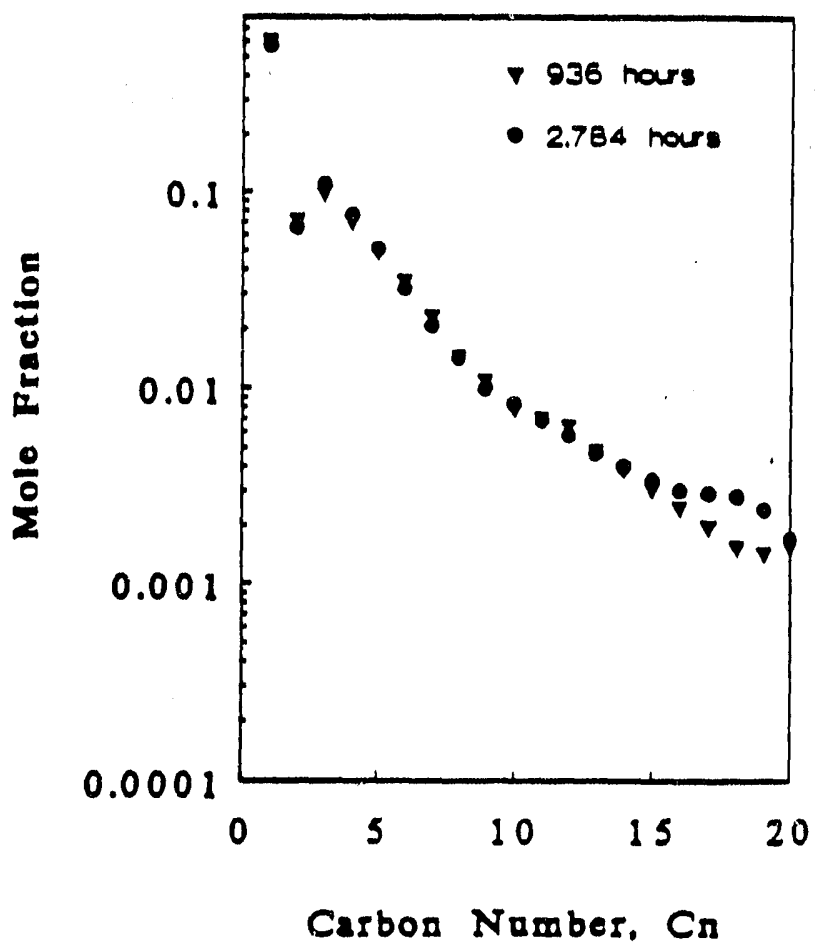

Fig. IV-4 Hydrocarbon selectivity was stable throughout alkene addition experiments $\left(220^{\circ} \mathrm{C}, 0.79 \mathrm{MPa}\right.$. Entering $\left(\mathrm{H}_{2} / \mathrm{CO}\right)=1.62,\left(\mathrm{H}_{2} / \mathrm{CO}\right)$ in reactor -1.65 . Feed rate $=0.017 \mathrm{Nl} / \mathrm{min} /$ gcat (unreduced basis)). 


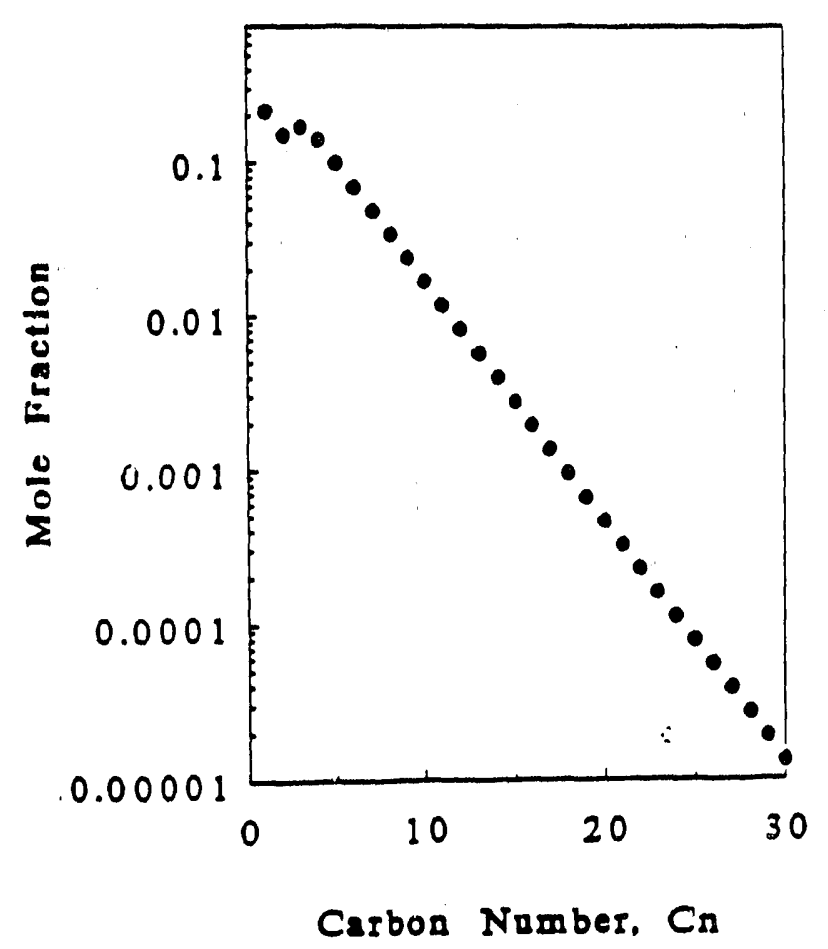

Fig. IV-5 Model accounting for initiation and termination by $\mathrm{C}_{2}$ and $\mathrm{C}_{3}$ alkenes appears similar to single- $\alpha$ model, except at low carbon numbers $\left(p_{1}=0.7\right.$, $\mathrm{p}_{2}=0.3$, and $\mathrm{p}_{3}=0.1$ ).

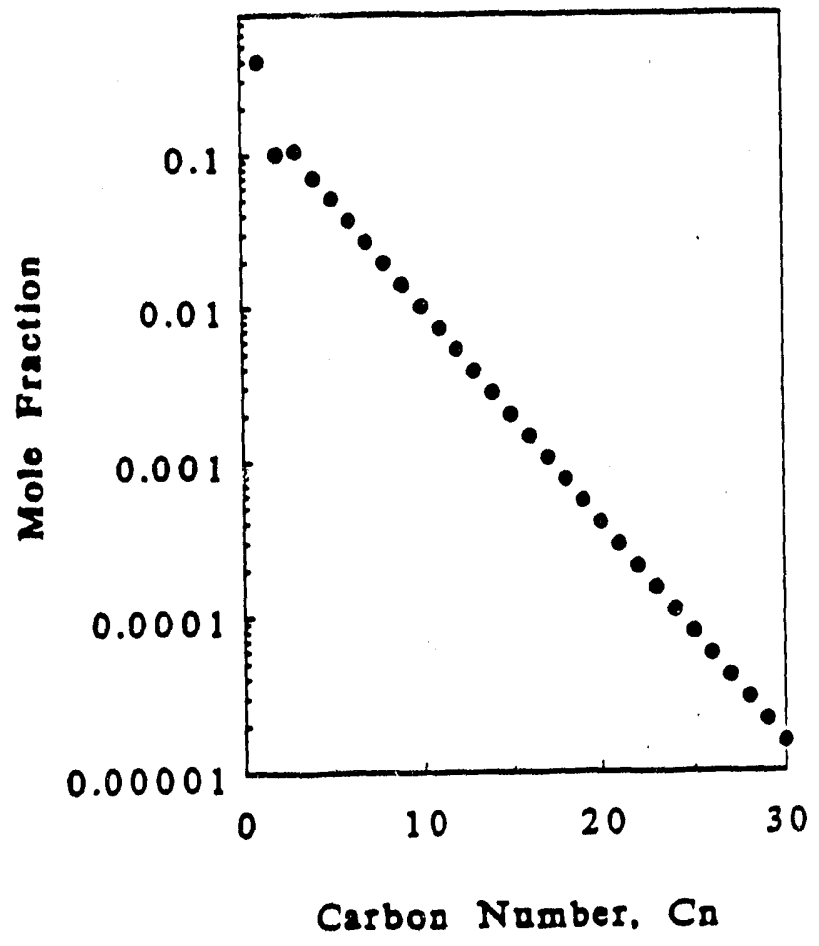

Fig. IV-6 Model accounting for initiation, termination, and propagation by ethene appears similar to single- $\alpha$ model, except at low carbon numbers $\left(\theta_{1}=0.5\right.$, $\theta_{2}=0.1, \alpha=0.62$, and $\Gamma=0.2$ ). 


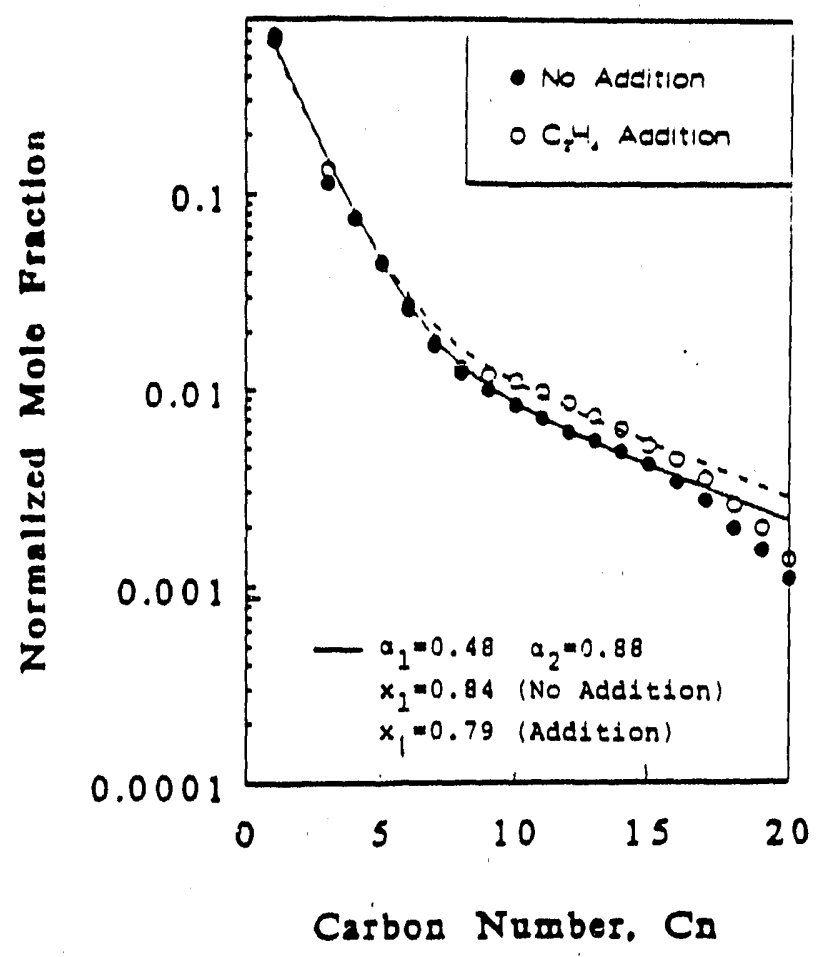

Fig. IV-7 Fitting of ethene addition results to a model which accounts for separate contributions by a stepwise growth process and a 1-alkene incoproration process. (Same data as Figure 1a).

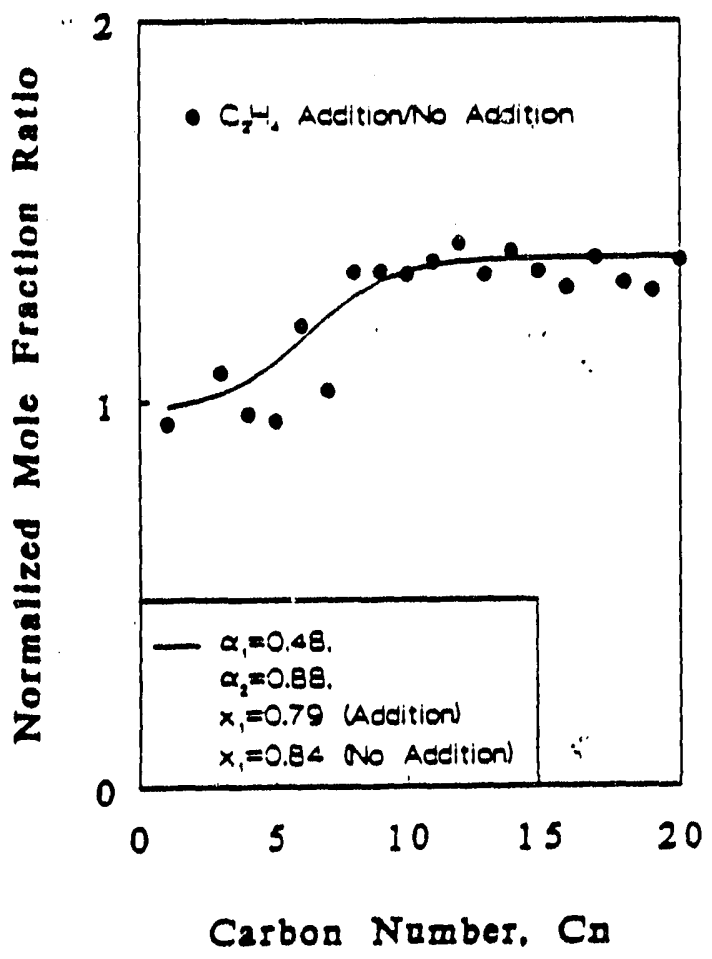

Fig. IV-8 Alkene addition data can be interpreted by a model which accounts for separate contributions by a stepwise growth process and a 1-alkene incorporation process. (Same data as Figure 1a). 


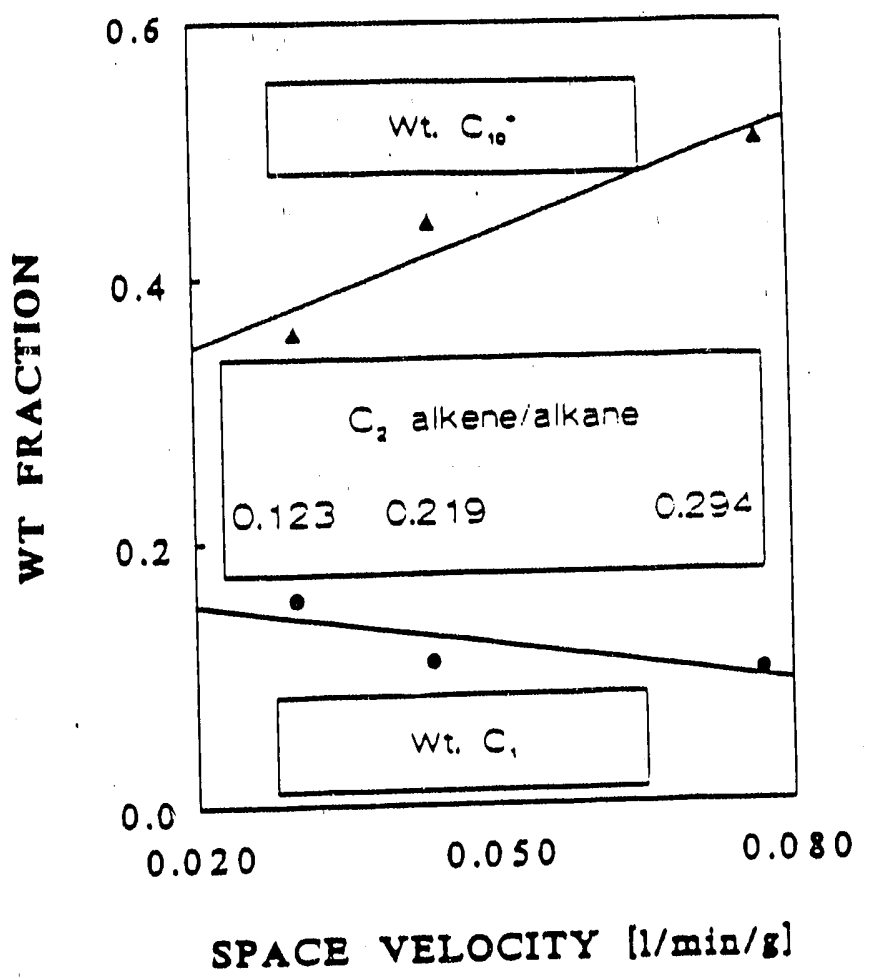

Fig. IV-9 Space velocity affects the yield of $C_{1}$ (undesired) and $C_{10}+$ (desired). Data labels show the in situ ethene to ethane ratio.

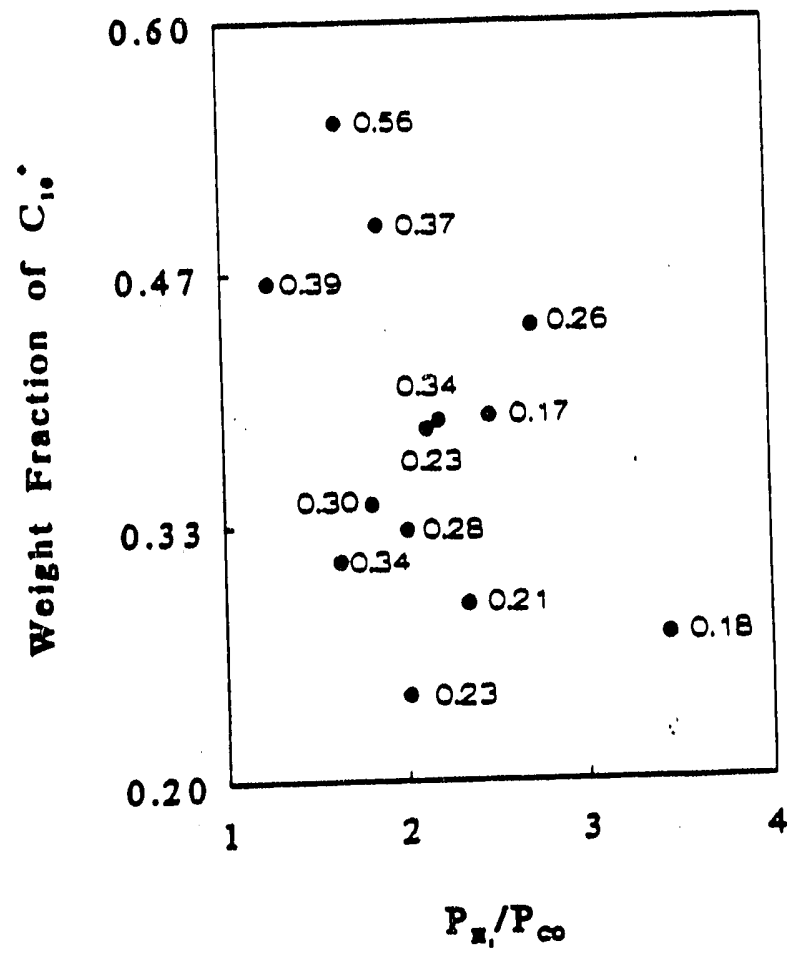

Fig. IV-10 $\left(\mathrm{H}_{2} / \mathrm{CO}\right)$ ratio affects the yield of desired $\mathrm{C}_{10}+$. Data labels show the in situ ethene to ethane ratio. Effect is consistent with hypothesis that $\alpha_{2}$ is caused by incorporation processes. 

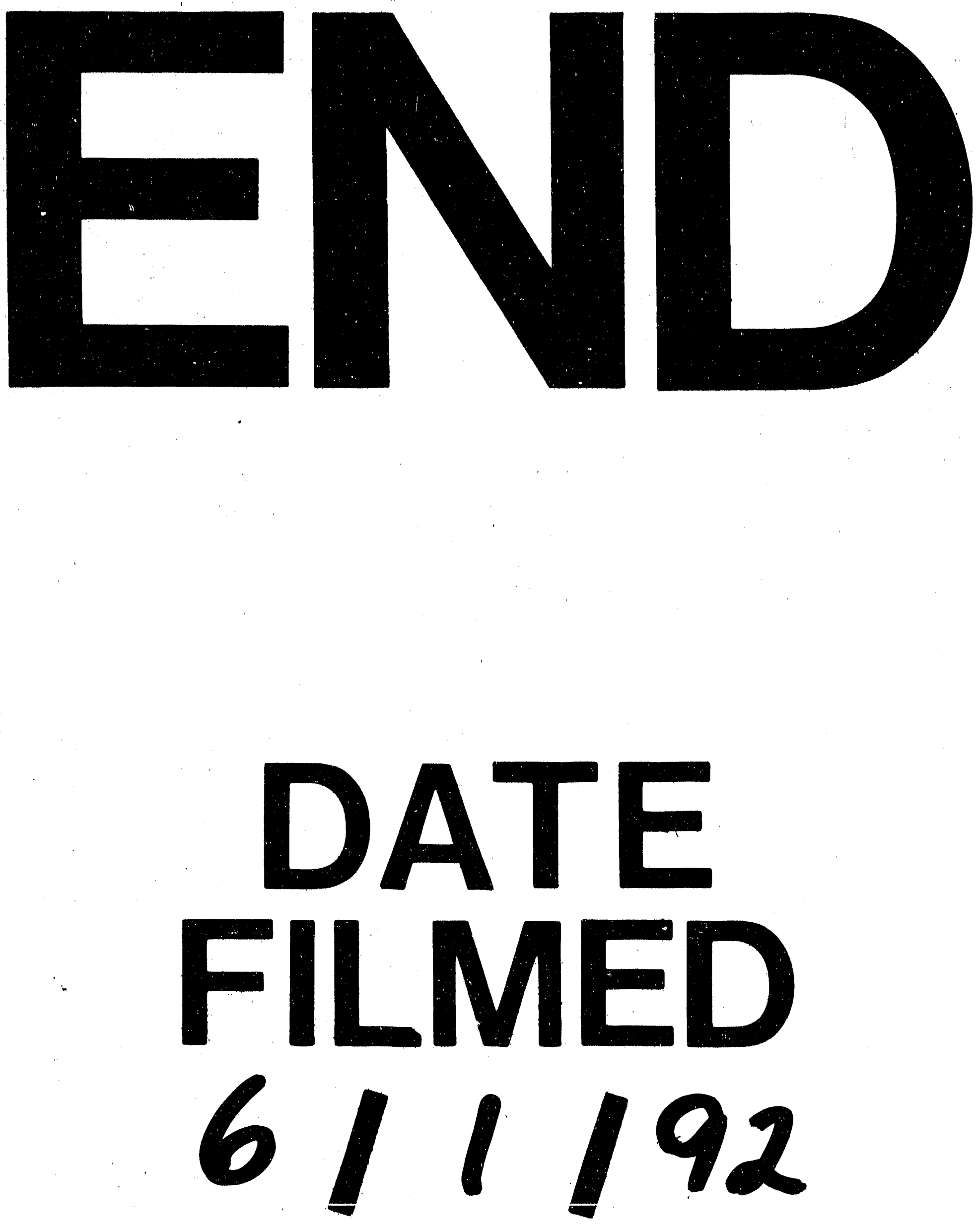


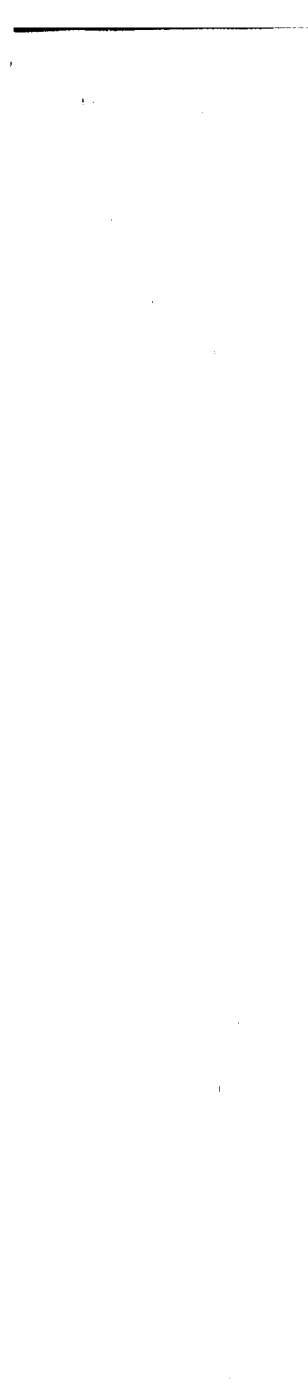

$=$ 